Andrews University

Digital Commons @ Andrews University

1999

\title{
Technology Partnership Curriculum Initiative: A Descriptive Case Study of its History, Development, and Implementation
}

Ingrid Wright-Jones

Andrews University

Follow this and additional works at: https://digitalcommons.andrews.edu/dissertations

Part of the Curriculum and Instruction Commons, and the Educational Assessment, Evaluation, and Research Commons

\section{Recommended Citation}

Wright-Jones, Ingrid, "Technology Partnership Curriculum Initiative: A Descriptive Case Study of its History, Development, and Implementation" (1999). Dissertations. 1565.

https://digitalcommons.andrews.edu/dissertations/1565

https://dx.doi.org/10.32597/dissertations/1565

This Dissertation is brought to you for free and open access by the Graduate Research at Digital Commons @ Andrews University. It has been accepted for inclusion in Dissertations by an authorized administrator of Digital Commons@ Andrews University. For more information, please contact repository@andrews.edu. 


\section{Andrews \$university}

Seek Knowledge. Affirm Faith. Change the World.

Thank you for your interest in the

\section{Andrews University Digital Library of Dissertations and Theses.}

Please honor the copyright of this document by not duplicating or distributing additional copies in any form without the author's express written permission. Thanks for your cooperation. 


\section{INFORMATION TO USERS}

This manuscript has been reproduced from the microfilm master. UMI films the text directly from the original or copy submitted. Thus, some thesis and dissertation copies are in typewriter face, while others may be from any type of computer printer.

The quality of this reproduction is dependent upon the quality of the copy submitted. Broken or indistinct print, colored or poor quality illustrations and photographs, print bleedthrough, substandard margins, and improper alignment can adversely affect reproduction.

In the unlikely event that the author did not send UMI a complete manuscript and there are missing pages, these will be noted. Also, if unauthorized copyright material had to be removed, a note will indicate the deletion.

Oversize materials (e.g., maps, drawings, charts) are reproduced by sectioning the original, beginning at the upper left-hand comer and continuing from left to right in equal sections with small overlaps. Each original is also photographed in one exposure and is included in reduced form at the back of the book.

Photographs included in the original manuscript have been reproduced xerographically in this copy. Higher quality $6^{n} \times 9^{n}$ black and white photographic prints are available for any photographs or illustrations appearing in this copy for an additional charge. Contact UMI directly to order.

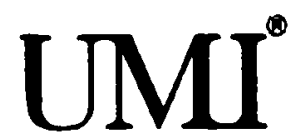

Bell \& Howell Information and Leaming 300 North Zeeb Road, Ann Arbor, MI 48106-1346 USA $800-521-0600$ 
Andrews University

School of Education

\title{
TECHNOLOGY PARTNERSHIP CURRICULUM INITIATIVE: A DESCRIPTIVE CASE STUDY OF ITS HISTORY, DEVELOPMENT, AND IMPLEMENTATION
}

\author{
A Dissertation \\ Presented in Partial Fulfillment \\ of the Requirements for the Degree \\ Doctor of Philosophy
}

by

Ingrid Wright-Jones

July 1999 
UMI Number: 9937629

\section{UMI Microform 9937629}

Copyright 1999, by UMI Company. All rights reserved.

This microform edition is protected against unauthorized copying under Title 17, United States Code.

\section{UMI \\ 300 North Zeeb Road \\ Ann Arbor, MI 48103}




\title{
TECHNOLOGY PARTNERSHIP CURRICULUM INITIATIVE: A DESCRIPTIVE CASE STUDY OF ITS HISTORY, DEVELOPMENT, AND IMPLEMENTATION
}

\author{
A dissertation \\ presented in partial fulfillment \\ of the requirements for the degree \\ Doctor of Philosophy
}

by

Ingrid Wright-Jones

APPROVAL BY THE COMMITTEE:

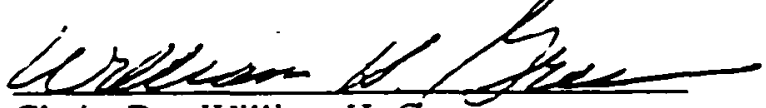

Chair: Dr. William H. Green

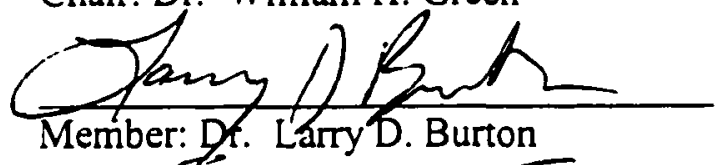

Shene 17 if Feed

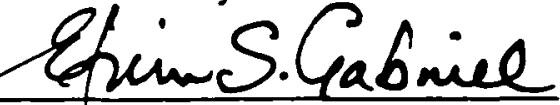

Member: Dr. Elvin F. Gabriel

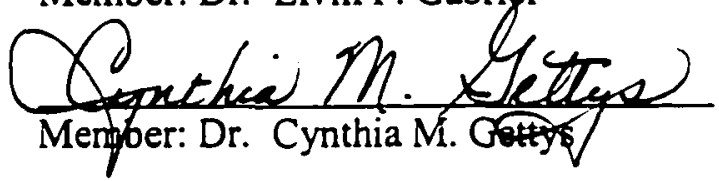

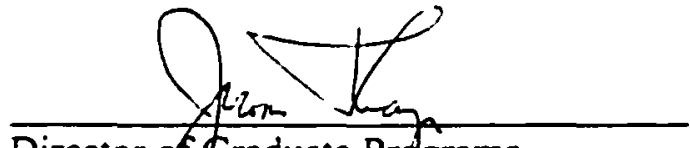

Director of fraduate Prdgrams

Dr. Jerome D. Thayer

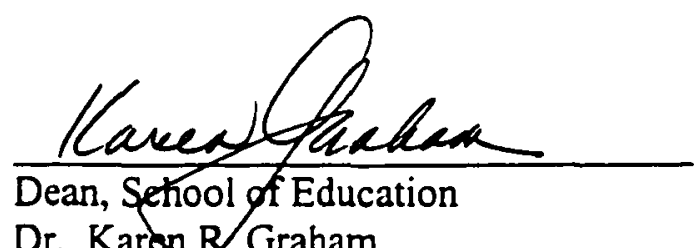

Dr. Karan B. Graham

$$
7 \cdot 20-99
$$

Date approved 


\begin{abstract}
TECHNOLOGY PARTNERSHIP CURRICULUM INITIATIVE: A DESCRIPTIVE CASE STUDY OF ITS HISTORY, DEVELOPMENT, AND IMPLEMENTATION
\end{abstract}

$$
\text { by }
$$

Ingrid Wright-Jones

Chair: William H. Green 


\section{ABSTRACT OF GRADUATE STUDENT RESEARCH}

Dissertation

Andrews University

School of Education

Title: TECHNOLOGY PARTNERSHIP CURRICULUM INITIATIVE: A DESCRIPTIVE CASE STUDY OF ITS HISTORY, DEVELOPMENT, AND IMPLEMENTATION

Name of researcher: Ingrid S. Wright-Jones

Name and degree of faculty chair: William H. Green, Ph.D.

Date completed: July 1999

\section{Problem}

Curricular reform has a pathetic history. Curriculum documents, some of the major tools of reformers, have had a minor effect on transforming education because the power of pedagogy has been ignored (Cuban, 1993). Teachers in the Seventh-day Adventist (SDA) system voiced similar concerns about curriculum documents. Additionally, they felt that their 2-4-day in-service training did not adequately prepare them to implement curricular changes. This initiative, aimed at restructuring both the content and process of teaching, was to be implemented in a distance-learning pilot project in eight one-teacher schools. 


\section{Purpose}

The purpose of this study was to: (1) define the Technology Partnership Curriculum Initiative and to delineate its component parts; (2) chronicle the story of its background and development; and (3) describe its initial implementation during the 1997 1998 school year.

\section{Methodology}

The study used a descriptive, qualitative case study method. Data collected through interviews, observations, surveys, documents, and artifacts were used to chronicle the story of the Technology Partnership Curriculum Initiative.

Data were collected from two primary informants and four secondary informants who were selected by purposive sampling. These data were used to tell the story of the initiative from its beginning through its implementation in the Technology Partnership Pilot Project during its first year.

\section{Findings and Conclusions}

The study highlighted some of the challenges involved in developing and implementing innovative curriculum initiatives. It highlighted the need to (1) provide clear operational definitions of initiatives; (2) provide a substantial amount of time for initial and on-going staff-development training; (3) use research to provide "data feedback"; and (4) develop norms and guidelines for building collaborative relationships between all the entities that are involved in a complex project such as the Technology Partnership Curriculum Initiative. 
To my husband, John Sr., and my children, Carlina. John Jr., and Dhonielle who have encouraged me to reach this milestone 


\section{TABLE OF CONTENTS}

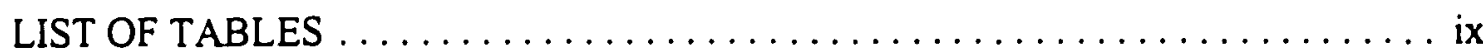

Chapter

I. INTRODUCTION $\ldots \ldots \ldots \ldots \ldots \ldots \ldots \ldots \ldots \ldots \ldots \ldots \ldots \ldots \ldots$

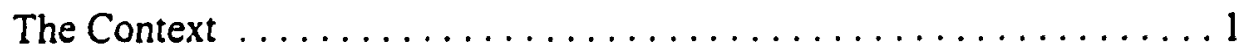

Organization of the North American Division of

Seventh-day Adventists. ......................6 6

SDA Philosophy of Education . .................... 7

Restructuring in North American Division of SDA ........... 8

Rationale for the Study $\ldots \ldots \ldots \ldots \ldots \ldots \ldots \ldots \ldots$

The Problem ................................. 12

Purpose and Research Questions . . . . . . . . . . . . . . . 12

Significance/Benefits of the Study . ................... 13

II. HISTORICAL OVERVIEW OF THE TECHNOLOGY PARTNERSHIP

CURRICULUM INITIATIVE $\ldots \ldots \ldots \ldots \ldots \ldots \ldots \ldots \ldots \ldots$

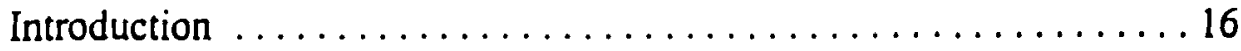

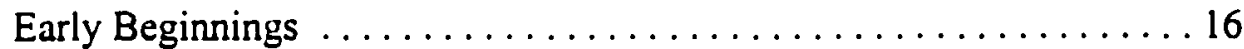

Working With Joel Barker ........................ 18

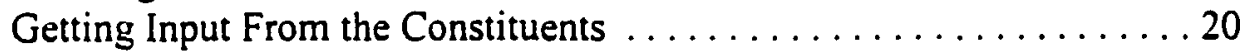

Report of the Education Commission ................... 22

The Education Management Group (EMG) Pilot . . . . . . . . . 28

The Technology Partnership Pilot Project . . . . . . . . . . . . . . . 30

Vision .................................. 31

Mission................................. 31

Pilot Goals ............................. 32

Technology Partnership Units of Study . . . . . . . . . . . . . 33

A Visit to EMG Studios .......................... 34

The Southwest University/Technology Partnership Visit .........36

The Selection of the Schools $\ldots \ldots \ldots \ldots \ldots \ldots \ldots \ldots \ldots \ldots \ldots \ldots$

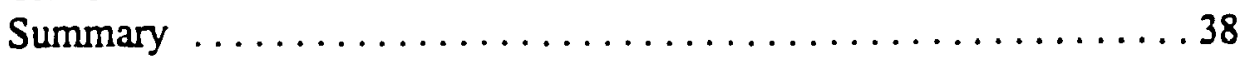

iv

Reproduced with permission of the copyright owner. Further reproduction prohibited without permission. 
III. LITERATURE REVIEW $\ldots \ldots \ldots \ldots \ldots \ldots \ldots \ldots \ldots \ldots \ldots \ldots \ldots \ldots$

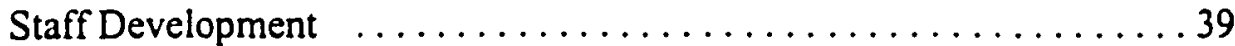

Teacher Change ........................ 42

The Rand Change Agent Study . . . . . . . . . . . 44

The CBAM Model ....................45

Discrimination Efforts Supporting School Improvement . . . . 46

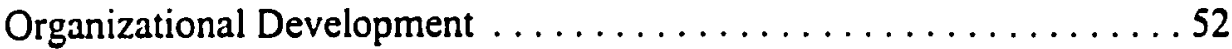

Total Quality Management ................ 57

School/University Partnerships .............. 59

Technology and Educational Change $\ldots \ldots \ldots \ldots \ldots \ldots 6 . \ldots \ldots$

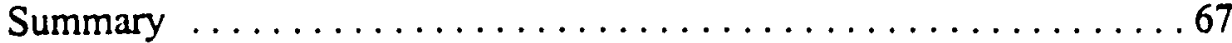

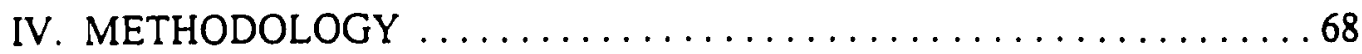

The Design . ........................... 68

Role of the Researcher ........................69

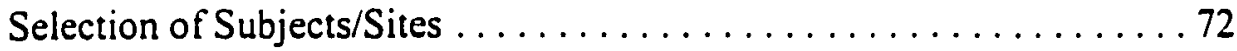

Data Collection Schedule ... . . . . . . . . . . . . . . . 73

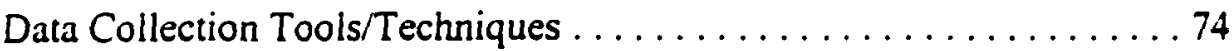

Interviews . . . . . . . . . . . . . . . . . . . 74

Unstructured Interviews . . . . . . . . . . . . 75

Growth States Interviews . . . . . . . . . . . 76

Interview for the Innovation Configuration . . . . . 76

Observation and Field Notes . . . . . . . . . . . 78

Surveys/Questionnaire .................... 79

Gregorc Style Delineator . . . . . . . . . . . . . . . . 79

Other Surveys .................... 80

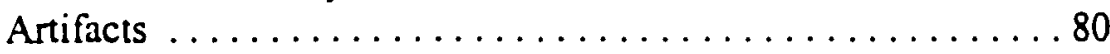

Data Compilation ..................... . 80

Data Analysis Techniques $\ldots \ldots \ldots \ldots \ldots \ldots \ldots \ldots \ldots \ldots$

Trustworthiness ......................... 81

Outline of the Complete Dissertation $\ldots \ldots \ldots \ldots \ldots \ldots \ldots$

V. THE INNOVATION CONFIGURATION (IC) $\ldots \ldots \ldots \ldots \ldots \ldots \ldots .64$

Procedures for Designing an Innovation Configuration Checklist $\ldots .85$

Definitions of Innovation Configuration-Related Terms . . . . 85

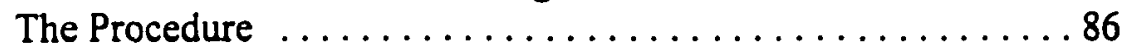

Step 1: Identifying Innovation Components $\ldots \ldots \ldots 86$

Step 2: Identification of Additional Components and

Variations .................... 87

Step 3: Enlarge Pool of Components and Variations . . . 87

Step 4: Checklist Construction . ..........887 
Step 5: Mark Users' Checklist ............... 88

Step 6: Data Analysis .................. 88

Developing an Innovation Configuration for Technology

Partnership ......................... 88

Step 1: Identifying the Components $\ldots \ldots \ldots \ldots . .88$

Step 2: Verification of Components and Variations ....89

Step 3: Major Data Collection ................ 91

Step 4: Checklist Construction $\ldots \ldots \ldots \ldots \ldots \ldots . .92$

Step 5: Data Analysis ...................... 92

Definition of Terms Used in the Technology Partnership

Innovation Configuration .................. 92

Summary $\ldots \ldots \ldots \ldots \ldots \ldots \ldots \ldots \ldots \ldots \ldots \ldots . \ldots \ldots$

VI. STAFF DEVELOPMENT/ORIENTATION FOR IMPLEMENTING TECHNOLOGY PARTNERSHIP CURRICULUM INITIATIVE . . . . 100

Introduction $\ldots \ldots \ldots \ldots \ldots \ldots \ldots \ldots \ldots \ldots \ldots \ldots \ldots \ldots \ldots$

Pocono Union Administrators Institute . . . . . . . . . . . . 101

The Structure and Setting of the Institute $\ldots \ldots \ldots \ldots \ldots 101$

The Participants ............................ 01

The Content of the Training .................... 102

Concept Attainment ...................... 102

Teacher Study Groups ................... 103

Summer Institute ............................ 105

The Structure and Setting of the Institute $\ldots \ldots \ldots \ldots \ldots 105$

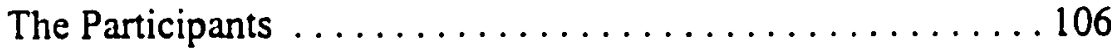

Focusing on the Technology Partnership Curriculum Initiative .107 Orientation for the Technology Partnership Pilot Project ......... 108

The Structure and Setting of the Orientation Session ...... 108

The Participants ............................ 108

The Content of the Orientation .................. 109

Introduction to the Technology Partnership Curriculum Initiative .....................110

Live Interaction With Educational Management Group 111

Overview of Instructional Frameworks ..........112

The Equipment and Services for the Pilot Project .... 113

Logistical Concerns .....................114

Simulated Broadcast Session .................115

Analysis of the Staff-Development Process . . . . . . . . . . . . 117

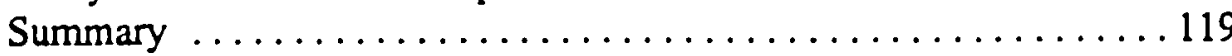

VII. THE TECHNOLOGY PARTNERSHIP CURRICULUM DEVELOPMENT

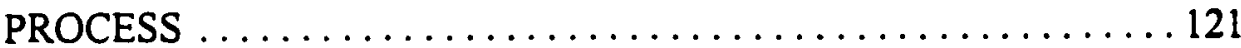

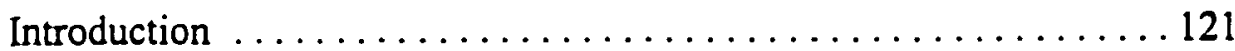

First Meeting of the Curriculum Development Team .......... 122 
Creating the Framework for Technology Partnership . . . . . 122

The First Steps ...................... 122

Unit Descriptors ...................... 125

Curriculum Development at Southwest University ............ 126

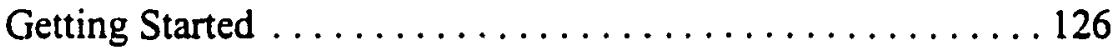

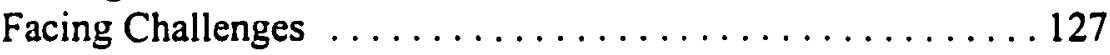

Making Progress .......................... 129

Final Meeting of Curriculum Development Team ........... 131

Revisiting Technology Partnership Innovation Configuration . 132

The Revision of the Units of Study . .............. 134

Support for the Technology Partnership Curriculum Initiative . 135

Processing the Curriculum Development Process . ........ 136

Outcomes of September's Session . . . . . . . . . . . . . . . 139

Analysis of the Curriculum Development Process ............ 139

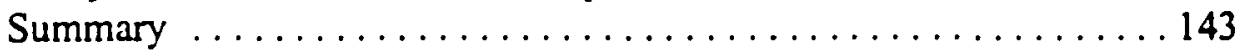

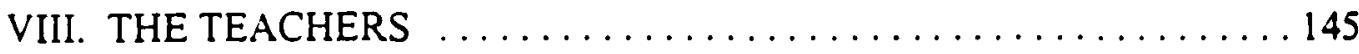

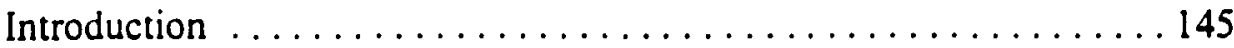

Annie ..................................... 145

Her School .......................... 148

A Typical Day: Annie's Story ................... 149

My Observation-Day $1 \ldots \ldots \ldots \ldots \ldots \ldots \ldots \ldots \ldots 152$

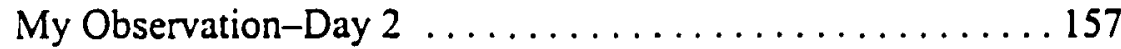

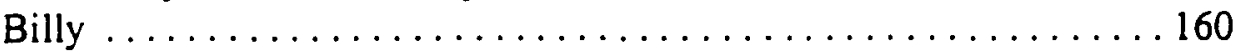

His School ............................... 63

A Typical Day: Billy's Story .................. 64

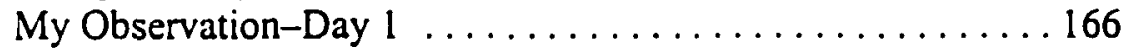

My Observation-Day $2 \ldots \ldots \ldots \ldots \ldots \ldots \ldots \ldots \ldots \ldots$

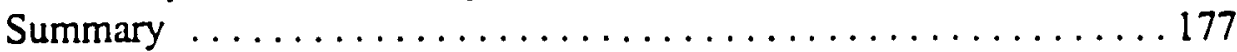

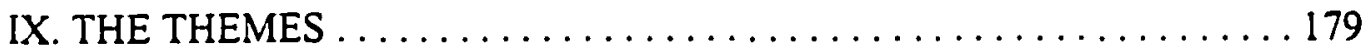

Introduction ................................. 179

"Managing Change" ............................. 179

The Roles of On-site the Teacher $\ldots \ldots \ldots \ldots \ldots \ldots \ldots 180$

The Use of Technology ..................... 185

The Use of Cooperative Groups . . . . . . . . . . . . . . . . . . 189

Management of Students' Assignments . . . . . . . . . . . . 192

"Instructional Support" . . . . . . . . . . . . . . . . . . . . . . . . 197

Faculty Meetings . . . . . . . . . . . . . . . . . 198

Staff-Development Training . . . . . . . . . . . . . 199

The Challenge .......................... 199

Staff-Development Opportunities .............200

An Issue and a Temporary Solution ............201

Embedding Instructional Support in the Workplace . . . 203

vii 
Students' Reactions to the Strategies . . . . . . . . . . . 205

Effect of the Pilot on the Teachers .............. 207

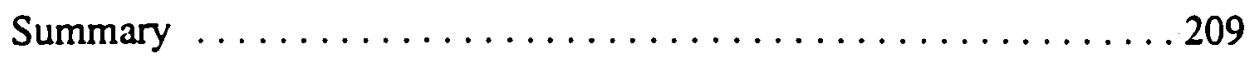

X. CONCLUSIONS AND RECOMMENDATIONS $\ldots \ldots \ldots \ldots \ldots, 211$

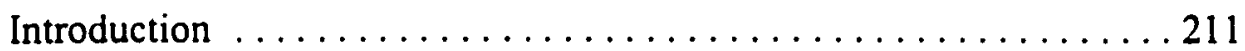

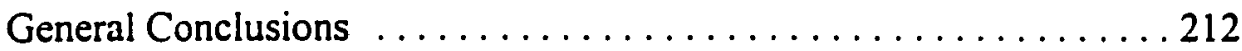

Innovation Configuration ..................... 212

Staff-Development Training $\ldots \ldots \ldots \ldots \ldots \ldots \ldots 214$

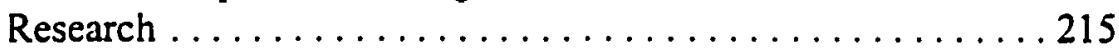

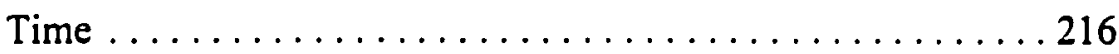

University/School Partnerships ................217

General Recommendations ....................... 219

Specific Recommendations for the Developers of Technology

Partnership ............................221

Recommendations for Further Study . . . . . . . . . . . . 224

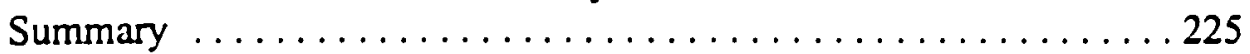

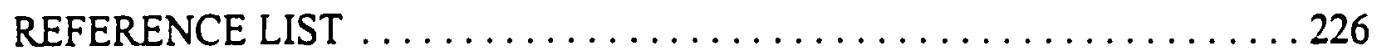

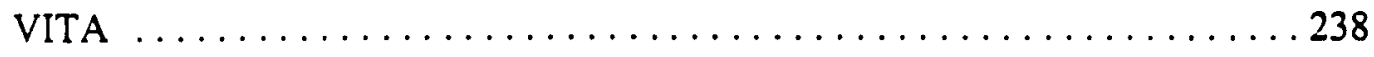

viii 


\section{LIST OF TABLES}

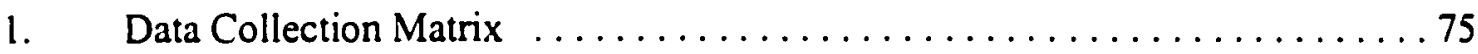

2. Initially Identified Components of Technology Partnership ...........90

3. Edited List of Initially Identified Components of Technology Partnership . . .91

4. Proposed Technology Partnership Innovation Configuration ...........93

5. Innovation Configuration for Technology Partnership Units of Study . . . . 96 


\section{CHAPTER ONE}

\section{INTRODUCTION}

\section{The Context}

During the last half of the 20th century, the field of education has been inundated with initiatives to restructure, renew, and improve the educational system in the United States. This educational focus has been the subject of various committees and research studies, all of which resulted in an investment of millions of dollars in educational research. In 1983, the National Commission on Excellence in Education, a team which had been commissioned to examine the quality of American education, presented its classic report entitled A Nation at Risk. This report provided a wake-up call to the American people concerning the sad state of affairs of the nation's public schools. It was the impetus for many educational reform initiatives.

A Nation at Risk started a wave of reform that focused on higher standards for teachers and students; it included, for example, more stringent requirements for teacher certification, detailed and tested curriculum competency requirements, and policies for improvement in areas such as dress codes, attendance and discipline (Fullan, 1993; Ornstein \& Hunkins, 1998). Partnerships have been formed between the schools and other institutions with the aim of strengthening the capacity of the schools to meet 
students' needs. This report has encouraged many institutions of higher education to reexamine the quality of teacher education programs and take steps to improve them.

Whether the theme was innovation or school reform, throughout the $1980 \mathrm{~s}$ education was publicly scrutinized and evaluated. These same sentiments were echoed by the Carnegie Forum on Education and Economy in A Nation Prepared: Teachers for the 21" Century (Camegie Forum on Education and Economy, 1986). The report proposed that the 1980s will be remembered for two developments: a sweeping reassessment of the basis of the U.S. economic strength and grave concern about the quality of American education.

Prior to the 1980s, there had been concerns about the quality of American education. These concerns came to the forefront in 1957, after the launching of the Russian satellite, Sputnik. The implications of this launching induced fear in the hearts of the American people because they made connections between this event and the state of the nation's schools. Many perceived the launching of Sputnik as not only a loss of technological superiority but a reflection of America's intellectual inferiority to this communist nation. This perception disturbed many who already harbored covert fears about the inadequacy of the American educational system (Dow, 1991).

Subsequently, the ascent of Sputnik impacted American education because it became an impetus for some school improvement efforts. It encouraged the American people to place pressure on federal government officials, who up to this time had taken a somewhat hands-off approach to federal involvement in education, to enact legislation that affected funding in this area. One of these enactments was the National Defense Act 
of 1958 which provided funds to improve the curriculum in schools in several areas, two of which were science and math. Another enactment was the Elementary and Secondary Education Act (ESEA) of 1965 which focused on disadvantaged students. This act provided Title I funds, sometimes called compensatory funding, which were directly aimed at raising the achievement levels of disadvantaged, poor. and minority students (Ornstein \& Levine, 1997).

Dow (1991) indicated that. even before Sputnik, the postwar concerns and criticism of American education were gaining momentum. The popular newspapers of that era hailed the merits of the Soviet educational system and questioned the quality of education in the U.S. Then. 25 years after Sputnik, the Commission on Excellence gave a grim report indicating that "a rising tide of mediocrity" was one of the culprits responsible for the sad state of affairs in our educational system. Why was there such a dismal report after all the reform effort during those 25 years? Had not our schools dramatically improved in the aftermath of Sputnik?

The cry for reform continued to foster reports, summits, and studies on how to fix the system. In 1990, President Bush called a summit of governors from across the United States. His aim was to set national goals for education that hopefully would be realized by the end of this millennium. The implementation of this vision, Education 2000 (U.S. Department of Education, 1994), is an ambitious project which began with six lofty goals. The goals for the year 2000 are as follows:

1. All children in the U.S. will start school ready to leam.

2. High school graduation rate will increase to at least $90 \%$. 
3. All students will leave Grades 4,8 , and 12 having shown competency over challenging subject matter.

4. Students in the U.S. will be first in the world in mathematics and science achievement.

5. Every adult American will be literate.

6. Schools in the U.S. will be free of drugs, alcohol, violence, and unauthorized firearms.

In 1994, through the Educate America Act, Congress re-affirmed these national goals and added two more. These two goals were:

7. Every school will promote partnerships and will increase parental involvement.

8. Teachers in America will have access to programs that would provide professional development.

The intent of the original as well as the additional goals was to attempt to unite the efforts of local communities with state-wide efforts to provide a high-quality education, and to prepare students for responsible citizenship and productive employment in our society.

The U.S. Department of Labor Secretary's Commission on Achieving Necessary Skills (SCANS) report of 1991 followed the vision of Education 2000 and identified the skills that students of the $21^{\text {st }}$ century need to be taught. This report shared a common theme with many other reports on educational reform; it underscored the need to effectively prepare students to meet the challenges of the up-coming century. 
Bruce Joyce (1991), a prominent researcher in the field of education, examined the writings and activities of proponents of school improvement initiatives (Barth, 1980; Goodlad, 1984; Johnson \& Johnson. 1990; Lezotte \& Levine. 1990; Schmuck \& Runkel, 1985; Slavin, 1983, 1990a, 1990b) and identified the emergence of common themes. $\mathrm{He}$ presented his synthesis in an article called "The Doors to School Improvement." $\mathrm{He}$ identified the five "doors" or themes as collegiality, research, site-specific information. curriculum initiatives, and instructional initiatives-by which a system or school restructure or revitalize its existing program.

Curriculum initiatives have been the "door" that has received a considerable amount of attention over the last few decades. Some of these initiatives include the whole-language approach, outcome-based education, developmentally appropriate practice, cooperative learning, interdisciplinary curriculum, and mastery learning. According to Ellis and Fouts (1993), proponents for each of these initiatives tout them as the key to improvement of school life for both teachers and students. Based on their review of these initiatives, they reflected that many school administrators, like wandering nomads, have moved from innovation to innovation in search of the next educational enterprise that promises to improve schools.

My interest in the research on curriculum initiatives was sparked during the summer of 1993 after I attended a summer institute designed to improve instruction. During the institute I was introduced to curriculum development which was connected to innovative models of teaching that were positively affecting student achievement (Joyce \& Weil, 1996; Kagan, 1994). At that time, I was working in a small parochial school in 
the North American Division of Seventh-day Adventists and wanted to learn more about how I could influence this system with research findings that were relevant to its curriculum.

\section{Organization of the North American Division of Seventh-day Adventists}

The North American Division (NAD) of Seventh-day Adventists (SDA) is 1 of 12 worldwide divisions (regions) that constitute the Seventh-day Adventist church; the headquarters of the global church and the North American Division are located in Silver Spring, Maryland. The North American Division consists of the United States of America. Canada, and some Atlantic and Pacific island nations and territories.

The NAD and all the other divisions are divided into fairly large sections called unions. The nine unions in the U.S. are further divided into 58 smaller multi-state regions called conferences. Conferences are made up of churches. From the SDA global organization down to the individual churches, the mission is the same. It aims to meet the needs of its members and others in the global community in the areas of spiritual relationships, evangelism, health and welfare, and education.

The educational system of the SDA church consists of elementary schools, academies (high schools), colleges, and universities. Worldwide, there are over 5,400 educational institutions (SDA Yearbook, 1998). The North American Division alone has approximately $1,000 \mathrm{~K}-12$ schools which are managed by school boards at the local church level and supervised by the local conference board of education. About $80 \%$ of these schools are small schools, which are defined as schools with one to three teachers. 
An office of education exists at every level from the local conference to a global organizational body. The function of each office is to supervise and provide for the needs of educational institutions within its regional jurisdiction.

\section{SDA Philosophy of Education}

For over 100 years, the SDA church has operated an educational system that is based on a holistic development of each individual. This development is defined as "the harmonious development of the physical. mental, and spiritual powers. It prepares the students for the joy of service in this world and for the higher joy of wider service in the world to come" (White. 1903, p. 13). This broad definition was a guiding principle in the lengthy philosophical statements that were written decades ago: a more concise statement has recently been written (Curriculum Futures Commission, 1997, p. 4).

This concise statement acknowledges the Godhead--God the Father. Son, and Holy Spirit--as the ultimate source of truth, the fallen nature of man. the Bible as the revealed will of God, and the oneness of purpose of the Godhead--to restore humanity from its lost state. The aims of Adventist education are to (1) foster the maximum development of one s potential, (2) nurture thinkers rather than mere reflectors of other men's thoughts, (3) to foster loving, unselfish service, and (4) teach the beliefs of the SDA church within the context of a loving relationship with Jesus Christ and to foster that relationship with others. 


\section{Restructuring in the North American Division of SDA}

An effort to assess Adventist education began in 1987 when the North American Division Curriculum Committee (NADCC), a standing committee connected to the NAD Office of Education, commissioned Dr. Paul Brantley, a researcher from Andrews University in Berrien Springs, Michigan, to collect curriculum and instruction data biannually within its system. The findings from this systematic collection of data highlighted various curricular concerns which needed to be addressed (Brantley, 1987. 1989, 1991, 1993, 1995b).

In 1994, the 16-member Curriculum Futures Commission, a group of educators commissioned by the NADCC, started its work to develop changes for a secondary curriculum that would be geared to the 21 st century. This commission was divided into two subcommittees, the Core Curriculum Subcommittee and the Research. Trends and Development Subcommittee. The commission met six times over a 27 -month period. Focus on Adventist Education for the 21" Century (FACT 2I) was the document which emerged from their work (Curriculum Futures Commission, 1997).

The Core Curriculum Subcommittee members developed a new philosophy (see p. 7) that was more concise than previous philosophical statements. They also identified 10 broad goal statements with essential elements, or student outcomes, that would be used to meet those goals (see pp. 6-9). Though the commission's work was primarily for secondary education, the North American Division Curriculum Committee, which received and voted $F A C T 21$, quickly recognized that the Core Curriculum Subcommittee's work could be applied to all K-12 schools. Schools could now use the 
goal statements and essential elements to create a curriculum that would incorporate ideas from the past with identified trends for the $21^{\text {st }}$ century.

The Research. Trends, and Development Subcommittee reviewed the latest research and trends relating to educational change and identified nine preferred practices that were essential for ideal SDA secondary schools (see pp. 10-13). The primary objectives of this committee were to (1) continue this development and identify preferred practices for elementary schools; and (2) to create World Wide Web home pages for each practice that would be an ongoing resource for stakeholders and other individuals all across the world.

\section{Rationale for the Study}

Early in my teaching career I became keenly aware of frustrations about curriculum materials and in-service presentations which were designed to guide the implementation of the Seventh-day Adventist philosophy of education (Curriculum Futures Commission. 1997, p. 4). The philosophy based on the premise of a harmonious development of the physical, mental, and spiritual capabilities of students did not seem to be adequately reflected in the curriculum. The frustrations I experienced were mirrored by other educators in the North American Division.

Many of these educators were ambivalent about curriculum guides, testing, and the use of textbooks in the classroom (Brantley, 1991, 1993). In addition, these educators also reported experiencing feelings of inadequacy in implementing the curriculum, even after participating in $2-4$ day teacher in-service sessions at the annual teachers' 
convention (Brantley, 1991, 1995b). Appropriate follow-up and support for implementing innovative curricular initiatives were simply not provided. Teachers at every level felt isolated-to a much greater extent than did conference personnel. This isolation works against implementation and professional renewal and is particularly acute among new teachers, teachers in small schools, and those who teach at the secondary level (Brantley, 1991. 1993. 1995b).

Changes in curriculum quite often meant changes in curriculum guides and/or textbooks. Attempts to influence instructional processes were given only through inservice workshops which did little to change actual classroom practice (Brantley, 1993). Cuban (1993), in his article "The Lure of Curricular Reform and Its Pitiful History," documented the history of the implementation of curriculum. His review of the research indicated that curricular implementation has had a pitiful and ineffective history and it has not affected teaching practice as it relates to school change. Curriculum documents-guides, textbooks, testing and other such documents, some of the major tools of reformers have had minor effect in transforming education because the power of pedagogy has largely been ignored. Reform efforts have done little to affect the way teachers teach in the classroom.

In light of the grim review of curriculum documents' lack of inherent power to change classroom practice, I began to wonder about a new NAD curriculum project, being discussed at Southwest University, one of the SDA institutions of higher education. The Technology Planning Committee, a sub-committee of the NAD office of education voted in the spring of 1997 to partially sponsor a pilot project that would blend 
technology with curriculum. This project, called the Technology Partnership Pilot Project. was to be implemented during the1997-98 school year. (Southwest University, Pocono Union, and Technology Partnership are pseudonyms used for the purposes of anonymity and confidentiality for the entities being discussed in this chapter.)

In this project, a broadcast teacher would use satellite technology to teach students in eight one-teacher schools. Technological resources would be used to build a learning community which would encourage creativity and change in the delivery of Adventist education while enhancing student learning across the curriculum. This initiative held the promise of being different. How would the Technology Partnership pilot be different from other curriculum initiatives? Would it address the concerns that surfaced in Brantley's synthesis of the Profile findings (1995b)? Would it address the work of the Future's Commission in FACT 2l? Would this initiative repudiate Cuban's (1993) findings on the research of curricular reform?

Some of these questions could be answered if the content and implementation process of the Technology Partnership initiative were described. Plans were made for this initiative to include the work of the NADCC Future's Commission--the philosophy, essential elements, and some the preferred practices such as an integrated curriculum, innovative teaching strategies, and the use of technology listed in FACT 21. Realizing that some aspects of this initiative had been conceptualized approximately 4 years earlier and that this would be an innovative curriculum project, Dr. Adam Smith from Southwest University was interested in collecting qualitative data to chronicle its history, development, and implementation. 


\section{The Problem}

I knew little about the Technology Partnership project at that time, so I was plagued with nagging questions about the initiative: What is it? What are its component parts? How would it be different from other curriculum initiatives? How was it developed and implemented? Besides improving the quality of Seventh-day Adventist education, one of the stated goals of the initiative was to relieve the teaching load of the educators in one-teacher schools; how would this goal be accomplished? How would it impact students? How would students react to being taught via satellite technology? Would the satellite teacher be able to adequately teach the concepts students needed to learn?

Although I joined the research team at Southwest University to assist with data collection for this project. I made a decision to focus my dissertation on the study of the Technology Partnership Curriculum Initiative during the first year of its implementation. I felt that the study would enable me to find answers for the questions that plagued me.

\section{Purpose and Research Questions}

The purposes of this study were to: (1) define Technology Partnership and to delineate its component parts; (2) chronicle the story of its background and development; and (3) describe the development and initial implementation of the Technology Partnership Units of Study.

This study specifically addresses the following research questions: 
1. What is the Technology Partnership Curriculum Initiative? What is the story behind the development of this initiative?

2. How will the Technology Partnership Units of Study be developed and how will they be implemented in the pilot project?

3. What are the implications of Technology Partnership for future curriculum development for Adventist education in the North American Division.

\section{Significance/Benefits of Study}

A recurring theme in the implementation of curriculum innovation is that the success of any innovation depends on the implementation process including a systematic and ongoing staff development component designed with elements like those included in the Joyce and Showers training model (Henriquez-Roark, 1995; Joyce \& Showers, 1995; Showers. Murphy, \& Joyce. 1996). This model of staff development includes a study of the theory of the innovation. demonstration. practice and feedback. coaching, and teacher study groups.

The report of Profile '89, the biannual survey and assessment of SDA curriculum in North America (Brantley, 1989), indicated that staff development designed according to the Joyce and Showers model (1995) needed to be incorporated into the curriculum development process. This recommendation represents a shift from the system-wide approach of using 2-to-4-day teachers' convention to provide awareness for the use of newly developed or adopted curricular materials. One recommendation from Profile ' 89 stated that whereas curriculum materials are "tools of the trade" they should not be 
considered panaceas because they are not meant to be substitutes for competent teaching. This view is supported by Cuban (1993), who indicated that curricular content, no matter how important it may appear. is worthless in a classroom unless it is connected to strong relationships between teachers and students, as well as to appropriate teaching practices.

The cumulative message that has emerged from all of the Profile Studies since 1987 indicates that NAD educators do not feel that they are adequately prepared to implement the curriculum in their schools. Even though they have cited yearly teachers' conventions as their first choice of training, few feel that these conventions have provided them with an adequate amount of training and follow-up for implementing curricular initiatives (Brantley, 1995b).

The recent report of the North American Division's Curriculum Futures Commission. FACT 21, has reinforced the recommendation of the Profile Studies by calling for change in the curriculum development process. Could the Technology Partnership Pilot Project be an initial step toward this change process? To date, no qualitative studies have been conducted to document and describe the curriculum development process within the SDA system. The Profile surveys have been the only system-wide tools used to attempt to assess perspectives on curriculum. This study of the Technology Partnership pilot project is one of the first qualitative inquiry into a curricular initiative that is being sponsored by the NAD (Book 4, Section L, p. 2). This project includes several unique features for SDA change efforts:

1. Integrated curriculum with interactive teaching models, as well as an emphasis on higher-order thinking skills 
2. Collaboration of a university with teachers who are developing and implementing curriculum

3. Satellite technology as a major element of the delivery of the curriculum

4. Multiage/multigrade classrooms in one-teacher schools involved in a national project.

Because the unique features of this project would provide valuable information for those involved in educational change processes, it would be beneficial to include detailed, qualitative descriptions to chronicle this entire process. The benefits of this study have significant potential to affect multiple levels of school organization within the North American Division.

The description of the process could provide documentation for key stakeholders in the Pocono Union and/or North American Division to use in guiding them through the remaining phases of the development and implementation of this initiative. It could also provide documentation for both the Pocono Union and the North American Division to use in the replication. adoption, or adaptation of the process in other settings. The benefits of this study could be further extended in its contribution to the body of knowledge about school change and implementation of innovations, especially in small multiage/multigrade schools in North America and possibly overseas. A historical overview of the project is presented in chapter 2 . 


\section{CHAPTER TWO}

\section{HISTORICAL OVERVIEW OF THE TECHNOLOGY PARTNERSHIP CURRICULUM NITIATIVE}

\section{Introduction}

This chapter provides background information relevant to this study. It includes a brief description of the Technology Partnership Curriculum Initiative, the story behind its development, and the plans for its initial implementation. The names of the schools and all informants have been changed to assure anonymity of all responses and confidentiality of all records. The quotations included in this chapter are taken from the interviews and artifacts and are referenced as a volume, section, and page number in the field notes.

\section{Early Beginnings}

Technology Partnership Curriculum Initiative began in 1993, from a thrust to restructure and improve education in the San Fernando Conference, one of the northeastern regions of the NAD. This thrust was initiated by the president of the conference, Dr. Sam Hale. He established a commission on education and presented the challenge of restructuring. Though much of the motivation for establishing the commission grew out of financial challenges facing the conference, Dr. Hale wanted this 
group to go beyond dealing with finances. He wanted them to also focus on how this conference would structure and deliver education in the $21^{\text {st }}$ century. Three subcommittees were formed which dealt with the following areas: (1) finance, (2) curriculum for the 21 st century, and (3) organization and structure for two areas in that conference.

The work of the Twenty-first Century Curriculum Committee was especially significant. The members embraced Dr. Hale's challenge of defining how they would build an educational system to deliver education for the next century, if given a blank slate. The committee worked toward the accomplishment of two objectives: (1) to anticipate both the challenges and opportunities of the remaining years of the $20^{\text {th }}$ century and while anticipating the needs of the $21^{\text {st }}$ century; and (2) to explore creative and innovative approaches for teaching that take advantage of new technology that could be used by all schools, but particularly those that were small and isolated from areas with large SDA population.

Bettie Richards, an associate superintendent of education in the San Fernando Conference, acted as the facilitator for the Twenty-first Century Curriculum Committee. During the first year she reported:

We worked for a year just trying to gather resources, looking at what was out there, trying to analyze what was going on in curriculum, taking a look at what business people were having to say about what curriculum should look like; what were some of the problems and concerns. (Book 4, Section E, p. 13) 
Eighteen individuals served on the curriculum committee. Several of them were teachers. Leon, one of the teachers, worked with this committee for 3 years. He shared some of the thoughts of the committee during the beginning phase of their work.

At the time we were tossing around ideas, trying to come up with what we were seeing as necessary for the $21^{\text {st }}$ century.... On our part the textbook -oriented education was not part of what we were seeing. The textbook needed to be put on the shelf and used as resources, not handed out at the beginning of the year and the last page of the book finished on the last day of the year.... It was a move from that old textbook paradigm. (Volume 4, Section C, p. 4)

\section{Working With Joel Barker}

In January 1994, Bettie and the chairman of the curriculum subcommittee attended a conference on restructuring schools in Phoenix, Arizona. At this conference Bettie was introduced to Joel Barker who presented his vision of educational change. Through Barker, Bettie became familiar with the Ecological, Futures, and Global (EFG) Curriculum Collaboration, a group of innovative master teachers from around the world, who worked with Barker and his colleague Barbara Barnes to develop and write curriculum.

The EFG curriculum (Barnes, 1998) is based on three domain competencies and core skills that integrate concepts from all content disciplines in a way that brings meaning to learning while recognizing the value of each human being. The broad goal of the EFG curriculum is to help students see their global and ecological responsibility so that they are able commit to the responsibility of preserving the future of our planet. Bettie liked the design of the EFG curriculum. In 1994, she, Leon, and seven other 
members from the curriculum team spent 2 weeks with Barker, Barnes, and their associates, who helped the group conceptualize a framework for change. They worked together to clarify the SDA vision and philosophy. Barker and his associates constantly kept the team focused on the mission of SDA educators and what was unique to Adventist education. Barker encouraged the team to use ideas from the EFG design and to apply or adapt them to the Adventist philosophy.

This collaboration also aided the committee members in validating the holistic philosophy of Adventist education, which focuses on four broad areas or domains: physical, mental, spiritual, and social development of individuals. They began to think about what would be indicators of mastery or competency for students in the four domains. Barker assisted the committee in formulating a descriptor about what the competency in each domain would look like. For approximately one year after the session with Barker, the committee worked on writing competency statements designing at least six to eight competency statements which were aligned with the descriptors for each domain. Leon described it as a "move from textbook orientation to competencybased education" (Volume 4, Section C, p. 4). The work in this area constituted the learning design for this new curriculum effort.

Leon, who had a background in advertising, was responsible for helping the team select a name for the curriculum project. He proposed the name Technology Partnership Curriculum Initiative and drew a logo which included four curved lines depicting the four domains of the curriculum project. He described the creative thoughts which stimulated him at the time as "two of my random wanderings" (Volume 4, Section C, p. 4). 


\section{Getting Input From the Constituents}

The curriculum committee received input from teachers about the new learning design and the entire Technology Partnership Curriculum Initiative between 1993 to 1995. They regularly shared information at teacher in-services. They told about their initial visit with the EFG collaborative members. After that, they regularly disclosed information about what the committee was doing. The committee asked the teachers for feedback. Bettie described the initial responses from some of the teachers as "utter chaos." Some reported that they were already doing the things that were indicated in the new curriculum design while others did not understand the design or were alarmed that it did not advocate the use of textbooks. Bettie estimated that the initial response of about $60 \%$ of the teaching staff of San Fernando Conference to the Technology Partnership Curriculum Initiative was not positive. Approximately $40 \%$ of the teachers embraced the vision of this new initiative. They were saying "All right! Absolutely! Let's go!" (Book 4, Section E, p. 19).

The committee members decided to experiment with this curriculum effort. During the summer of 1995 they conducted the first Technology Partnership summer workshop. This was the committee's first attempt at integrating curriculum. In reference to the participants who attended this first workshop, Bettie said, "We were looking for pioneers" (Book 4, Section E, p. 19). Approximately 40 volunteers attended. The teachers in this first session worked on understanding and using 4MAT, a learning styles model (Joyce \& Weil, 1996), and Storypath (McGuire, 1997), a strategy that is similar to simulation. 
Another Technology Partnership workshop was held the next summer. As the curriculum committee members continued to share some of the proposed plans for Technology Partnership, they became discouraged by some of the responses they received from teachers. The feedback from other leaders in the system from whom they expected support was also disappointing. Accepting expected resistance, the curriculum committee decided to continue the development of Technology Partnership.

During the fall of 1995 , the curriculum committee sought input from the entire constituency. They sent out a survey asking the constituents for input on what the current system was doing. Constituents were asked to rate, on a scale of $1-4$, how important each of the new competencies were to SDA education, and how they felt the conference schools system was currently doing in preparing students to master these competencies. They were also asked to suggest additional competencies that should be included in the Technology Partnership initiative.

Surveys were sent to churches, home and school organizations, and at least 17,000 homes within the San Fernando Conference. Approximately 400 individuals responded to the survey. The results were tabulated and compared to (1) the current research and trends in school improvement; (2) the Valuegenesis report (Dudley, 1992), a survey of the perception of students attending SDA and other parochial schools on issues relative to their religious faith; and (3) the results from surveys which were conducted in public schools and the business world (Volume 5, Section M, pp. 30-31). 


\section{Report of the Education Commission}

The work of the Education Commission was presented to delegates at a constituency meeting in November 1995. The curriculum committee set up displays in the foyer of the school building in which this meeting was held. The displays showed how teachers had experimented with some of the ideas the committee was going to present to the constituents. Bettie indicated that the displays made it look like "the curriculum was guiding the entire process of change" (Book 4, Section E, p. 18). Leon recounted how the lobby of the school building had seven tables with displays. He described some of the displays.

I had [a] table that dealt with learning styles. I had materials about learning styles there. I had a video about learning styles there, which showed a classroom where the teacher was designing instruction from an understanding of learning styles. We had a table that dealt with character education. We had a table that dealt with technology. A table ... dealt with the cooperative relationship between church, home, and school ... [and] with business's responsibility in education. (Book 4, Section C, p. 3)

Bettie also remembered one of displays in the lobby that demonstrated the redesigning of the curriculum for the $21^{\text {st }}$ century. She indicated that

in the middle of the foyer was a display of an integrated unit of study. It happened to be a nature one. We built a big tree. We had kids actually there doing a variety of activities--some science activities, some math activities. It was more dramatic at that time to just show how all the curriculum could be related around one topic. They actually saw kids working, but then they saw the products around the edges. (Book 4, Section E. p. 18)

Bettie indicated that the curriculum subcommittee, mostly made up of teachers, wanted to show all the possibilities of the new learning design they were about to propose 
and thus create strong support for their request to continue working with the Technology Partnership design. The report of their work, which included the input from the survey, was published in a document entitled the Final Report (Volume 5, Section M, pp. 1-53). It outlined the following challenges:

1. The "harmonious development" of students' physical, mental, spiritual, and social skills is finding only average success. Adventist schools have only a $63 \%$ rate of success for meeting essential competencies in these four domains.

2. Few accountability measures ensure "harmonious" growth in these four domains, particularly with the competency of "the joy of service" (White, 1903).

3. According to the Valuegenesis report (Dudley, 1992), 4 out of every 10 Adventist adolescents are marked by an undeveloped or underdeveloped faith, thus putting them at risk for falling into lifelong church inactivity (Dudley, 1992, p. 41).

4. Student textbooks and teacher lectures traditionally present "the truth as something already formulated to be learned and followed" (Dudley, 1992, p. 283). Very few opportunities are given for students to discover truth and to apply it to their daily lives.

5. Student leaming and achievement are often irrelevant in relation to the "real" world. The current curriculum is not equipped to prepare students for the challenges of the year 2000 , such as the ability to:

a. Access information that is expanding exponentially

b. Understand the growing multicultural, multilingual nature of society 
c. Direct one's self positively through an ever-increasing maze of societal problems (dysfunctional families, divorce, career changes, higher cost of living, poor health, environmental concerns, ad infinitum)

d. Work cooperatively with others in an increasingly competitive world e. Reason and solve problems in a society that becomes more and more complex.

6. The nationwide push to improve the quality of schools, through initiatives such as the National Education Goals, reflects a call from society, as a whole, to improve educational standards. This emphasis will have its impact on Seventh-day Adventist as we seek to provide a workable alternative to public education for Adventist children and youth. In the report Risk and Promise (North American Division Board of Higher Education and Board of Education, K-12, 1990), only 54\% of Adventist parents perceive that SDA schools offer better programs than public schools If polls show that public education has improved, or at least is perceived to have improved, will Adventist parents become increasingly dissatisfied with Adventist schools?

7. Constituencies are calling for greater attention to the individual needs of students. These include differences among students' learning styles, language and cultural backgrounds, as well as special learning problems and giftedness (Daley \& Seltzer, 1987). Currently, no uniform approach is being used, conference-wide, to address these needs, although some useful strategies have been presented at teacher inservices. 
8. The educational system is often viewed as a stand-alone entity that is not closely tied to other ministries of the church, such as youth ministries, church ministries. family life, and evangelism. Efforts to connect these ministries would contribute to the advancement of students, families, schools, and churches.

The committee's immediate goal of the restructured curriculum plan was to change Adventist education in the San Fernando Conference, but they also hoped to have a national and global impact on Adventist education. A mission for Technology Partnership was outlined. The mission was to help students understand and accept the gift of God's grace as the basis for salvation and encourage them to accept Jesus as their Savior and friend; its aim was also to create a climate for academic excellence and physical well being that enables students to participate in active Christian service in both the church and community (Volume 5, Section M, p. 44).

A vision grew out of the survey that was completed by educators, parents, students, the board of education, conference members and members of the commission on education across the San Fernando Conference. A significant part of the work of this committee was a 7-point focus, which was to help articulate the vision of Technology Partnership. The 7-point focus included:

1. The harmonious development of the physical, mental, spiritual, and social powers. The essential competencies created for these four domains were to be connected in units of study which would integrate curriculum content and would each include the concept of service to others. 
2. Staff development training for teachers. Since the curriculum was to be organized around major concepts. themes, problems, and issues that require students to use critical thinking and language processing skills. instruction would employ various teaching strategies. ranging from direct to experiential. Teachers would therefore need professional development opportunities that focus on these teaching strategies to implement the new curriculum.

3. Meeting the individual needs of children. Research in the field of education and psychology has identified several effective methods of teaching such as cooperative learning, 4MAT, multiple intelligences, and others which are designed to meet the individual needs of each child. Use of a variety of these methods ensures that each child would be afforded the opportunity to reach the essential competencies of the four domains.

4. A realistic, effective assessment system. A variety of assessment tools besides standardized achievement tests would be utilized to measure and reflect students yearly growth in each of the four domains. Some of these tools would include portfolios, performances, and demonstrations. These assessments would evaluate higher order thinking and problem-solving skills, and objectives in the affective and psychomotor domains. The aim would be to have students develop their maximum potential.

5. The involvement of the school constituency. The committee viewed the school program as a total system. They called for each subsystem-students, teachers, parents, school boards, church members, and conference administration to work cooperatively within the system. They also called for renewed efforts to connect the 
various ministries of the church, so that the educational system and the ministries could support each other. This would involve modification of traditional structures, policies. and procedures.

6. The integration of technology into the learning environment. This focus called for schools to use technology as an essential tool for delivering and receiving instruction. In the restructured system, technology would be one way to improve productivity, manage information, and display knowledge.

7. A commitment to character development. Under ideal conditions, the school's role is to reinforce the religious beliefs and values which children have learned at home and at church. However, since conditions in homes and churches are less than ideal, the restructured plan for education includes a commitment to character development so that when students leave school, they would possess a sense of the sacredness of life in all of its relationships and an understanding of their salvation and responsibility to listen carefully and communicate honestly with others.

The report from the San Fernando Conference Education Commission to its constituents was unanimously and enthusiastically voted at the November 5, 1997, conference constituency meeting. The curriculum committee was given the permission to proceed with the development of a curriculum that met the expectations of the 7-point focus outlined in the Final Report (Volume 5, Section M, pp. 32-36). Shortly before this report was voted, San Fernando Conference also elected a new educational superintendent. 
Additionally, there were changes in conference administrators. Many of the new administrators were concerned about keeping the conference financially afloat. These changes in conference and educational leadership affected the subsequent work of the curriculum committee. The new team also focused on aspects of the educational work other than curriculum. The financial support that the conference received from constituent churches was decreasing; as an end result. funding for a new curriculum project like Technology Partnership was not available. There was little motivation from conference curriculum committee to aggressively develop Technology Partnership Curriculum Initiative after this meeting.

A few months later, Bettie Richards transferred to the Maracas Conference to serve as one of their associate superintendents of education. She took the vision of Technology Partnership with her. It was this conference which became the guardian of this initiative when the idea of a distance learning pilot project was born.

\section{The Educational Management Group (EMG) Pilot}

The seed which led to the development of the Technology Partnership Pilot Project was planted in the spring of 1996. Dr. Harry Sales, the director of education of the Pocono Union, and other representatives from this union traveled to Scottsdale, Arizona, to visit the headquarters of Educational Management Group (EMG), a company that provides technological services to schools throughout the United States. What particularly fascinated Dr. Sales was the availability of satellite communication service from EMG which made interactive distance learning possible in SDA schools. During 
the visit. EMG extended an offer that would allow the North American Division to pilot the use of their interactive distance-learning services without charge for the satellite time in up to 20 SDA schools during the 1996-97 school year.

Dr. Sales began to envision the possibilities of using distance-learning resources via satellite technology to improve the learning environment and to increase the technology infrastructure in schools. In the fall of 1996, the group of K-12 administrators from the Pocono Union, which included superintendents and associate superintendents from eight regional areas, wrestled with the ramifications of implementing such a program in 20 schools during the $1996-97$ school year. The implementation would be a financial challenge for many of the schools since most of them had already formulated budgets for the 1996-1997 school year. The administrators at this fall meeting were concerned that many of the small schools would not be able to afford this project during the 1996-1997 school year. However, the administrators also concluded that given a reasonable amount of time, these schools would be able to raise the necessary funds.

Recognizing the challenge, the group decided to involve only 15 schools in this pilot project with EMG. The 15 schools which opted to take part in this pilot project during the 1996-1997 school year were schools with more than three teachers. The remaining five slots for schools in the program would be relegated to one-teacher, multigrade, small schools in the following academic year. This decision to make a special effort to include small schools was significant. The distance-learning pilot project would be made accessible to both larger and small schools in the North American Division. 


\section{The Technology Partnership Pilot Project}

In January of 1997, a group of administrators from the Pocono Union, NAD, and two representatives from EMG held a meeting at the union headquarters to dialogue about the intricacies of bringing the distance-learning pilot into five one-teacher schools for the $1997-98$ school year. As a result of this dialogue, the idea of blending the Technology Partnership curriculum design and the distance learning project emerged. Dr. Sales saw this project as a way to "save" small SDA schools.

Many of the schools had more students than one teacher could handle but not enough funds to finance two teachers. While that was Dr. Sales`s initial goal, Bettie and her conference educational superintendent, Tom. wanted to blend technology with the curriculum. This would serve as an instructional model for the teacher while relieving him/her of the responsibility of teaching all grades and all subjects. The on-site classroom teachers would only be expected to teach Grades 1 through 4. Grades 5 through 8 would be taught by the broadcast teacher.

As the project was being developed for the five small schools, EMG was persuaded to allow three additional small schools to become a part of the pilot project. During the first year, the project would link students in Grades 5 through 8 from these eight schools in seven states--Florida. Michigan. Virginia, Oregon, North Dakota, Wisconsin and Pennsylvania--to a teacher whose studio was located in one of the Southern states.

The idea of the Technology Partnership Pilot Project was a bold and innovative plan that required sound financial support. EMG was providing in-kind support with a 
donation of 200 hours of free satellite time. The cost for the equipment, special telephone lines, and other incidental costs for each of the eight sites was passed on to the participating schools. In addition, however, financial support was needed for salaries, equipment for the studio, as well as a variety of expenses related to the project. The proposed plan was taken to the NAD Technology Planning Committee. Since this committee was interested in partially funding a project which would integrate technology and curriculum, and they chose Technology Partnership as that project.

The mission, vision, and goals of the Technology Partnership Pilot Project outlined on a fact sheet (Volume 5, Section L, p. 1) are as follows:

\section{Vision}

The vision of the Technology Partnership pilot project is to use digital interactive satellite resources to build a different learning community which encourages change and creativity in the delivery of uniquely Adventist education which will enhance student learning across the curriculum.

\section{Mission}

The vision of the Technology Partnership Pilot Project is to assist the on-site small-school teacher in leading students to a developing, dynamic, transforming relationship with Christ while displaying mastery of the essential competencies and core skills that are fundamental to Adventist education in the $21^{\text {st }}$ century. 


\section{Pilot Goals}

The pilot goals were to:

1. Deliver Technology Partnership Units of Study to students in Grades 5-8 in eight 1 -teacher schools across NAD. These units are expected to:

a. Teach to the competencies of the four domains of Technology Partnership-physical, mental, spiritual, and community

b. Integrate content skills of the NAD science, social studies, language arts, and reading curriculum guides

c. Immerse students in state-of-the-art communication technologies

d. Culminate with service and/or outreach activities as a natural outgrowth of the content studied

e. Address the learning styles of all students

f. Include teaching strategies and structures that promote higher-order thinking skills

g. Assess student competency using relevant, dynamic assessment; Create a cost-effective alternative to school staff in small schools where a teacher's assistant is needed.

2. Provide resources for students of small SDA schools such as:

a. Church leaders, scientists, and other specialists

b. State of the art technology

c. Video and print curriculum supplement 
3. Model teaching strategies and structures of Technology Partnership Units of Study for training Adventist teachers using the Technology Partnership Satellite Network, the EMG network system which was being used in the pilot

4. Establish an infrastructure for worldwide communication and further educational and church programming

\section{Technology Partnership Units of Study}

The work of developing the Technology Partnership Units of Study began in March 1997. The development of the curriculum was a critical part of this project. The framework upon which this curriculum was built made provisions for development in the four domains/areas--physical. mental, spiritual and community domain, addressed in the Adventist philosophy of education (Curriculum Futures Commission. 1997, p. 7) and the pilot goals. This framework also included: (1) the Technology Partnership competency statements, goals in the four domains that students were to aspire to; (2) the student outcomes or essential elements of $F A C T 21$; and (3) the skills and concepts from the North American Division curriculum guides.

A group of educators from Maracas Conference, along with Dr. Ebony Johnson, the associate superintendent of education for the Bayside Conference, and two professors from Southwest University, Dr. Nancy Beck and Dr. Joe Mills, formed the initial team which met in March 1997 to begin the groundwork of blending the competencies, essential elements, skills, and concepts in an integrated curriculum. They worked for approximately a week to produce skeletal outlines and simple descriptors for five units of 
study. The outlines for these five units were then used to create detailed unit plans for use by the broadcast teacher and hopefully by other educators in the SDA system.

\section{A Visit to EMG Studios}

Shortly after this initial meeting of the curriculum development team, in April 1997, a team of educators from Pocono Union and Southwest University visited EMG studios in Scottsdale, Arizona, with the aim of continuing the development of the pilot project. The team consisted of 10 educators including seven people from the Pocono Union: three teachers. two associate superintendents, one superintendent and one director of education; and three professors from the university. Dr. Sales, the director of education for the Pocono Union; Bettie Richards, the coordinator of the pilot project; Leon, the proposed broadcast teacher; and Drs. Smith, Beck, and Mills from Southwest University were also a part of this team.

During this visit the team toured EMG's facilities, examined some of the equipment in their studios, saw what services they offered, and gained understanding about how those services might be utilized. It was also a time for some of the key persons involved with the initiative to meet and dialogue face-to-face. They were able to see how broadcasting a day's lesson in a unit of study would look. During this "day" of the pilot project, Leon, the proposed broadcast teacher, and Dr. Joe Mills, from Southwest University, taught students at two schools involved in the initial EMG pilot during the 1996-1997 school year. During that broadcast, a day was equivalent to one 24-minute and two 12-minute segments of teaching/interaction time with students. Although 
students were able to see and hear the instructors on their television monitors, they were able to interact with them only via telephone. These three broadcast sessions were punctuated by 35 and 30 minute block of time when the group was not interacting via satellite.

Bettie thought that being able to broadcast this session was very helpful. As she reflected on this session she said:

It gave us a lot of feedback as to what would work and what would not. For the most part, it worked better than we even planned. The group work and assignments seemed to go well, as the students responded in such a way as to show understanding in the concepts being presented and the format we had planned to use. (Book 5. Section B, p. 6)

Bettie also explained that the team saw and experienced first-hand how the studio would operate and what kind of equipment was necessary for the pilot project.

Dr. Smith expressed concerns about the pilot project to Dr. Sales, after he had seen some of the resources of EMG. Though he did not disagree with the amount of money, time, and hope being invested in the project, he stressed the importance of providing training for the teachers in the strategies that were included in the pilot's goals. He indicated that the change in teaching processes would be a key success factor for the project. He also expressed that whereas teachers and students would initially be motivated to be involved with the pilot project, this motivation would be short-lived. Dr. Smith also warned that placing children who were already watching too many hours of TV into a program which involved more TV watching was unhealthy (Book 4, Section L, p. 1). 


\section{The Southwest University/Technology Partnership Visit}

Approximately a week and a half before the initial meeting of the curriculum development team in March of 1997, Dr. Adam Smith from Southwest University, attended the Association of Seventh-day Adventist Secondary Administrators (ASDASA) conference in Daytona Beach, Florida. Southwest University is one of seven SDA institutions of higher education in the NAD offering undergraduate and graduate programs. At this conference, Dr. Smith was invited to attend a meeting in which the development of the Technology Partnership initiative was being discussed. He was very interested in the project and was willing for his department to assist with its development and implementation. Some who were present at that meeting felt that the university could provide support in the areas of curriculum development, staff development, and research (Book 4. Section L. pp. 24, 25; Book 4, Section L, p. 1). Dr. Smith was excited about the opportunity for the university to be involved in a project involving the educational change processes which he advocated.

After this conference, two of the professors from Southwest University volunteered to contribute to the Technology Partnership initiative in the areas of curriculum development and research. These were the two professors who joined the curriculum development team that met in March1997 to build the frameworks for the development of the units of study. To add to this involvement, the university was willing to do even more. In April 1997, Dr. Smith, serving unofficially as a university liaison, hosted the Southwest University/Technology Partnership visit. Several key K-12 administrators and Technology Partnership developers from the Pocono Union who were 
involved in the project attended to formally dialogue with university administrators and the School of Education faculty about this project.

At least four professors from the School of Education were willing to work on the curriculum development. staff development, and research components of this project. A team, of which I was a part, immediately began to work on the research component; they made plans to begin collecting data about the development, implementation. and impact of the project. This would be the first time that those at the university level and those who worked more closely with educators in schools would attempt to collaborate in this way on a curriculum project that would be partially funded by the North American Division Technology Planning Committee (Brantley, 1995a).

\section{The Selection of the Schools}

Since this project was under the sponsorship of the North American Division it was decided that the schools which would be a part of the pilot would be selected from the nine regions that made up the unions in this division. The union directors of education would be responsible for selecting the schools. Those selected were to be oneteacher schools whose local school board and teacher were willing to embrace a change in curriculum that involved the use of technology. The school boards also had to be willing to invest funds in securing the equipment and services for implementing the curriculum. Only eight schools representing five unions--Southern, Lake, Columbia, Mid-America, and Pacific--chose to be involved in this pilot during the 1997-1998 school year. 


\section{Summary}

This chapter presented a historical overview of the Technology Partnership Curriculum Initiative. It traced its beginning in the San Fernando Conference and documented significant events that led to its adoption as one of the projects that the North American Division Technology Planning Committee would partially fund. Also included in this chapter are some details about how schools were selected to be a part of the Technology Partnership pilot project. The contributions of other entities such as Southwest University and Educational Management Group which were in support of this project is also described here.

This chapter is important because it provides a context for the research study. It tells the Technology Partnership story in chronological sequence. It introduced all of the major players who have influenced the conceptualization of Technology Partnership. It also introduced most of the other individuals who would be involved in its development and implementation in the pilot project during the 1997-98 school year. A brief overview of the literature related to this research is included in chapter 3. 


\section{CHAPTER THREE}

\section{LITERATURE REVIEW}

This section of the study includes a selected review of the literature on educational change with an emphasis on staff development, teacher change, organizational development, and technology and change. It provides a brief summary of historical information, the findings of some of the classic/significant studies. including the most recent research findings in the selected areas.

\section{Staff Development}

Staff development is a term that is very commonly used in the literature on school improvement efforts. It involves the organized efforts by schools and institutions of higher education to train teachers in innovations and to support them during the implementation process. Research has documented an intimate relationship between staff-development training and the process of restructuring or improving schools (Fullan, 1991; Sparks. 1983).

Research studies during the early history of staff development were scarce and not very promising. In 1957, the authors for the National Society for the Study of Education (NSSE) found only 50 research studies that were relevant to staff development. Only 6 of 
those were experimental studies in the areas of teacher training, curriculum improvement, and implementing innovations. Most of the findings from this limited emperical base suggested areas that needed to be further researched. Nearly every major work during this time up to the early 1970s documented the failure of staff development efforts (Corey, 1957; Gusky, 1986; Richey, 1957).

Nicholson and Joyce (1976) reported that, though the knowledge base on staff development had broadened considerably by the mid-' 70 s, most of the literature was descriptive or conceptual with only a small number of books or articles mentioning current studies. Fullan (1982) and Miles and Huberman (1984) discovered an increase in the amount of research on staff development integrated with studies of curriculum and innovations. They pointed out that though the picture of staff development during the 1970s and early 1980s was one of unsuccessful implementation of curriculum innovation, some studies did provide information on the relationship and importance of staff development to the successful implementation of innovation.

One of these studies was research reported by Joyce and Showers (1995). Their research, which led to the development of the Training Model, yielded critical elements that are important to the design of staff-development programs. After examining the research on approximately 200 effective staff-development programs, Showers, Joyce, and Bennett (1987) identified several key components which helped to ensure success of these programs. The model they designed as a result of their research findings on staff development include a presentation of the theory of the innovation, demonstrations of the skills to be learned, practice with feedback, and coaching. Teachers are likely to transfer 
the training, as well as keep and use new strategies and concepts, if they receive coaching from either a peer or an expert while they are trying the new ideas in their classrooms.

Showers et al. (1996) and Henriquez-Roark (1995) studied an effective staffdevelopment program in Richmond County Public Schools in Richmond County, Georgia. They found that in addition to the use of the Training Model (Joyce \& Showers, 1995), the use of teacher study groups-groups of four to six teachers meeting regularly for training to adopt and implement innovations-is essential to the transfer of training in the classroom practice. According to Henriquez-Roark (1995), the teachers involved in groups reported that they grew professionally because the study groups:

1. Supported and encouraged implementation of innovations and long-term change

2. Provided structure that was essential for acquiring new teaching skills and strategies

3. Exerted the pressure and motivation required to continue practice

4. Encouraged teachers to increase their repertoire of teaching strategies

5. Motivated teachers to focus on curriculum and instructional issues

6. Promoted improved teacher interactions

7. Stimulated better teaching because teachers were able to add a variety of teaching strategies and ideas to their instructional repertoire.

During the 1990s, studies have focused more on the outcomes of staff development activities. Researchers during this decade have continued to defend a variety of elements which have positively impacted staff development. Sparks (1997) 
advocates a different kind of staff development that is school-focused. job-embedded, and delivers results. The Newman and Wehlage (1995) study of "successful school restructuring" in more than 1,500 schools discovered that in successful schools, efforts are expended to make a positive difference in students' learning and performance. These schools focused on authentic pedagogy; teaching that requires students to think; to develop an in-depth understanding of how to apply academic learning to important realistic problems, and student learning. The results of this study underscores the need for teachers to be trained in order to deliver this kind of instruction in their classroom.

Sparks (1997) discussed how trends in the area of staff-development training have focused on content and content-specific pedagogy. He indicated that recently developed standards in the various disciplines require teachers to lead students to a depth of understanding that often was not present in their college courses. Cawelti (1995) speaks of the need for teachers to have opportunities to acquire deeper understanding of content and to be instructed by teachers who model instructional practices appropriate to that content. Effective staff-development efforts must address the need to initiate and support this kind of learning for teachers if they are to be expected to change their practices.

\section{Teacher Change}

Another key area in the change process that is closely related to staff development is the research on teacher change. A large body of research, more than 2,000 studies, in the field of education, anthropology, rural sociology, and medical sociology has 
documented the phenomenon of individuals' initial resistance to change (Rogers, 1962; Rogers \& Shoemaker. 1971). House (1974) wrote about the personal cost to teachers to change and embrace new innovations. He cited the amount of time and energy that is required to learn new skills and roles without the evidence that this investment would yield dividends and without the hope of immediate return as a useful index to understand the magnitude of resistance to change efforts. Marris (1975) makes the point that all real change involves loss, anxiety, and struggle. Teachers' attitude toward change has been described by Lortie (1975). He discovered that many proposals for change strike them as frivolous since they do not address issues of boundedness, psychic rewards. interpersonal support. time scheduling, disruptions from students, and so forth.

The Berlin and Jansen (1989) perspective on teacher change indicates that teachers change only if they are convinced that the new way is good for them--if it would lead to increased student learning. Fullan (1991) adds to the knowledge base on the subject of teacher change by highlighting factors that are involved in this process. He points out that the change with which teachers contend could include (1) the use of new or revised materials, (2) the use of new teaching strategies or approaches, and (3) the change in pedagogical assumptions and beliefs. Of the three the last is the most difficult. He implies that the outcome of the change teachers make will be determined by how such factors, such as these will be addressed or ignored.

Three major studies have contributed to the knowledge base on educational change as it relates to teacher change, staff development, and building organizational cultures in schools. These studies include the Rand Change Agent Study, Dissemination 
Efforts Supporting School Change (DESSI), and the Concerns-Based Adoption Model (CBAM).

\section{The Rand Change Agent Study}

The Rand Change Agent study (Berman \& McLaughlin, 1978) was a 4-year national study conducted between $1973-1978$ by the Rand Corporation under the sponsorship of the U.S. Office of Education. The study examined and evaluated a nationwide sample of 293 educational innovations funded by federal agencies and implemented in public schools in 18 states. Many change-agent programs were specifically focused on reading, career education, and bilingual education. These federal agencies offered temporary federal funding to school districts as "seed money" to initiate and implement a designated innovation. It was assumed that if an innovation was successful, the district would use other sources of funds to continue the project.

These programs were the first major federal-level attempt to affect change in educational practices in specific locales. The study found that the adoption of a project did not ensure successful implementation. It also discovered that successful implementation did not guarantee long-term continuation of projects once federal funding was no longer available. In general, it was discovered that it was very difficult for policy to change practices.

McLaughlin (1998) elaborated on the difficulty of policy being used to implement and sustain even the smallest change. He stated, "What actually happens as a result of a policy depends on how policy is interpreted and transformed at each point in the process, 
of the Rand study illustrates how factors such as educational methods, project resources, scope of project, implementation strategies, organizational climate and leadership, teacher attributes, and district management capacity and support affect the outcomes in the implementation of innovations.

\section{The CBAM Model}

Studies on teacher change inspired the development of the Concerns-Based Adoption Model (CBAM) by Hall and Loucks (1977). This model enables an organization that is involved in educational change to examine the process that the institutions and individuals experience when implementing innovations. This model views the teacher as a key facilitator of change in school improvement processes. It is described by its authors as a "client centered diagnostic/prescriptive" (Hall \& Loucks, 1978, p. 39) approach because it takes into consideration teachers ${ }^{\star}$ concerns at various stages in the change process. CBAM provides a series of instruments for formulating, implementing, and assessing curricular innovations. Innovation. according to Gaikwad (1991), refers to the new program or process being implemented or to key changes being made in an existing program.

CBAM consists of three systems: the innovation configuration, a tool which can be used for operationally defining an innovation; the Stages of Concern (SoC), a diagnostic tool of CBAM which focuses on the "concerns" that teachers experience during a change effort; and the Levels of Use (LoU), another diagnostic tool which measures the levels of use of an innovation or new school improvement practices. • 
The major assumptions of CBAM are:

1. Change is a process, not an event; it occurs over time.

2. Change is made by individuals; they must embrace and demonstrate the desired behavior in practice before it can be said that a change has occurred.

3. Change is a highly personal experience; allowance should be made for differences in individuals since each react differently to change. This change involves developmental growth in feelings, skill, and competence in respect to the use of an innovation.

4. Change is best understood in operational terms; teachers will relate to change in terms of what it means to them and how it would affect their classroom practices.

5. The focus of facilitating change should be on the individuals. the innovations. and the context.

The research findings on the CBAM model have contributed a wealth of valuable information for change facilitators to use in encouraging teachers use of new or innovative programs. If used appropriately, it can assist the change facilitators in reducing the threat which change poses for individuals. It can also increase the likelihood of the educational institution integrating innovations with a high level of use.

\section{Dissemination Efforts Supporting School Improvement (DESSI)}

DESSI (Loucks, 1983) was a large 3-year study on change initiatives which was funded by the U.S. Department of Education. Its findings allowed us to look at schools improvement and change from a perspective that was different from the ones which 
came from discouraging reports of studies such as Goodlad (1984), the President's National Commission on Excellence in Education (1983), and Rand Change Agent Studies (Berman \& McLaughlin, 1978). DESSI used qualitative measures such as interviews, questionnaires, observations, and field notes to track 61 innovations from their federal sponsors to over 400 classrooms in 146 school districts in 10 states. From this sample the researchers probed 12 sites for an entire year to understand the dynamics of the school improvement process.

The purpose of the study was to examine the effects of the strategies the government was using to encourage school improvement by the dissemination of new practices that had been developed with federal support. The sites involved in the study either (1) received funding to develop innovative projects, (2) adopted nationally validated programs through the Education Department's National Diffusion Network and state-validated programs through their state department of education's dissemination program, or (3) purchased special education resources from publishing companies.

The study was able to identify several factors which contributed to the successful implementation of those programs. Those factors included:

1. The commitment of the teachers

2. Carefully developed, well-defined curriculum and instructional practices

3. Training, conducted by credible people such as former teachers, that included follow-up activities

4. Adequate support and assistance from a variety of players; some of these included other teachers, principals, district staff, and external trainers 
5. Attention to elements that contribute to institutionalization (ensuring that the new practice remained), including financial appropriations, orientation for new staff members. and writing the new program into the curriculum guidelines.

More recent studies and commentaries on success factors that are relative to teacher change advocate building collaborative, collegial relationships which focus on teachers participating in processes involving collective inquiry. Fullan (1997) documented the issues warring against building this type of collegial relationship and the deep change in teachers that requires new ways of thinking and behaving. These issues include: (1) the growing alienation among teachers: (2) balkanization and burnout of teachers who support reform; and (3) the multiplicity of fragmented and disconnected change initiatives.

Hargreaves (1997) supported Fullan's view by citing the findings of a large body of research. Several of the findings relate to issues relative to the failure of change efforts. According to Hargreaves, the tindings indicate that change efforts may fail because

1. The reason for the change is poorly conceptualized or not clearly defined. It is not clear who will benefit from the change, and what the change will achieve for the student is unclear.

2. The change is so broad and ambitious that teachers feel they have to work on too many initiatives; it is too limited and specific so that little real change occurs.

3. The change is too fast for people to cope with or too slow that they become bored and want to move on to something else. 
4. Key staff, who can contribute to the change or might be affected by it, are not committed or they are overly involved so that they seem like an innovative elite group. In either case, resistance and resentment are the consequences.

5. Leaders are either too controlling, too ineffectual, or use early success as an impetus to move on to other initiatives.

6. The change is followed by isolation and is undermined by other unchanged structures such as standardized tests and traditional report cards. Conversely, the change may be poorly coordinated with other changes, which makes it difficult for teachers to focus their efforts.

Karrer's (1996) conclusions from her study on teachers' thinking and the change process indicate that teachers' personal beliefs and theories about teaching and learning are very powerful factors in the process of change. Although changes in beliefs are not clearly seen until late in this process, the power of those beliefs influences the process from the beginning. These beliefs can influence how a teacher perceives the expectations of the people and structures of schooling, the nature of the vision a teacher develops, and the judgments of success or failure a teacher assigns to attempts to change.

Fullan (1997) argues for a new approach to change which embraces the need to pay attention to the emotional aspects of change. He contends that the emotional side of change has been ignored or misunderstood. He believes that through the examination of the emotions we can gain new insights into the dynamics of change as well as new understanding about how to make change work more constructively. Fullan also postulates that the situation of change is profoundly problematic, and that we are down to 
our last virtue: hope. He feels that we stand less of a chance of effecting change by pursuing the techniques of innovation than we do by working on a deeper understanding of the complex interrelationships of emotion. hope. empathy, and moral purpose.

Hargreaves (1997) supported Fullan's conviction that change efforts need to focus on emotional learning with this statement:

At the moment, many of our attempts to improve children's learning are directed from the neck up. Assessment standards, reading methods, higher-order thinking skills, problem solving-they all address only what goes on in children's heads. Focusing on strategic planning, cognitive leadership, or organizational learning, for example, similarly biases our change efforts toward the intellectual dimensions of teachers" work. Our change priorities fail to develop what Goleman (1995) calls the emotional intelligence of students and teachers alike: emotional intelligence that actually adds value to the students' classroom learning and the teachers' professional learning. (p. 2)

Though a large number of studies on Fullan's and Hargreaves convictions is

lacking, Goleman's (1995) review of the emotional intelligence gives additional support

to this viewpoint. Goleman wrote:

Much evidence testifies that people who are emotionally adept-who know and manage their own feelings well, and who read and deal effectively with other people's feelings-are at an advantage in any domain of life, whether romance and intimate relationships or pick up the unspoken rules that govern success in organizational politics. People with well-developed emotional skills are also more likely to be content and effective in their lives, mastering the habits of mind that foster their own productivity; people who cannot marshal some control over their emotional life fight inner battles that sabotage their ability for focused work and clear thought. (p. 36)

Support for this viewpoint in the current literature calls for teachers to become collaborative community of learners. Research has shown that colleagues working together can share burdens, reduce duplication, provide moral support, and provide 
opportunities for the collective strength of teachers to be utilized (Hargreaves. 1994; Henriquez-Roark, 1995; Johnson, Johnson. \& Smith, 1998; Rosenholtz, 1989).

The views about paying attention to emotional learning are related to studies on self-efficacy. Gibbons and Kimmell and their colleagues (1997) define self-efficacy as a person's perceived ability to perform on a task or produce a desired outcome. Selfefficacy can be viewed as the conviction that one can successfully execute the behavior required to produce the outcomes in conjunction with a person's estimate that a given behavior will lead to a certain outcome (Goldfried \& Robins. 1982). Efficacy expectation affects one's choice of activities, how much effort will be expended, one's maturation in coping skills, and how long one will persist in the face of obstacles (Bandura. 1982: Locke, Frederick, Lee, \& Bobko, 1984).

According to Bandura and Adams (1977), we develop our expectations about our ability to perform certain actions or tasks from four sources of information. They include performance accomplishment, modeling, verbal persuasion, and emotional arousal. In the first source, the performance accomplishment, efficacy expectations are developed through repeated experiences of success. Therefore it is crucial for staff-development programs to be designed to effect positive changes in several dimensions--teachers' attitudes, beliefs, and practice--that would be long lasting. These programs should be so well designed that the skills learned can be integrated into classroom practice so that it would provide opportunities for teachers to repeatedly experience success with children (Loucks-Horsley, et al., 1989). The literature indicates that teachers' success in 
positively impacting students with innovative practices will greatly enhance their feelings of self-efficacy and their emotional well-being.

\section{Organizational Development (OD)}

Educational change not only embraces staff development and teacher change but it includes building synergistic, collaborative cultures within educational organizations. Emphasis on systems thinking reinforces the notion that individual learning and organizational changes must occur simultaneously and support one another if the gains made in one area are not to be obliterated by continuing problems in another (Sparks \& Hirsh, 1997). Sparks (1997), writing about this connection, said. "Because staff development is embedded in systems that profoundly affect its effectiveness, school leaders must address structural issues as well as the learning needs of individual employees" (p. 1). They should pay attention to organizational development principles.

Organizational development (OD) is a term familiar to industrial and governmental organizations since the 1950s. In education, organizational development has much to do with the organizational behavior, culture, and climate of schools. A definition of OD supplied by Fullan, Miles, and Taylor (1978) summarized from statements in the literature is:

Organizational development (OD) in school districts is a coherent, systematically planned, sustained effort at system self-study and improvement, focusing explicitly on change in formal and informal procedures, processes, norms, or structures, and using behavioral science concepts. The goals of OD include improving both the quality of life of individuals as well as organizational functioning and performance with a direct or indirect focus on educational issues. (p. 135) 
Sparks and Hirsh (1997) suggest that organizational development within a school system could take many forms. It could involve the teaching of special skills to school employees who will facilitate meetings and assist in conflict resolution. It could involve the training of process observers who attend meetings to provide feedback to participants on the group's performance. It could also involve the use of outside consultants who diagnose and design interventions around common organizational problems, such as communication problems, interpersonal conflicts, and fragmented improvement efforts. Thus the meaning of organizational development even embraces the behavior of individuals within the culture these educational organizations.

Owens (1998) describes the study of organizational behavior as the study of the "internal needs and personality characteristics of the individual in dynamic tension with the environment created by the educational organization" (see p. ix). He states that school, like any other social organization. has "power. structure, logic, and values which combine to exert strong influence on the ways in which individuals perceive the world, interpret, and respond to it" (see p. xvii).

The literature on school improvement has endorsed the necessity for schools to view their faculties as a community of learners if they are to experience success in change efforts. Joyce and Calhoun (1996) argue that, for schools to become learning communities, significant organizational changes are necessary. They commented that school improvement efforts have been hampered by several obstacles: no embedded time in the workday to engage in collegial inquiry; no structures or systems for democratic decision-making; no "fluid, information rich environment" (see p. 179), and the absence 
of a system for effective staff development. Consequently, school improvement efforts, aimed at implementing strategies, have had success only with those which could survive in an environment that is inhospitable to collegial interchange.

Owens (1998) strongly encourages those who aspire to be successful in educational leadership to understand the interplay between individuals and the social environment in the world of work because of the power it exerts in giving rise to organizational behavior; thus, working with and through individuals, the leader can achieve the goals of the organization.

The history of organizational development is tied to that of social and humanistic psychology. Kurt Lewin is widely accepted as one of the pioneers, if not the founding father of these branches of psychology. One basic concept in understanding organizational behavior is that it is heavily influenced by the characteristics of the organizational environment. This idea was espoused by both Lewin (1935) and Murray et al. (1938), and others who were working independent of each other.

Through its more than 60 years of development. organizational behavior has been characterized by two main viewpoints. One is the perception of educational organizations as hierarchical, bureaucratic systems exercising power and authority from the top down; the individuals who work within these structures must comply with the organizational demand. The other strand is the perception of educational organization as human social systems in which the members are viewed as the most valued resource in creating a working environment that continually supports personal growth and 
development with the goal of influencing the most effective and appropriate organizational behavior (Owens, 1998).

The vernacular and research of school restructuring that calls for empowerment, site-based management, and participative decision making are closely related to the study of organizational development. In reporting on a major study of OD in schools, Fullan et al. (1978) pointed out the problematic nature of assessment of OD efforts to develop the self-renewal, problem-solving capacity of school organizations. Many of the OD projects are partial. incomplete. short-term. and lack planning, scope. and sustained effort. Many short-term human relations training or situational conflict resolution sessions are incorrectly labeled OD. School districts that are successful with OD tend to instutitionalize it and maintain it over time (Owens, 1998).

Schmuck and Runkel have conducted some of the most comprehensive research studies in the field of OD in education. They began their work in 1967, and published their initial findings in 1974. They caution against accepting superficial claims about any effort at change. Their findings regarding $O D$ in educational settings include:

1. Administrative support is critical to success.

2. OD will be beneficial with faculties who have been involved in agreement on goals of the project/organization.

3. Working with a skilled OD consultant can help a group to bypass potential problems.

4. The likelihood of success is greater when a faculty has a readiness for change and welcomes the $O D$ project. 
5. An OD project can have four phases: (a) entry, (b) diagnosis of organizational problems. (c) institutionalization of the change effort, and (d) maintenance.

John Goodlad's (1975) work with OD inspired him to undertake a 5-year research and development study relative to the problems associated with the "continuing, frustrating failure of promising innovation to alter school practice in desired ways" ( $p$. xi). One of the critical propositions in Goodlad's research was that the entire school can and should be considered as being receptive to and capable of changing; also. as schools change their cultural characteristics, so will the individuals who work in them change.

An experimental intervention aimed with developing the capacity for selfrenewal in schools was conducted through training faculties in a four-step process named DDAE (dialogue. decision making, action. and evaluation). In schools where DDAE was being used most effectively, there was: (1) more cooperative teaching arrangements, (2) more friendship networks among teachers, and (3) more task-oriented communications among teachers.

From his study, Goodlad (1975) realized that "the regularities of the school sustain certain practices, through expectations, approval, and reward" (p. 113). He also discovered that teachers working individually are usually not able to successfully combat these regularities or to create the school-wide structures and processes that are necessary to sustain new practices. The findings from Goodlad's research suggested the need to focus on the entire culture of the school--its curriculum, overt and covert rules, verbal and nonverbal communication, physical properties, pedagogical regularities, leadership 
behavior, and other elements. Total Quality Management (Bonstingl, 1992) is one model which includes principles for building the kind of school culture which Goodlad suggests.

\section{Total Quality Management (TQM)}

Edward Deming `s work on Total Quality Management (TQM) has somewhat dominated contemporary thought on OD. Deming's fame came from the positive impact of TQM on Japanese industrial management during the decades of the 1950s through the 1980s. Prior to the 1980s. Deming's work was largely ignored and resisted by management in the United States; however, his success in Japan began to positively influence American industries. By the 1990s educational organizations in the United States were beginning to pay attention to the principles he espoused (Bonstingl, 1992).

From his work in Japan, he discovered that the knowledge gained from his statistical analysis of product quality was not significant enough to effect a lasting improvement of an organization. He realized that effective changes would be implemented only when ideas about human resource development within organizations were embraced. He then began to devote time to ideas disseminating the concept of cooperation in the workplace: power-sharing, shared visioning, win-win conflict management, and other related ideas (Owens, 1998).

Several lessons from the work of Deming parallel the findings from the research on educational change (Owens, 1998): 
1. The shortcomings of organizational performance have more to do with managerial methods than with the inadequacies of the workers. In restructured programs. school leaders are moving toward the role of a facilitator of change and work hard toward building a strong sense of the school as a learning community (Joyce \& Showers, 1995).

2. One of the central problems in achieving total quality was the traditional ways of doing things, one of the inherent traits of top-down management style. This concept also highlights the changes in assumptions and beliefs that must precede a change in practice (Fullan, 1991). The culture of inertia in educational organization which needs to be changed is well-documented (Goodlad, 1984; Lortie, 1975). This same cultural quality has been labeled "learning impoverished" by Rosenholtz (1991), "learning disabled" by Senge (1990), and "organizational defensive routines" by Argyris (1993).

3. Enlisting the willingness of workers to do a good job and urging a greater degree of cooperation between managers and workers in mutual problem solving have a positive effect on organizational development. Several researchers have documented the importance of building a collaborative culture in the workplace (Glickman, 1990; Lezotte \& Levine, 1990).

4. Making the needs of the customer foremost impacts the quality of organizational performance. Increased student learning is a powerful rationale for sustaining school improvement and organizational development (Joyce \& Showers, 1995; Joyce \& Weil, 1996). 
5. The Japanese concept of kaizen, or a continuous ongoing process, is basic to organizational change. Peer coaching and study groups have been advocated by Henriquez-Roark (1995), Joyce and Showers (1995), and Showers et al. (1996) as a means of providing ongoing support.

\section{School/University Partnerships}

Other organizational structures, aimed at improving education, strengthening positive relationships, and promoting growth of educational organizations. are school/university partnerships, currently being called Professional Development Schools (PDS). The affiliation of schools and universities is not a new idea. Earlier configurations to promote cooperation between these entities were mostly limited to the lab school concept and by the assumptions that "college faculty were knowledge producers and the schools were simply the sites for research and teacher preparation" (Banschbach \& Prenn. 1993. p. 278).

A review of the current literature on school/university partnerships revealed studies that were mostly limited to the establishment of PDS partnerships. Although several have attempted to develop this kind of organizational structure (American Association of Colleges for Teacher Education, 1996; Berg \& Murphy, 1992; Glickman, 1993; Goodlad, 1988) its operation is complex and problematic. One of the most visible organizations that has used this type of collaboration as a fundamental strategy is a group of research institutions initially called the Holmes Group (1990), which has since been renamed the Holmes Partnership. 
Although the structure, governance, and operation of PDS are diverse (Fullan, Galluzzo, Morris, \& Watson, 1996; Hardin \& Kunkel, 1994), the type of school/university partnership conceptualized by the Holmes Partnership represents schools that would serve themselves and professional education the same way teaching hospitals serve medical education (Murray, 1996). The guiding principles for the Holmes Group's PDS partnership (Holmes Group, 1990, p. vii) include the following: (1) teaching and leaming for understanding; (2) creating a learning community; (3) teaching and learning for understanding for everybody's children; (4) continuing learning by teachers, teacher educators, and administrators; (5) thoughtful, long-term inquiry into teaching and learning by school and university faculty working as partners: and (6) inventing a new institution.

Kochan and Kunkel (1998) reported a study of school/university partnerships conducted in South Alabama. Auburn University initiated a PDS and extended collaboration by uniting with other institutions to establish a group of PDS partnerships. Auburn used funds acquired from the Alabama Power Foundation to unite with four other institutions of higher education and their partner schools to form a coalition of PDS called the Learning Coalition. The coalition's aim was to create, within an agreed upon framework, a community of learners sharing a common purpose, operating in a diverse manner, learning from one another and being a catalyst in the state. In developing the partnership, the coalition used the Holmes principles (Holmes Group, 1990) in conjunction with the guidelines they had framed. 
A survey, completed by 17 teachers and administrators from both the schools and the universities examined priorities of their partnership, major problems they were encountering, and primary benefits of these relationships. The results were consistent with other research (Kochan. 1996). The respondents cited improving preservice teacher education as the top priority and research and inquiry as a last priority. The problems faced by the partnerships were placed in three categories: management issues, commitment, and communication. Linda Darling-Hammond (1994) in her study of PDS classified similar findings as institutional, financial, and policy challenges. The respondents cited the major benefits of the partnerships established through the Learning Coalition as developing collaborative learning communities. improving preservice education. providing an exemplary P-12 education. and providing continuing education for professionals.

The challenging nature of using a PDS model as a tool for achieving OD goals was highlighted in an earlier and similar study of the Laboratory District Teacher Education Center, a partnership of 14 school districts and Mankato State University in Mankato, Minnesota. Several kinds of isolation hindering collaboration between schools and universities were discovered (Banschbach \& Prenn, 1993). These included isolation caused by (1) the physical distance between schools in rural areas; (2) the traditional spatial and temporal organization of schools as identified by Lortie (1975); and (3) the cultural distance between schools and universities of which Goodlad (1988) wrote.

The importance of a significant investment of time in order to experience some degree of success with this organizational configuration cannot be overstated. After 4 
years the center reported "the beginnings of collaboration among the Center schools that extend beyond the initial program" (Goodlad, p. 122). As important as goals, structures. and accountability measures are to the operation of these partnerships, they were not cited by this study as the variable that was mostly responsible for its degree of success. The study cited the mentor teachers as being the agents most responsible for the beginnings of collaboration. The journals and assessments of their mentoring experience attested to the mentors' perceptions of being renewed. They reported that they had: (1) enriched their classroom skills; (2) learned new teaching strategies in response to mentees' needs; and (3) learned from the mentees themselves.

Levine (1997) supports the conviction of a significant investment of time as a key variable in the process of the changing goals, structures, and relationships in university/school partnerships. He indicated that the magnitude of change as required by this organizational design requires a long-term commitment. Kochan and Kunkel (1998) reported that it took 3 years for most of the partners in the Learning Coaiition to speak frankly and openly with one another within and across institutional sites. They pointed to: (1) rewarding participants, (2) focusing on successes, (3) providing specific training in overcoming resistance to change, (4) building collaborative teams, (5) connecting the efforts of PDSs with research responsibilities, and (6) effective communication, as strategies to prepare and strengthen individuals who participate in PDS endeavors. Building collaborative cultures within educational organizations is a complex and difficult task. Fullan and Hargreaves (1996) described collaborative cultures as being "difficult to pin down in time and space, living as they do mainly in the interstices of 
school life" (p. 57). This task cannot be accomplished overnight because it is intimately linked to the idea that change is a process that occurs over time (Fullan, 1991; Hall \& Hord, 1987). Total Quality Management and Professional Development Schools are existing models which can be utilized to develop this capacity to collaborate within educational organizations.

\section{Technology and Educational Change}

The role that technology plays in the educational change process involving student learning has been seriously questioned (Clark, 1983; Hannafin \& Savenye, 1993). Several decades ago two types of technologies in schools were supposedly revolutionizing the field of teaching (Ellis \& Fouts, 1994). They were audio/visual instruction and instructional television.

Audio/visual instruction held the promise of replacing textbooks and dull lectures from the teacher. Instructional television had the potential of replacing teachers or possibly bringing excellent teaching to a vast number of students. The potential to elevate students to a higher level of academic standards seemed more easily obtainable. In spite of these lofty dreams, the promises of the then technological revolution were never realized. Hannafin and Savenye (1993) observed that "each technological 'breakthrough' in the past resulted in disappointment followed by disillusionment and eventually abandonment" (p. 26). 
Even though the technologies listed above are still in existence. the emphasis on the upcoming century has shifted to an emphasis of interactive computer technology. The issue that was raised by Ellis and Fouts (1994) in relation to this type of technology is whether its use in restructuring education will deal with how teachers teach and how students learn at school.

Papert $(1980,1993)$ campaigned for a radically restructured school which replaced textbooks, lecturing, and passive learning with information that could be accessed electronically. In this restructured school. students use a variety of computer related media such as videodiscs, CD-ROMs, HyperCards, camcorders. telecommunication, and satellite configurations using uplinks, downlinks, online databases, etc.. to create a learning environment with self-directed learners who will be solving real-life problems.

Clark (1983) took a different position than those who advocated views similar to Papert's. He believed that researchers should stop examining the relationship between the media and learning until a new learning theory was developed. He felt that "media are mere vehicles that deliver instruction but do not influence student achievement any more than the truck that delivers our groceries causes changes in our nutrition" (p. 445). Clark (1994) proposed that whenever a medium or media attribute seems to produce learning outcomes, there is ample evidence from both quantitative and qualitative inquiry that the substitution of another medium and/or attribute of a medium will produce the same or similar learning outcomes. In essence, he is suggesting that in any choice of media, it is the instructional method that is the active causal variable. 
Kozma (1994) suggested that, rather than trying to pull the media and the methods employed in its use apart, we should examine the cognitive and social mechanisms by which students interact with them as they learn. He studied a computerbased chemistry environment in which students conducted experiments to understand equilibrium systems and how they change. He concluded that in order to know what causes learning, one should look at it as it occurs because he believed that learning is influenced by both media and methods together.

Ellis and Fouts (1994) examination of the research literature on educational technology discovered that much of the research was emergent rather than definite and that it was directed toward the use of computers. They found the research findings to be somewhat confounding because they saw that it was very difficult to isolate a single variable to show cause and effect with efficacious outcomes in the learning process. Therefore, one is seldom sure which variable--the teachers' presence, motivation, the teaching and learning method, the use of the technology, the different types of programs-might be interacting with the technology to produce a certain result. Understanding the effect these variables have on the quality of the research is important when interpreting the findings (Becker, 1987; Clark, 1985a, 1985b, 1991, 1992). Although the research findings about the effect of educational technology is somewhat problematic, examination. of the reviews of the research synthesized by Ellis and Fout's (1994) has yielded the following results:

1. Students motivation to learn and their attitudes toward school have been positively impacted by the use of computers. 
2. Integrating the use of computers with traditional instruction produces higher academic achievement in several subject areas than do traditional methods alone.

3. When computers are used as an aid to learning, students tend to learn and retain more.

4. Successful technology programs in schools have been positively related to the provision of effective and adequate training for teachers.

In a more recent study, Wenglinsky (1998) supported Ellis and Fouts (1994) view of the problematic nature of studies on educational technology. He claimed that relevant studies are often flawed by factors such as the ratio of students to computers or the perpupil expenditure on technology as a representation of computer use when correlating technology use with student outcomes. He found that such contextual factors as teachers receiving training in how to use computers to teach high-order thinking skills were related to students' achievement gains between two groups of students.

Wenglinsky drew his conclusion from data collected by the 1996 National Assessment of Education Progress (NAEP) to examine the effects of computer use on student achievement in mathematics. He used teacher responses to a NAEP questionnaire to connect computer practices in the classroom with math scores for a large sample of over 13,000 fourth- and eighth-grade students. The result indicated that the effect of technology is highly dependent on the context in which it is used. 


\section{Summary}

The research on staff development, teacher change, technology, and organizational development presents a view of different aspects of educational change. Each of these aspects of the change process is linked to the other and to the implementation of any school improvement initiative, especially those related to curriculum reform. Designing effective staff development is a key link to teacher change. the use of technology in education, and organizational development in schools. Using the literature review to understand the work that has been done is paramount to building a foundation to develop and conduct the study of the Technology Partnership Curriculum Initiative. It is helpful to the understanding of the context of the study and to making connections between the findings of previous research and the Technology Partnership initiative. The study utilized several qualitative research techniques, which are outlined in the next chapter. 


\section{CHAPTER FOUR}

\section{METHODOLOGY}

\section{The Design}

Since a significant part of this research is an attempt to define, describe, and relate a story about the Technology Partnership Curriculum Initiative. I chose a qualitative, descriptive case study research design to best achieve this goal. This type of research is commonly used in curriculum development research because it allows for discovery, deep understanding, and insight into a complex phenomenon.

A case study is defined by Merriam (1998) as a systematic examination of a specific phenomenon--a program. an event, a person, a social group, a process, an institution. Cronbach (1975) sees case study design as an interpretation by context. an approach which aims to uncover the interaction of significant factors which are characteristic of the phenomenon. Case studies, according to Yin (1994), are also unique in their ability to deal with several different types of data such as interviews, observations, documents, and artifacts.

In investigating this design, I discovered that a case study could be descriptive, presenting detailed accounts of the phenomenon under study; it could be interpretive, 
including rich, detailed descriptions which are used for illustrating, supporting, or challenging existing theoretical assumptions; or it could be evaluative, which includes the pervasive qualities of descriptive and interpretative studies, as well as, being able to weigh this information to produce judgment (Merriam, 1998).

\section{Role of the Researcher}

Guba and Lincoln (1981) see qualitative researchers in similar roles as anthropologists, social scientists, connoisseurs, critics, essayists. oral historians, novelists, and poets: this is particularly true in the sense that they emphasize, describe, evaluate, compare, evoke images. and create for their audience the sense or feeling actually experienced in the research project.

Though I was minimally involved in a few of the sessions-providing feedback from journals; sharing ideas about implementing cooperative learning and Dimensions of Learning during the training and development of the units of study; taking part in discussions on the research agenda for this project; sharing during the teacher orientation session-my role as the researcher in this study was primarily that of a non-participant observer. As a member of the research team for Southwest University, I was primarily responsible for collecting qualitative data about the Technology Partnership initiative. Many times during the development for this first year, I had to remind myself that my principal responsibility was that of data collection. 
My keen interest in curriculum development was one of the factors that drew me to this project. I wanted to observe teachers and administrators being trained to use innovative teaching strategies; to sit with the curriculum development team and observe their involvement in this process; and to witness the implementation of the Technology Partnership curriculum.

As I began to frame my study, I was excited about being involved in an initiative which I believed would enable students to be "thinkers rather than reflectors of other men's thoughts" (White, 1903, p. 17). After entering the teaching profession, I deeply desired to help my students reach this goal. However, I realized that I had not been prepared in my teacher education training to instruct in ways that would enable students to be thinkers. I had attended some of the 2- and 3-day in-service sessions and felt frustrated about implementing techniques that had been enthusiastically promoted by the presenters.

As I began to study the literature on educational change, I realized that the findings of Goodlad (1984) concerning teachers' overreliance on lecture, and students' passive listening to instruction, were an accurate description of what was happening in my classroom. As I sought to understand my own philosophical beliefs, which were anchored in a Christian worldview, I recognized a dichotomy between the Seventh-day Adventist philosophy of education, in which I believed, and the way in which I was trained to teach. Though the Christian worldview acknowledges that Jesus used a variety of methods, I believe that SDA schools, just like most other schools, have institutionalized the lecture method that supports an idealistic, philosophical worldview. 
In retrospect, however, there were occasional demonstrations as well as a limited amount of practice in a few methods classes; however, when I graduated from the teacher education program in a college within the SDA system, I had learned well the method that was modeled most often-lecture. I sought training and support for changing my methods of teaching at Southwest University's summer institute. During the institute the participants we were given the opportunity to do peer teaching as well as practice the methods learned with elementary students. I experienced the joys and the frustrations of both utilizing these methods in my classroom and helping to train other teachers to use them. These experiences supported my belief that it would be difficult to implement the Adventist Education for the Twenty-first Century Curriculum Initiative without including a strong staff development component.

The results of the Profile (Brantley, 1995b) studies had validated the need for some vital changes in the area of curriculum. Teachers in the SDA system reported in these studies that they felt isolated and unprepared to implement innovative teaching strategies. By investing a substantial amount of money in Technology Partnership Curriculum Initiative, the North American Division, I believed, was endorsing a commitment to search for ways to effect a change in Adventist education in the future. Since over $80 \%$ of the schools in the North American Division are small schools, I believed that although there were hopes that this project would affect Adventist education in general, it was an earnest effort to provide support for those who work in these settings. 
I also believed that it would be difficult for those who worked in the conference/union settings to see the value of endorsing a structured, process-oriented. staff-development program using a design like the Training Model (Joyce \& Showers, 1995). Because many had not been exposed to this model, it was difficult for them to understand the need for that kind of training. I had been trained in the Joyce and Showers (1995) Training Model and in the use of the Models of Teaching (Joyce \& Weil, 1996). I felt that without initial and ongoing staff-development training, both the broadcast and site teachers would be severely challenged during the implementation of the curriculum. As I approached the study of the Technology Partnership initiative, I was consciously aware of some of my assumptions and biases about teacher change and particularly about change within the SDA system.

\section{Selection of Subjects/Sites}

The purpose of this research guided the selection of the subjects. Since a significant part of the study involved writing the Technology Partnership story and a chronicle of the curriculum development process, I needed to include those involved in the story itself.

I used nonprobabilistic sampling, which Chein (1981) calls a purposive sampling. A purposive sampling is based on the assumption that if one wants to discover, understand, and gain insight, one needs to select a sample from which one can learn the most (Merriam, 1998). Goetz and LeCompte (1984) call this same concept criterionbased sampling--finding a sample which matches the pre-established criteria. 
The criteria for selection of the informants were closely aligned to the goals of the study: (1) they played a significant role in the development of the vision of Technology Partnership from its inception in the San Fernando Conference in 1993 to its transplantation in the Maracas Conference in the spring of 1997; or (2) they played a significant role in the development and/or implementation of the Technology Partnership Units of Study.

The coordinator for the Technology Partnership Curriculum Initiative, Bettie Richards, provided assistance in this area. Since she was thoroughly involved in this visioning process in the San Fernando Conference, she was able to supply names of some of the individuals who would meet the above criteria.

My primary informants were the two teachers in whose classroom I had observed. My secondary informants were the project coordinator, the broadcast teacher, and two professors from Southwest University who had worked closely with the pilot project. Cost effectiveness was a significant factor in my selection of sites that would be involved in this study. Since all the sites were one-teacher schools, I choose the two that were closest to areas in which I had to attend to other business.

\section{Data Collection Schedule}

The data for this project were collected at major events that impacted the development of the Technology Partnership initiative throughout a 2-year span of time. It began officially in May 1997, when the team of educators from Pocono Union went to visit Southwest University and ended in May 1999. The latter phase of this time was 
used for clarifying information that related to the Technology Partnership story during the 1997-1998 school year. Table 1 shows the major times when data were collected.

\section{Data Collection Tools/Techniques}

Data collection techniques included the following tools/techniques: (1) unstructured interviews; (2) semi-structured interviews called Growth States interviews (Joyce \& McKibben, 1982); (3) the Innovation Configuration (IC) interviews (Hord, Rutherford, Huling-Austin, \& Hall, 1987); (4) observations: (5) surveys--the Gregorc Style Delineator (Gregorc. 1982); (6) reflective journals; and (6) artifacts. Data were collected during the 1997-1999 school years.

\section{Interviews}

Interviews are an essential source of information in a qualitative case study because most case studies are about human affairs. The story and the events in these affairs are best reported and interpreted through the eyes of specific well-qualified informants who can provide important insights into the particular situation (Yin, 1994). The use of interviews in research is necessary when (1) it is impossible for us to observe behavior, feeling, or how people interpret experiences in the world around them, (2) when we want information on past events that are impossible to reproduce (Merriam, 1998), (3) to confirm what has been observed, and (4) to triangulate data for a research study. I used a blend of unstructured and semi-structured interviews as a major data collection tool throughout this entire study. 
TABLE 1

DATA COLLECTION MATRIX

\begin{tabular}{|c|c|c|}
\hline Date & Event/Phase & Data Collection Tool/Method \\
\hline May 1997 & $\begin{array}{l}\text { Southwest University/Pocono Union } \\
\text { Visit }\end{array}$ & Observations and interviews \\
\hline June 1997 & $\begin{array}{l}\text { Institute for Pocono Union } \\
\text { Administrators }\end{array}$ & Observations, interviews, artifacts \\
\hline June/July 1997 & $\begin{array}{l}\text { Summer Institute for Southwest } \\
\text { University }\end{array}$ & $\begin{array}{l}\text { Observations, interviews, cognition } \\
\text { essays, surveys, artifacts }\end{array}$ \\
\hline July 1997 & $\begin{array}{l}\text { Orientation Session for the Technology } \\
\text { Partnership pilot project }\end{array}$ & $\begin{array}{l}\text { Observations, interviews, surveys, } \\
\text { artifacts }\end{array}$ \\
\hline September 1997 & $\begin{array}{l}\text { Meeting of Technology Partnership } \\
\text { Curriculum Development Team }\end{array}$ & Observations. questionnaire, artifacts \\
\hline March 1998 & $\begin{array}{l}\text { Two-day visit to one of the sites in this } \\
\text { study (Morris Town Elementary } \\
\text { School) }\end{array}$ & Observations, interview \\
\hline April, 1998 & $\begin{array}{l}\text { Two-day visit to one of the sites in this } \\
\text { study (Miles Elementary School) }\end{array}$ & Observations, interview \\
\hline June/July 1998 & $\begin{array}{l}\text { North American Division curriculum } \\
\text { committee meeting }\end{array}$ & Interviews \\
\hline $\begin{array}{l}\text { September } 1998 \text { to } \\
\text { May } 1999\end{array}$ & (Clarification phase) & Interviews, arifacts \\
\hline
\end{tabular}

\section{Unstructured Interviews}

Unstructured interviews are essentially used for exploration (Merriam, 1998). They were chosen because exploration was key to the data collection in this study. There was a story behind this project. The need to chronicle this story was an important part of this research. This type of interview was chosen because it allowed me the freedom of hearing the story in the passionate words and language of those who were involved with Technology Partnership from its inception. Eisner (1991, p. 183) made reference to the 
issue of understanding what is or has happened in a particular setting by saying that "we need to listen to what people have to say about their activities, their feelings, their lives." This type of interview allowed this kind of understanding to take place.

\section{Growth States Interviews}

The Growth States Interview, developed by Joyce and McKibben (1982), was the semi-structured interview employed in this study. These interviews provided pertinent personal data about the individuals who were critically involved in the development and implementation of the Technology Partnership Curriculum Initiative. The result provided insights into their growth activities, their knowledge, and their beliefs and outlook about teaching.

This interview protocol has four categories which describe a person's inclination for professional and personal growth. It includes: (1) The story of why one became a teacher, (2) one's involvement in formal staff-development activities. (3) informal contacts, networking with others, and (4) activities outside the classroom that influence professional duties. The information gathered from these interviews could be used as a guide to determine whether the profile of each individual describes someone who would add or subtract energy from the environment in which he/she works. The Growth States interview was used to create a profile of each teacher who was involved in this study.

\section{Interviews for the Innovation Configuration (IC)}

In a search to understand how teachers are using a certain innovation the innovation must be understood in operational terms. This understanding helps to describe 
how a program will look when it is implemented in the classroom. An Innovation Configuration (IC) (Hord et al., 1987) can provide this clear description. The concept of Innovation Configurations emerged from research on the process of educational change and it represents the patterns of use that result when an innovation is put into actual classroom practice. The patterns of use help to develop the IC checklist (Heck, Stiegelbauer, Hall, \& Loucks, 1981), which identifies the component parts of the innovation and variations in the use of each part. The IC process is facilitated by semistructured interviews.

An innovation configuration was of critical value to the curriculum development process. The Technology Partnership IC identified eight components that were to be included in the Technology Partnership Units of Study. The components include the following:

1. A competency-based curriculum

2. An integrated curriculum

3. A community event/experience

4. An integration of technological skills

5. A focus on learning needs

6. A variety of teaching methods

7. A focus on dynamic assessment

8. A project-based curriculum.

The IC was intended to serve as a rubric to guide the curriculum development team in creating the Technology Partnership Units of Study. This instrument could also 
be used as a tool to guide and evaluate the development and the implementation of the curriculum in the classrooms because each component provides a description of both student and teacher behavior as it relates to the units of study.

\section{Observations and Field Notes}

In qualitative research, observation is a critical tool in the data collection process. It allows the researcher to view the activities of the people involved in a given study, to see the physical characteristics of a setting, and to help them feel like they are a part of the scene. I observed several aspects of the study: the curriculum development process; the training of teachers and administrators who would be involved in the implementation phase of the curriculum; and the implementation process at two sites involved in the Technology Partnership pilot study during the 1997-1998 school year.

Some of the observation sessions included: (1) 1 day with the team from Pocono Union and Southwest University; (2) a week of training with the administrators from Pocono Union; (3) 4-weeks of training with the summer institute at Southwest University, which included a 2-week session with the curriculum development team; (4) l-week with the teachers and administrators at the orientation session for the pilot project; (5) and 1 additional week with the curriculum development team at its last official meeting in September 1997. I also spent 2 days observing at the two schools included in this study. At each of these sessions, field notes were taken to document different aspects of the Technology Partnership story. 
Surveys/Questionaire

\section{Gregorc Style Delineator}

The Gregorc Style Delineator is a self-analysis inventory developed by Anthony Gregorc (1982), which is helpful in understanding the mindstyle of those involved in the study. This inventory provides vital information about how the subjects in an environment tend to think and learn. Gregorc believes that a person's thinking and learning capabilities are revealed by two abilities, perception and ordering.

Perceptual abilities indicate how information is grasped or understood. Gregorc proposes that perception can be displayed on a continuum with two qualities, abstraction and concreteness. Ordering abilities describe the ways in which information is systematized, arranged and referenced. These abilities can also be placed on a continuum showing sequentialness to randomness.

Individuals can use this instrument to do a self-analysis to see the scores for their strengths within the four designated categories: concrete/sequential (CS), abstract/sequential (AS), abstract/random (AR), and concrete/random (CR). The rationale for using this inventory is that it provides some way of understanding how the individuals involved with the Technology Partnership Curriculum Initiative related to the development and implementation processes. This instrument also provides a context in which to present the Technology Partnership story. 


\section{Other Surveys}

A "Prebroadcast Survey" was given to all the teachers at the orientation session to gather information related to of their perceptions about their duties. responsibilities, and the amount of time they spent preparing and teaching various subjects in a multigrade classroom. It was also used to gain an understanding of their perceptions of their role in the project and the impact of the project on the students. Surveys were also given to assess individuals' perceptions of the benefits of the training/orientation sessions.

\section{Artifacts}

The artifacts of this study included journals, E-mails, training materials, articles written about the initiative, documents prepared for dissemination to constituents in San Fernando Conference. documents involved in the pilot study, the FACT $2 l$ report, and other applicable documents from the North American Division. Additional artifacts included units and other resource materials prepared by the curriculum development team and the training program for those involved in the pilot study.

\section{Data Compilation}

The data from the observation, interviews, documents, and field notes were compiled into six volumes. Volumes 1,2 , and 3 contains the materials from the training and orientation sessions. Volume 4 contains transcriptions of interviews.

Volume 5 includes journals, E-mail, field notes, and artifacts. Additional artifacts were placed in volumes 6 and 7. 


\section{Data Analysis Techniques}

A significant amount of the data from this study was organized topically and chronologically, and presented in a narrative that was largely descriptive. Later, much of the data were categorized inductively whereby themes, patterns, and the discovery of new insights and understanding emerged. Notes, comments, observations, and queries about the information were recorded. These notes helped me to initially isolate the most significant aspects of the data and identify points that needed to be clarified. The major ideas that cut across much of the information were listed. These categories were used to prepare a domain analysis. The domains were helpful in my search for patterns and regularities-ideas that occur frequently enough to make them noteworthy. The patterns and regularities were then transformed into categories or themes into which subsequent items from the data were sorted (Merriam, 1998; Goetz \& LeCompte, 1984).

\section{Trustworthiness}

The issue of trustworthiness of the findings of research involves the researcher, data collection tools/methods, methods of analysis, and the conclusions that are drawn from the data. Since qualitative research uses the full spectrum of data to generate hypotheses and build theory rather than test hypotheses and theory, it must address the questions of validity and reliability in ways that are different from those that are used in quantitative research. Merriam (1998) advocated the use several techniques to enhance validity and reliability. From that resource, I chose triangulation, member checks, long- 
term observation, peer examination, researcher's biases, rich, detailed descriptions, and the investigator position.

Triangulation involves the use of multiple investigators, multiple sources of data, or multiple methods to confirm the emerging findings.

Member checks involves taking the data and tentative interpretations back to the people from whom it was derived and asking them if the results are credible.

Long-term observation at the research site or repeated observations of the same phenomenon involves the gathering of data over an extended period of time in order to increase the validity of the findings.

Peer examination involves asking colleagues to comment on the findings as they emerged.

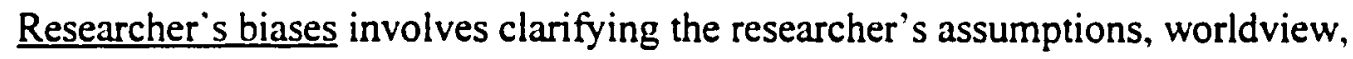
and theoretical orientation at the beginning of the study.

$\underline{\text { Rich, detailed description involves providing enough description so that readers }}$ will be able to determine how closely their situations match the research situations so that they can ascertain whether the findings are transferrable.

In this study, I have attempted to use these techniques to meet the standard of trustworthiness in the following ways:

1. The data were collected and triangulated from multiple sources including interviews, observations, surveys, and written documents.

2. The data were collected over an extended period of time and involved several contacts with the key participants. 
3. Data were reviewed by the key informants who were interviewed. Tentative interpretations were reviewed by peers.

4. The study included detailed descriptions obtained from the teachers at the sites which were selected for in-depth study.

5. A statement about my biases was included in this chapter.

\section{Outline for the Completed Dissertation}

Chapter 5 is devoted to a discussion of the development of the Innovation Configuration (IC) for Technology Partnership Units of Study. Chapters 6 presents a description of the staff-development training/and orientation sessions which were available for the participants involved in this curriculum initiative, while chapter 7 describes the curriculum development process for the Technology Partnership Units of Study. A description of the implementation of the pilot project in two schools is detailed in chapter 8. Chapter 9 is a discussion of the themes which emerged from the analysis of interviews with the two key informants in this study. Chapter 10 presents conclusions, and recommendations from this study. This final chapter also includes recommendations for further study.

The names of the project, conference entities, educational institutions, and all the informants in this study have been change to assure anonymity of all responses and confidentiality of all records. The quotations included in this dissertation are taken from the interviews and artifacts and are referenced as a volume, section, and page number in the field notes for this study. 


\section{CHAPTER FIVE}

\section{THE INNOVATION CONFIGURATION (IC)}

In this chapter I use the Innovation Configuration (IC) to describe the essential components of the Technology Partnership Curriculum Initiative. An Innovation Configuration is used to operationally define and describe the goals as well as the attributes of educational programs. It is one of the instruments that emerged from the development of the Concerns-Based Adoption Model (Hord et al., 1987).

In a prior study (1977) Hall and Loucks discovered that individuals who claimed to be nonusers of an innovation were actually practicing some of the same aspects of the innovation as persons who claimed to be users. In addition, some who claimed to be users were not demonstrating the attributes of the innovation they were supposedly practicing. The findings from this research led to the development of "minimum criteria" for users. This criteria would specify the use of minimum attributes of the components of an innovation that would enable an individual to be classified as a user.

The idea of creating an innovation configuration for Technology Partnership emerged from a meeting of the research team at Southwest University. Since this was a new program, the IC would identify the behaviors of users, the implementation processes, the materials and attributes essential for implementation. The IC would provide 
operational descriptions that would serve as guidelines for the development of the curriculum and the implementation process.

\section{Procedures for Designing an Innovation Configuration Checklist}

Before the procedure for developing an innovation configuration is described, it is essential to present some of the basic terminology that is associated with this design. These definitions are those used by Heck et al. (1981), Gaikwad (1991), and HenriquezRoark (1995).

\section{Definitions of Innovation Configuration-Related Terms}

Innovation Configuration: The operational patterns of an innovation that result when it is implemented by individuals in different contexts.

Components: The major operational features of an innovation. Usually it describes teacher behaviors, student activities, or the use of materials.

Critical Components: Refers to the components that must be used if the innovation is to be implemented.

Related Components: Related components that are not considered essential to implementation but are recommended.

Checklist: The listing of the components of an innovation with the possible variations that would be proposed if it were implemented in an educational setting.

Dimensions: The various characteristics or attributes of a component. Dimensions may be used alone or combined to make variations in a component. It is simply one characteristic or attribute by which a component may differ from another. 
Variations: The different ways to put a component in operation in the setting where the innovation is being used.

Fidelity: The degree of consistency to which the critical components of an innovation are utilized.

The Procedure

The basic procedure for developing an innovation configuration includes six steps. The finished product is a checklist of components and variations of the innovation being studied. A review of the literature on the development and use of the Innovation Configuration can be found in several sources (Gaikwad, 1991; Heck et al.; 1981; Hord et al.. 1987: Henriquez-Roark. 1995). Summaries of the general procedures for developing an IC are included in the steps below.

\section{Step 1: Identifying Innovation Components}

Making the components operational, or describing parts of the innovation, is achieved by reviewing as much descriptive material about the program as possible. Then the developer and/or some authority on the program are interviewed. The outcome of this first step is a clear picture of what constitutes the innovation as the developers want it to be used by educators or others and a proposed list of components with a few variations for each component. Questions that could delineate components of the innovation include:

1. Would you describe the innovation to me? 
2. What does the innovation look like when it is implemented? What will I see teachers and students doing in the classroom if this innovation were in use?

3. What are the most essential components of the innovation?

\section{Step 2: Identification of Additional Components and Variations}

After the developer's interview, users are interviewed and observed in order to clearly conceptualize what users are doing when implementing the innovation. Interviewing allows individual users to define the innovation as she/he sees it. The interview questions for users are similar to those answered by the developers. Observation is especially valuable when an innovation includes multiple-user roles. It also provides a means of validating the data collected in interviews. A wide range of users can provide additional information to edit and expand the initial checklist.

\section{Step 3: Enlarge Pool of Component and Variations}

This step involves interviewing and observing a larger sample of users. The data which is collected at this step can be analyzed to identify components of the innovation. Additional variations of components can also be obtained at this stage.

\section{Step 4: Checklist Construction}

At this step, an Innovation Configuration component checklist can be constructed using the data collected in steps 1 through 3 . This checklist can be designed by arranging the components and their variations in a logical format. 


\section{Step 5: Mark Users' Checklist}

In this step, teachers mark the checklist indicating their use of the innovation, or the checklist indicating use could also be marked by using data from interviews. The result is a rating of each teacher's use of particular variations within each component.

\section{Step 6: Data Analysis}

Though there are many ways to analyze the data collected on a component checklist, the most common type of analysis involves the use of a computer or manual computation of component frequencies. Profiles can be created using raw tallies of the frequency of how components are used by teachers in a variety of situations such as within a team, grade level, school, or district.

Developing an Innovation Configuration for Technology Partnership

Since the innovation configuration for Technology Partnership was being developed simultaneously with the curriculum initiative itself, it could not utilize all the steps that would be included in an innovation that has already been implemented. Further study needs to be given to verify use and to refine the proposed configuration for the Technology Partnership. The steps described below were taken to create the Technology Partnership Innovation Configuration.

\section{Step 1: Identifying the Components}

Since the Technology Partnership initiative was still in a stage of infancy, not much material on the subject. I began this stage by reading available information that 
was available on the initiative. This included information printed in the Final Report, a report presented by the Commission on Education to the constituency of San Fernando Conference in the spring of 1995 (Volume 5, Section M, pp. 1-55). I also reviewed Fact 21 the 1997 report of the Future's Commission, a sub-committee of the North American Division Office of Education, and spoke with two of the developers of the innovation.

Next, I interviewed Bettie Richards, one of the developers of the Technology Partnership initiative, using the following questions:

1. How would you describe the Technology Partnership initiative? What are the essential components of this initiative?

2. What will the program look like when it is implemented?

3. What will the broadcast teacher do? What will the local teachers do? What will the students do? What will I see in the classroom when the innovation is in use? The initial checklist that emerged from this interview identifying the Technology Partnership Curriculum Initiative is shown in Table 2.

\section{Step 2: Verification of Components and Variations}

Since this innovation was not yet developed, observing the innovation in use or interviewing any of the users was impossible. Therefore, I faxed a copy of the transcribed interview along with the initial list of components of the Technology Partnership initiative for Bettie to review. I met with Bettie and another one of the key developers, Leon, a few weeks later. We looked at the innovation configuration that was 
developed by Henriquez-Roark (1995) on study groups. This document provided a visual picture of what the finished Innovation Configuration could look like.

TABLE 2

INITIALLY IDENTIFIED COMPONENTS OF TECHNOLOGY PARTNERSHIP

\begin{tabular}{|c|l|}
\hline Component & \multicolumn{1}{|c|}{ Description } \\
\hline 1 & $\begin{array}{l}\text { The development of units of study which would reflect the holistic philosophy of } \\
\text { Adventist education's physical, mental, and spiritual development }\end{array}$ \\
\hline 2 & The focus on staff development \\
\hline 3 & The focus on the individual needs of students \\
\hline 4 & A realistic, effective assessment system \\
\hline 5 & A partnership with the school constituency \\
\hline 6 & Integration of technology into the whole learning environment \\
\hline 7 & A commitment to character development \\
\hline
\end{tabular}

After these two developer saw the innovation configuration on study groups, I probed them with additional questions about the Technology Partnership initiative. I asked them to draw a graphic representation of the initiative. An edited list emerged that outlined the components of Technology Partnership in more succinct terms than originally stated (see Table 3). I knew that we had begun a process of communication about this initiative that had to be continued at a later time. Since the initiative was emerging, I felt that time for reflection and further development was essential to the process of clearly defining the components and the attributes of the Technology Partnership initiative. 


\section{Step 3: Major Data Collection}

Step 3 could not be accomplished because the Technology Partnership initiative was not yet developed. The list in Table 2 was reviewed by the Technology Partnership curriculum development team as they worked to develop the Units of Study during the Summer Institute at Southwest University. I gave this list to Leon and showed him the IC for study groups (Henriquez-Roark, 1995), so that he could visualize how the IC for Technology Partnership needed to look. He took this list and reviewed the components over the weekend. Early the next week. I interviewed him about how he envisioned each component being operationalized.

TABLE 3

EDITED LIST OF INITIALLY IDENTIFIED COMPONENTS OF TECHNOLOGY PARTNERSHIP CURRICULUM INITIATIVE

\begin{tabular}{|c|l|}
\hline Component & \multicolumn{1}{|c|}{ Description } \\
\hline 1 & Integrated curriculum \\
\hline 2 & Competency-based \\
\hline 3 & Project-based \\
\hline 4 & Service-oriented \\
\hline 5 & Technology integrated \\
\hline 6 & Learning styles addressed \\
\hline 7 & Business partnerships \\
\hline 8 & Development of teaching repertoires \\
\hline 9 & Dynamic assessment \\
\hline
\end{tabular}




\section{Step 4: Checklist Construction}

The interview with Leon yielded the first proposed description of the variations of each component of Technology Partnership. This was printed as the first draft of IC for this initiative. It included proposed variations that could be considered acceptable, most desired, and unacceptable. This draft needed to be edited, so it was circulated between Betty, Leon, and four of the members of the curriculum development team. This draft of the Technology Partnership Innovation Configuration is shown in Table 4.

\section{Step 5: Data Analysis}

Step 5 could not be executed because of a lack of data from users. Instead, the proposed IC for Technology Partnership was edited at a scheduled meeting of the Technology Partnership curriculum development team in September 1997. The team discussed each of the focus areas on the draft and suggested the necessary revisions and annotations to further explain any areas that might be unclear. The edited work is shown in Table 5.

\section{Definitions of Terms Used in Technology Partnership Innovation Configuration}

Some of the definitions included in this section were suggested by the developers of Technology Partnership and others were suggested by the curriculum development team. Marzano and his colleagues (1997), Joyce and Weil (1996), and Kagan (1994) were also used as sources in the definition of terms. 
TABLE 4

\section{PROPOSED TECHNOLOGY PARTNERSHIP INNOVATION CONFIGURATION}

\begin{tabular}{|c|c|}
\hline Focus 1 & Competency-based \\
\hline a. & One hundred percent of the competencies will be addressed. \\
\hline b. & Seventy-five percent of the competencies will be addressed. \\
\hline c. & Fifty percent and less of the competencies will be addressed \\
\hline Focus 2 & Integrated curriculum \\
\hline a. & One hundred percent of the year's identified curriculum is integrated. \\
\hline b. & Seventy-five percent of the year's identified curriculum is integrated. \\
\hline c. & Sixty-five percent and less of the year's identified curriculum is integrated. \\
\hline Focus 3 & Project-based \\
\hline a. & $\begin{array}{l}\text { At least one major project is completed in each semester and one smaller } \\
\text { project per unit. }\end{array}$ \\
\hline b. & $\begin{array}{l}\text { At least one major project is completed per semester and one minor project } \\
\text { per semester. }\end{array}$ \\
\hline c. & $\begin{array}{l}\text { At least one major project is completed a year and one minor project a } \\
\text { semester. }\end{array}$ \\
\hline Focus 4 & Service Oriented \\
\hline a. & At least one major service activity is completed each quarter. \\
\hline b. & At least one major service activity is completed each semester. \\
\hline c. & At least one major service activity is completed each year. \\
\hline Focus 5 & Technology integrated \\
\hline a. & $\begin{array}{l}\text { The use of technology* has to be essential-daily experiences with at least two } \\
\text { or more pieces of technology-in the completion of each unit. }\end{array}$ \\
\hline b. & $\begin{array}{l}\text { The use of technology"has minor importance-daily experiences with only one } \\
\text { piece of technology-in the completion of each unit. }\end{array}$ \\
\hline c. & $\begin{array}{l}\text { The use of technology* is an option-less than a daily use-in the completion of } \\
\text { the unit. }\end{array}$ \\
\hline Focus 6 & Learning styles addressed \\
\hline a. & $\begin{array}{l}\text { The units will meet the needs of all learning types through their seven multiple } \\
\text { intelligences. }\end{array}$ \\
\hline
\end{tabular}




\begin{tabular}{|c|c|}
\hline b. & $\begin{array}{l}\text { The units will meet the needs of most of the learning types through at least } \\
\text { five of the multiple intelligences. }\end{array}$ \\
\hline c. & $\begin{array}{l}\text { The units will meet the needs of a limited amount of the learning styles } \\
\text { through the use of less than five of the multiple intelligences. }\end{array}$ \\
\hline Focus 7 & Business partnerships \\
\hline a. & $\begin{array}{l}\text { Long-term relationships-at least one year-of the school and students with at } \\
\text { least three local business where the latter would provide finances, services, } \\
\text { and educational opportunities. }\end{array}$ \\
\hline b. & $\begin{array}{l}\text { Long-term relationships-at least one year-of the school and students with at } \\
\text { least three local businesses where the latter would provide finances, services } \\
\text { and educational opportunities for school/students }\end{array}$ \\
\hline c. & Less than three business relationships which lasted less than one year \\
\hline Focus 8 & Staff development \\
\hline a. & $\begin{array}{l}\text { Establishment of a study group system including bi-weekly meeting with a } \\
\text { long range training plan-at least five years with a focus on } 4 \text { MAT, Multiple } \\
\text { Intelligences, and Models of Teaching }\end{array}$ \\
\hline b. & $\begin{array}{l}\text { Establishment of a study group system including a monthly meeting with a } \\
\text { long range training plan-at least three years-with a focus on at least one of the } \\
\text { three frameworks-4MAT, Multiple Intelligences, and Models of Teaching }\end{array}$ \\
\hline c. & Teachers meeting with study group without the long range training plan \\
\hline Focus 9 & Dynamic assessment \\
\hline a. & $\begin{array}{l}\text { All assessments will be authentic-drawn from the students' personal lives, } \\
\text { multi-dimensional-including combinations of projects, written } \\
\text { applications-reports, essays, multi-media application-computer, etc., that } \\
\text { results in an end product that has long-term use in the student's life. }\end{array}$ \\
\hline b. & All assessments will be authentic but not necessarily multi-dimensional \\
\hline c. & $\begin{array}{l}\text { All assessments will be authentic, utilizing one dimension with no long-term } \\
\text { use in the students' life. }\end{array}$ \\
\hline
\end{tabular}


Communication Technologies: As defined by the developers and the members of the curriculum development team, this refers to the use of technology such as satellite, telephone; fax machine; VCR; and computers, which includes software, Email,Web/Internet, word processing, graphic applications, spreadsheets, data-base applications, CD-ROM.

Approaches: Theoretical frameworks such as 4MAT, Dimensions of Learning, and Multiple Intelligences.

Teaching Methods: The use of teaching strategies, structures, and techniques.

Teaching Strategies: Organized systems of instruction based on learning theory or the way scholars think in a discipline. Strategies have a research base supporting positive student outcomes. Examples of strategies include: concept attainment, advance organizer, Taba's inductive thinking strategy, memory devices, inquiry, direct instruction, cooperative learning, group investigation, role play, synectics, and simulation.

Teaching Structures: A process used across disciplines to promote learning. Examples of structures include: Think-Pair-Share (and variations), Corners, Roundrobin, Roundtable, What do you know; what do you want to know; what have you learned (KWL), and Pairs Check.

Teaching Techniques: A routine or procedure to accomplish a task, a way of getting something done; for example, random call, forming groups, turning in assignments, and checking papers. 
TABLE 5

\section{INNOVATION CONFIGURATION FOR TECHNOLOGY PARTNERSHIP UNITS OF STUDY}

\begin{tabular}{|c|c|}
\hline Focus Area $\# 1$ & Competency-based \\
\hline a. & $\begin{array}{l}\text { Unit activities are specifically designed to develop mastery in each competency } \\
\text { from the four domains. Individual competencies are included in more than one } \\
\text { unit each year. }\end{array}$ \\
\hline b. & $\begin{array}{l}\text { Unit activities are specifically designed to develop mastery in each competency } \\
\text { from the four domains. Individual competencies are included in at least one unit } \\
\text { each year. }\end{array}$ \\
\hline c. & Not all competencies are addressed each year. \\
\hline Focus Area $\# 2$ & Integrated Curriculum \\
\hline a. & Content skills from at least three disciplines are integrated. \\
\hline b. & Content skills from at least two disciplines are integrated. \\
\hline c. & Each discipline is taught separately. \\
\hline Focus Area $\# 3$ & Community Event \\
\hline a. & $\begin{array}{l}\text { Each unit will culminate in an event which serves a community. The community } \\
\text { event is both the product and the purpose for the development of the content. }\end{array}$ \\
\hline b. & $\begin{array}{l}\text { Each unit will culminate in an event that serves a community and relates to the } \\
\text { unit of study. }\end{array}$ \\
\hline c. & The community event is absent or has no authentic connection to the unit. \\
\hline Focus Area $\# 4$ & Technology Integration \\
\hline a. & A variety of communication technologies is used daily. \\
\hline b. & A variety of communication technologies is used. \\
\hline c. & Use of communication technologies is incidental or absent. \\
\hline Focus Area \#5 & Learning Needs \\
\hline a. & Individual learning needs are met by a variety of specific approaches. \\
\hline b. & Individual learning needs are met by the use of a specific approach. \\
\hline c. & There is no organized plan for meeting individual learning needs. \\
\hline Focus Areas \#6 & Teaching Methods \\
\hline
\end{tabular}




\begin{tabular}{|l|l|}
\hline a. & $\begin{array}{l}\text { Learning is facilitated through the use of a variety of teaching methods to } \\
\text { promote both basic and higher-order thinking skills. Student and teachers are } \\
\text { able to both articulate and reflect on the learning process. }\end{array}$ \\
\hline b. & $\begin{array}{l}\text { Learning is facilitated through the use of a variety of teaching methods to } \\
\text { promote both basic and higher-order thinking skills. }\end{array}$ \\
\hline c. & $\begin{array}{l}\text { There is a lack of variety of teaching methods, or the primary focus of learning is } \\
\text { on lower-level thinking skills. }\end{array}$ \\
\hline Focus Area $\# 7$ & Dynamic Assessment \\
\hline a. & $\begin{array}{l}\text { Assessment focuses on the meaningful use of knowledge and includes a variety of } \\
\text { data from multiple sources obtained over time. }\end{array}$ \\
\hline b. & $\begin{array}{l}\text { Assessment focuses on the meaningful use of knowledge and includes data from } \\
\text { multiple sources obtained over time. }\end{array}$ \\
\hline c. & $\begin{array}{l}\text { Assessment does not focus on meaningful use of knowledge and/or does not } \\
\text { include data from multiple sources obtained over time. }\end{array}$ \\
\hline Focus Area $\# 8$ & Project-based \\
\hline a. & Projects provide all experiences for student learning. \\
\hline b. & Projects provide most experiences for student learning. \\
\hline c. & Projects provide some experiences for student learning. \\
\hline
\end{tabular}

Dynamic Assessment: As defined by the developers, refers to assessment from multiple sources which includes a variety of data demonstrating the meaningful use of knowledge obtained for the purpose of making decisions; solving problems; and investigating, inventing, or improving something. The defining qualities of this term reflect the meaning of "authentic assessment" a generic term that is found in the literature on assessment in education. 


\section{Summary}

The Innovation Configuration (IC) provides a concrete description of the attributes, goals, and implementation requirements of innovations. Once a checklist has been developed, it can be used to introduce a program and communicate how the components and variations are to be implemented. During implementation, the IC checklist can be used to monitor or evaluate program use and progress in classrooms, schools, and school districts.

The development of the IC for Technology Partnership was an evolutionary process. During my first interview with Bettie, because the innovation had not been clearly conceptualized into concrete practices, it seemed that it was easier for her to talk about the history of Technology Partnership than to communicate about teacher and student behaviors during implementation. At the second interview, the two key developers, Betty and Lejil, struggled to articulate descriptions of the concrete practices of this initiative. I asked them to create a graphic representation of the innovation. They saw a copy of the Innovation Configuration for study groups (Henriquez-Roark, 1995). We used the data from the first interview and the graphic to edit the list of essential components. This list of components was instrumental in the creation of the first draft of the IC for Technology Partnership. The draft helped the developers and the curriculum development team to examine their views about the components and the attributes of the Technology Partnership Units of Study.

In September 1997, when the curriculum development team revisited the IC for the Technology Partnership Units of Study, they felt that further clarification of this 
document was needed. Several of the components were changed after it was clearly reiterated that Technology Partnership was a curriculum initiative. The team changed "service-oriented" to "community event" because this term reflected the application of student learning in the form of community service or outreach projects; "learning needs" which described how students needs were to be met, replaced "learning styles addressed": "teaching methods" was added because a variety of teaching methods were included in the units of study; and "staff development" was deleted because it was not a part of the curriculum but was viewed as a tool for implementing the curriculum. The result of this process was a document which not only reflected changes in its components, but modification of its attributes (see Table 5 ).

Developing the Innovation Configuration for Technology Partnership was essential to the curriculum initiative during the first year of the pilot project. It aimed to guide the development the units of study; it also provided a common language which could be used as a tool to communicate about the Technology Parnership initiative. Though it was revisited and revised it was not evaluated to see if it clearly defined the four domains in the units of study. 
CHAPTER SIX

\section{STAFF DEVELOPMENT/ORIENTATION FOR IMPLEMENTING TECHNOLOGY PARTNERSHIP CURRICULUM INITIATIVE}

\section{Introduction}

This chapter describes the staff development training opportunities which were available for those who were involved in the Technology Partnership Pilot Project. Staff development training and the provision of awareness information which impacted the development and the implementation of Technology Partnership Curriculum Initiative was provided on several different levels. The staff development training opportunities for the initiative included: (1) a 4 -day in-service training for the conference educational administrators of the Pocono Union; and (2) a 4-week intensive training for teachers and administrators at Southwest University's Summer Institute which was designed according to the Training Model (Joyce \& Showers, 1995).

The use of the Training Model involved participants in simulated study groups where the theory, demonstration, practice, feedback, and coaching of various teaching strategies were presented. Also associated with the staff development component was a 5-day orientation session for the teachers and administrators whose schools were 
involved in the Technology Partnership Pilot Project. The goal of this session was to begin to cultivated an understanding of the project itself, including the technology and logistics which were involved in implementing the initiative.

\section{Pocono Union Administrators Institute}

The Structure and Setting of the Institute

One of the first training sessions involving individuals who were affiliated with the Technology Partnership Curriculum Initiative was hosted by the Appalachian Conference in one of the Southern states in June 1997. It was significant that the Appalachian Conference hosted this session. for it was the only conference in this union which had used teacher study groups. a major component of the Training Model (Joyce \& Showers. 1995), to sustain an ongoing staff-development program. This 4-day training was sponsored by the Pocono Union office of education for conference administrators within the union. It was patterned after the bi-annual 4-week Summer Institute at Southwest University. The structure and setting of the institute are described in detail in Karrer (1996).

\section{The Participants}

Twenty-three individuals attended this session. Seventeen of these individuals represented seven of the eight conferences in the Pocono Union. The other attendees included the director and associate director of education of the Pocono Union, an elementary principal, the individual who was designated as the teacher for the satellite program, and a trainer and researcher from Southwest University. Six of the individuals 
involved in this session are connected with the Technology Partnership initiative. Dr. Smith from Southwest University and the associate superintendent of education in the Appalachian Conference provided the training for this session. Data were collected through observation. feedback forms, and journals.

\section{The Content of the Training}

Though this training session was patterned after a summer session which is held at Southwest University, it included only an overview of many of the strategies that are usually taught during this summer session (Karrer, 1996). Emphasis was placed on concept attainment as a teaching strategy, and study groups as a vehicle for implementing and sustaining innovations. An overview of Technology Partnership and the distancelearning pilot project was also presented to the group. During the first day of the training session Drs. Adam Smith and Ebony Johnson, the two trainers, demonstrated concept attainment lessons and provided sample lessons for group members to teach to each other. Ebony, who had organized the teachers in the Pocono Conference into teacher study groups, provided information and answered questions about how to begin these groups in each of the conferences. Concept attainment and teacher study groups are described below.

\section{Concept Attainment}

Concept attainment is a strategy wherein concepts are taught inductively. This strategy has three phases. Joyce and Weil (1996) describe concept attainment as one of the strategies in their book Models of Teaching. In phase one, students are asked to 
determine the attributes of a concept by comparing 7-10 examples (called exemplars) that contain characteristics of the concept with examples that do not contain those characteristics. Students also generate and test hypotheses about the concept. In phase two the students test their hypotheses by identifying additional positive or negative examples of the concept. The teacher assists with confirming the hypotheses, naming the concept, and formulating a definition according to the essential attributes of the concept. Additional examples can be generated in this phase. Phase three involves an examination of the thought processes of students as they are involved in this strategy.

Many of the administrators indicated that they saw concept attainment as a way to improve the retention of concepts and critical thinking of students. Concept attainment was also viewed as a way to reduce teacher talk, encourage students to participate in the learning process. and to promote discovery learning (Book 5. Section D. pp. 1-9).

\section{Teacher Study Groups}

Teacher study groups are described by Green and Henriquez-Roark (1993), Henriquez-Roark (1995), and Showers et al. (1996). A teacher study group is a team of three to six faculty members who meet regularly to undertake innovative problem solving and improve student achievement. The focus of the group is on curriculum and instructional practices that impact the teaching and learning process. All the participants of the group are of equal status and share in the group's leadership and power.

The members of the group provide companionship and support for each other while learning something new. The Training Model (Joyce \& Showers, 1995) is used as 
the design for training in this type of group. The group sets up guidelines for the agenda which includes a study of theory, demonstrations, practice, feedback, and coaching on whatever innovation is being studied. Teachers have reported growth in professional expertise as well as personal benefits from participating in study groups (HenriquezRoark, 1995).

Dr. Johnson provided information from an administrative perspective on conducting study groups, and two of her teachers who were involved with these groups visited the session and shared how they had been positively influenced. The majority of the administrators saw the study groups as an effective way to develop and ensure effective teaching of both higher-order thinking skills and social skills. Others saw study groups as a system to promote long-term change that encourages the professional, social, and emotional growth of a teacher (Book 5, Section D, pp. 11-19).

During the institute, data was collected through observation, journals, and a survey. Many of the administrators indicated that they saw a need for teachers to expand their repertoire of teaching strategies. Many even indicated a desire to work with their teachers to improve the teaching and learning processes (Book 5, Section D, pp. 21-31). The overview and involvement in different teaching strategies and leaming how they could be applied in the study groups were cited as the most meaningful part of the training. Although there was no single element of the training that seemed less useful or meaningful, a few concerns were noted about the need for more information on teacher study groups and how to get them started (Book 5, Section E, pp. 1-15). 


\section{Summer Institute}

The Structure and Setting of the Institute

The Summer Institute of 1997 conducted at Southwest University was another session which provided training in teaching strategies and was available for those involved in the Technology Partnership Curriculum Initiative. The institute was held in a large multi-purpose room of an elementary school. Round tables with chairs to accommodate at least four people set the stage for groups to work together as learning families. Potted plants. the smell of flowers. colored streamers, and containers of assorted supplies created an atmosphere of warmth and comfort.

The setting of the institute was a simulation of the hierarchy of the North American Division educational structure. On the first day of class the participants sat in groups of four to five at round tables. Each group was regarded as faculty belonging to a "school." There were 10 "schools." These "schools" were divided into two "conferences." Each conference was supervised by a superintendent and an associate superintendent. Both of the "conferences" were supervised by a "union" director of education, an associate director of education, and two doctoral students who were experienced in the use of the models of teaching. The key trainer, Dr. Adam Smith, played the role of director of the North American Division, and the two professors in his department assisting him with the training were designated associate directors of education of the North American Division.

During the institute, these simulated leaders were able to work closely with Dr. Smith to assist the faculty as they learned, practiced, and applied the new teaching 
strategies. The NAD associate directors assisted with training the faculty in specific models of teaching. The Union officials worked with technology, and collected research data on the institute. The conference officials were involved with supervising afternoon activities in the lab and assisting the students with completing their assignments. All the officials were involved in troubleshooting and implementing the day-to-day plans of the institute. In general, the simulation was a tool to manage the entire summer institute experience.

During the first few days, I observed the key trainer. Dr. Smith, as he patiently answered a number of questions that helped to clarify concerns about the syllabus, the requirements, and materials to be used during the institute. This was a phase in the Dimension of Learning framework (Marzano et al., 1997) which Dr. Smith was using as a framework to guide the daily presentation of information as well as cultivate positive attitudes and perceptions for the group. Although this institute was similar in structure, setting, and content to Summer Institute 1995 as described by Karrer (1996), one component that was different--the focus on the Technology Partnership Curriculum Initiative.

\section{The Participants}

At least 43 participants-teachers and administrators-attended Summer Institute 1997. Among this group was a delegation of three individuals from Norway, two from Brazil, and one from Aruba. Four individuals who were involved in the development and implementation of the Technology Partnership Curriculum Initiative attended this 4-week 
intensive training session. The Gregorc Style Delineator (Gregorc, 1982) revealed that there were 18 concrete sequentials, 9 abstract sequentials, 9 concrete randoms, and 7 abstract random in the group. The participants grouped themselves according to their mindstyles. They were also able to review information about their mindstyles and share details about how closely they were described by the inventory.

Focusing on the Technology Partnership Curriculum Initiative A brief overview of Technology Partnership was presented. and each team was given the opportunity to experiment with the development of one of the Units of Study. To do this, they used the skeleton outlines for Technology Partnership-an outline containing competencies and content skills, and a unit development template created by Green and Werner (Book 5. Section N. pp. 1-5). The units were used by the participants in the 2-week practicum experience. During the last 2 weeks of the session, students joined the program to provide an opportunity for the participants to practice the new teaching strategies that they were learning.

During the institute, a curriculum development team led by Joe Mills, one of the professors from Southwest University, worked on developing the units of study for the Technology Partnership Pilot Project. This team included some of the developers of the Technology Partnership initiative, and other participants in the institute who were studying curriculum design. Most of the journals indicated that those who attended the sessions felt that they received personal and professional benefits from attending the institute (Book 5, Section C). 


\section{Orientation for the Technology Partnership Pilot Project}

The Structure and Setting of the Orientation Session

It is about 9:00 Monday morning; eight long tables are arranged in the middle of a multi-purpose room to form a rectangle. Bright flowers, candy, and colorful folders containing materials were important parts of the decor of the room. Chairs were arranged on the outside of the rectangle. This session was being held in the multi-purpose room at the Maracas Conference office. The participants entered and sat in close proximity to the familiar face that accompanied them to this session. Bettie. the facilitator of this session, welcomed them and gave them an opportunity to introduce themselves and their immediate companions. This was the orientation session for Technology Partnership Pilot Project.

\section{The Participants}

Nineteen participants attended the orientation session. This group included the eight classroom teachers from the schools who were involved in the pilot project, administrative representatives for the schools, two conference superintendents, two associate superintendents, one school board chairman, one union associate director of education, one North American Division associate director of education. three teachers from a junior high school, and the broadcast teacher.

Though Bettie was the main facilitator for this session, several others participated or presented information that was relative to the project. These presenters 
included one professor and a research assistant from Southwest University; an administrator of an elementary school; a union director of education, a conference director of education; and a representative from Educational Management Group, the company which was providing the equipment and services for the pilot project.

The teachers who attended this training were from one-teacher schools across the United States. Schools in the states of Florida, Michigan, Wisconsin, Pennsylvania, North Dakota. Virginia, and Oregon were represented. One delegation of three teachers from a large school were to be involved in viewing the broadcast but would not be involved in the interaction with the eight one-teacher schools.

\section{The Content of the Orientation}

The teachers came to the orientation session to understand their role in the distance-learning pilot. The session began with Bettie`s introductory remarks. She spoke about some of the development in the San Fernando Conference which led to her move to the Maracas Conference. Next, she encouraged teachers to introduce themselves and their conference/union representatives. The conference representatives gave additional information on each teacher and explained why they were selected to be a part of the pilot.

Linda was introduced as being in charge of the evening optional activity-a trip to the Rainforest Café. Linda, a vice-principal of a nearby elementary school, assisted with the orientation session during that week. The session was designed as an awareness training which involved some theory, demonstration, practice, and feedback, but no 
coaching. The main foci of this training was an introduction to the Technology Partnership Curriculum Initiative, a live interaction with EMG, an introduction to three models of teaching, an introduction to the technology to be used in the distance-learning pilot, a simulated daily broadcast, and logistical issues and concerns.

\section{Introduction to the Technology Partnership Curriculum Initiative}

Several approaches were used to provide an introduction and overview of Technology Partnership Curriculum Initiative. On the first day Leon made a presentation on the shared language that was unique to the Technology Partnership initiative. The participants were asked to match the "Shared Language" words and meanings (Book 5 , Section L, pp. 2-4) that were printed on colored strips of paper. Through this activity they were introduced to some of the terms which would be used in the pilot project. This activity ended with the group reviewing the terms.

The participants were asked to read a handout on the Technology Partnership Pilot Project (Book 5. Section L, p. 1). This handout described the distance-learning pilot project. and defined its vision, mission, and goals. After reading the handout, they were asked to form pairs and share their thoughts. A Power Point presentation on the Technology Partnership was shown to the group. It addressed its origin and history, vision and goals, competencies, uniqueness, and connection to the philosophy of Adventist education.

An overview of the design for the Technology Partnership curriculum and the curriculum development process was presented to the group. Participants were able to 
preview a draft of "Keys," the first Technology Partnership unit to be taught via satellite, as well as the skeleton outlines of the remaining units. An article, and other handouts on Technology Partnership in the materials packet provided additional information concerning the distance-learning pilot project.

\section{Live Interaction With Educational Management Group}

During the latter part of the morning of the first day, there was a live interaction with Educational Management Group (EMG) in the broadcast studio. A representative from EMG led the group on a virtual tour of their studio in Scottsdale, Arizona. Whereas the group was able to see and hear the representative on the television monitor, the representative was able to only hear the group via telephone. The representative showed them the equipment in the studio at EMG and introduced the group to the Gateway 2000 Computer System. The Digital Receive System uses a wireless mouse and keyboard. The representative explained more about the kinds of services that were available to the schools in the pilot, and informed the teachers that they could call EMG studios to schedule their own personalized instruction on the use of the technology in the classroom.

Using the equipment in the studio, the students would have several other communication options for receiving instruction from the teacher. They would be able to do word processing, presentations, E-mail, access information via the search engines on the Internet, and communicate with the broadcast teacher and other schoois via the Pocono Union's chat room. All the teachers were given written information on how to access the needed information from EMG. 


\section{Overview of Instructional Frameworks}

An overview of three instructional frameworks were presented at this session:

Dimensions of Learning (Marzano et al., 1997), 4MAT (Joyce \& Weil. 1996), and Cooperative Learning (Johnson, 1997; Johnson \& Johnson, 1996; Kagan, 1994).

The Dimensions of Learning framework (Marzano et al., 1997) provided the participants in this session with a conceptual framework for organizing instruction. The presenter, Linda, began by giving an overview of the assumptions of DOL. She placed the participants in groups of five, gave them a handout on one of the five dimensions, and asked each person to present a summary of the main points.

These five dimensions of learning included: (1) positive attitudes about learning, (2) acquiring and integrating knowledge, (3) extending and refining knowledge, (4) using knowledge meaningfully, and (5) productive habits of mind. Linda ended this session with an overview of the strategies that are associated with the first dimension. This overview was completed in about 1 hour. Because the schedule for the week was so full, additional time was not allocated for discussing teaching strategies for the other dimensions.

The superintendent of education for Maracas Conference presented a 2-hour session on 4MAT (Joyce \& Weil, 1996). This model for designing instruction exemplifies a learning cycle of and illustrates insights into the learning process itself. It provides a foundation for understanding the core elements of learning and provides guidance in how to use these elements to improve the effectiveness of learning. This model explains learning in terms of the ways people perceive and process information. 
The 4MAT model has been used as a framework for examining wholeness in organization, balance in leadership and management techniques, and organizational change. During the session, the participants had the opportunity to take the 4MAT inventory to identify their learning styles. This inventory identified them as: (1) imaginative learners, (2) analytic learners, (3) common sense learners, and (4) dynamic learners. After the inventory was taken, participants were given the opportunity to disclose their learning styles. The session ended with a discussion on the use of 4MAT in teaching and learning experiences.

The session on cooperative learning was presented by Nancy Beck, one of the professors from Southwest University. She presented theoretical information about cooperative learning. Cooperative learning (Johnson, 1997; Johnson \& Johnson, 1996; Kagan. 1994) is an approach to learning which involves the interaction of students in groups. The emphasis of cooperative learning is based on five elements or principles: (1) positive interdependence, (2) face-to-face interaction, (3) individual accountability, (4) social or interpersonal skills, and (5) group processing. This presentation was done as the final session on the last day of the training session. No time was allocated that day to practice any of the cooperative structures.

\section{The Equipment and Services for the Pilot Project}

Technology was an important part of the distance-learning pilot project. Each school site was expected to have a Digital Receive Station (DRS) which included a Gateway 2000 computer, monitor, and a wireless keyboard and mouse. Some of the 
other pieces of equipment that were essential to the broadcast included an $M$ and $M$ box (which made audio return possible after the school dialed into the studio), a color printer, VCR, speaker phone, telephone, fax, satellite dish, satellite receiver, and a surge protector. These same pieces of equipment were in the broadcast studio along with a rack, which housed all the equipment. The mixer allowed Leon to make visual transition from the teacher on the screen to a video or some other graphic. The broadcast would travel via T1 lines to EMG's studio in Scottdale, Arizona. EMG would uplink it to their satellite and then the schools would downlink the broadcast to their satellite dish. which transmitted it to the DRS. These elements, including the connection of the telephone system to the broadcast studio, allowed the interaction to take place.

\section{Logistical Concerns}

A portion of each day was spent addressing logistical concerns connected with the pilot. Some of these concerns included:

1. The technology for the pilot--the installation, operation. and use of the equipment and the support services of EMG

2. Classroom/program management issues-grading, assignments, materials needed for student work, students with special needs, students transferring to one of the satellite schools, phones lines, field trips, sick days, Iowa Test of Basic Skills, an Internet Acceptable use policy

3. The broadcast and the broadcast teacher 
4. Communications/public relations for the pilot which included personal relationship between the broadcast teacher and the students, staff meeting with teachers in the pilot schools, program orientation and communication with the parents, confidentiality

5. Other miscellaneous concerns. Because all the schools in the pilot would have peculiar needs, it was important to discuss and understand the plan for handling them.

\section{Simulated Broadcast Session}

The simulated broadcast was held at a nearby elementary school on the fourth day of the training session. The program did not start at its scheduled time because of technical difficulties. It was patterned after the proposed teaching/interaction design for the pilot project. This design included an hour of on-line interactive time between the broadcast teacher and the students. The interaction began with a 15 -minute broadcast followed by a 45 -minute block of time for students to work on the assignment. The second broadcast was a half-hour session followed by another 45 minutes of assignment time. The day would end with a 15 -minute broadcast session.

During the first segment of the simulated broadcast, Leon taught an abbreviated version of a concept attainment lesson. He used positive and negative examples of objects to introduce the unit "Keys" and to teach about key concepts and processes students would need to assist them in being successful in the pilot project. As I observed this lesson it was evident that Leon was challenged by the use of this model. He struggled to effectively present the steps in the concept attainment process. Most of those 
who were involved with this session were unaware of this, so the lesson continued as planned. He interacted with the classroom teachers and administrators via telephone. An assignment was given at the end of this segment for the participants to work in separate groups to brainstorm ideas for a newsletter. Five groups were formed to work on this activity which they did during the 45-minute off-camera time block.

At the second session, the groups were asked to share their three best ideas for the newsletter. Several ideas were shared. Leon then gave another assignment. The participants were asked to prepare to write an article about what would be happening with their classroom during the distance learning project. Each group was asked to select the headlines and a layout for their article. The groups were asked to critique each other's work.

During the last broadcast session, the groups gave feedback on the assignment, and responses from one of the groups prompted laughter from everyone. One of the administrators coached Leon on points for improving his delivery. Before the broadcast ended, Leon apologized to the group for the technical glitches in the program.

After the program ended, Linda, one of the presenters, asked for positive feedback as well as suggestions for improvement on the program. Several concerns were expressed including (1) the use of the computer during the broadcast, (2) placing the broadcast studio in another location, (3) dividing some of the duties of the broadcast teacher with someone who could assist him, (4) the distraction created by the "double talk," which was created by the echo that was heard from the TV monitor from the voices of the individuals who responded to Leon via telephone during the interaction, (5) the 
need for more teaching rather than discussion; the dialogue during the broadcast seemed to have left very little time for teaching, and (6) training the students to speak into the telephone when they are giving feedback to the broadcast teacher.

During the orientation session many of the on-site teachers wanted to spend time understanding the use of technology in the program. There was a great deal of concern about the logistics involved in the day-to-day operation of the pilot such as schedules, calendars, and other elements which they felt were important. Although two of the key components of the project, the technology for the schools and the units of study, were not in place yet, the team of teachers who attended the orientation session manifested a high level of commitment to the project.

\section{Analysis of the Staff-Development Process}

Joyce (1992) described a model for staff development that includes a design for "the workshop," in which initial training is done, and a design for "the workplace," in which sustained training and ongoing support are the norm. The attributes of "the workshop" design include the presentation of theory, demonstrations, and practice. The attributes of "the workplace" design include immediate and sustained practice; peer support and coaching in study groups; ongoing assessment of implementation; and advance training and tracking of student outcomes.

This model was used to analyze the three training workshops. Of the three workshop sessions, the summer institute at Southwest University was closest to the ideal for the transfer of training and implementation of innovations in the workplace. 
According to the Training Model (Joyce \& Showers, 1995) if no workplace systems are in place to sustain the innovation, less than $10 \%$ of the participants will implement the training. Thus only $10 \%$ of those who attended the summer institute training would be expected to transfer without this support. Because of the uniqueness of the pilot project, it would be critical for the broadcast teacher and the teachers whose schools are involved in this project to have had initial training in a workshop as well as continued support in the workplace. Only Leon, the broadcast teacher. received a degree of initial training. The other classroom teachers simply received approximately 3 to 4 hours of information on the instructional frameworks which were included in the Technology Partnership Units of Study.

If there was only a $10 \%$ chance that Leon, because of the level of training he had had, would implement the strategies, expectations for implementation by those who had only a few hours of theoretical information would be even less. Though the classroom teachers were not expected to teach the students, their experiences in the classroom during the implementation process convinced my key informants in this study that they needed to be trained, especially in cooperative learning. This training would have equipped them to provide assistance whenever necessary to both the students and the broadcast teacher.

There were no systems in place to provide sustained practice and support for instructional processes in the workplace for Leon or the other teachers in the pilot project. Even though one focus for the pilot project was staff development, what was provided at the orientation and during the pilot project was not designed to bring about long-lasting 
changes in instruction. The faculty meetings with the pilot project teachers, which took place via telephone, mostly involved sharing issues and addressing some of the challenges related to the implementation phase. There were no sessions to train teachers to use the strategies that were included in the Technology Partnership Units of Study.

Little time was invested in providing the administrators of the Pocono Union with an experiential understanding of the content and process of the staff-development program that was needed for implementing the strategies to be included in the units of study. Therefore the grave necessity of intensive initial training and sustained instructional support in the workplace may not have been clearly understood. Though the training at Southwest University was available for all teachers in the North American Division, it was never provided for all the teachers in the pilot project. Thus, a plan for training for all the teachers in the pilot never materialized because it was never clearly conceptualized. Further analysis of this aspect of the pilot project is provided in chapter 9.

\section{Summary}

This chapter includes a description of two staff-development training sessions: (1) a 4-day session for administrators in the Pocono Union, and (2) a 4-week intensive session in the summer institute at Southwest University. It also included a 5-day orientation session for those who were involved in the distance-learning pilot project. Southwest University provided the training for both of the staff-development session. The university also assisted in providing awareness information during the orientation 
session. Two of the foci of the orientation session were the use of the technology and the logistical concerns of the pilot project.

The major conclusion drawn from these sessions involved the need for staffdevelopment training for the pilot project to be carefully designed according to a research-based model that would ensure transfer of training into classroom practice. Administrators, teachers, and members of the curriculum development could then be trained in instructional processes that would enable them to more effectively support. develop, and implement the Technology Partnership Curriculum Initiative. The curriculum development process for this initiative is described in chapter 7 . 


\section{CHAPTER SEVEN}

\section{THE TECHNOLOGY PARTNERSHIP CURRICULUM DEVELOPMENT PROCESS}

\section{Introduction}

The Technology Partnership curriculum development process bore some similarity to the staff development process. The development took place in collaborative teams which involved administrative representatives from an elementary school, the educational departments of a union/conference, university representatives, and classroom teachers. This process involved plans for the application of teaching strategies which were taught in some of the staff development training sessions. It also included the process of reflection through feedback sessions, journals, and surveys.

Most of the development of the Technology Partnership curriculum occurred in three major phases. These phases occurred at specific times: March, June/July, and September 1997. Because the scheduled times for the team to work on the Technology Partnership curriculum development were limited, hundreds of hours of additional time were invested by team members who worked alone or with a few others to perfect the units of study. 


\section{First Meeting of the Curriculum Development Team}

The development of the curriculum for the Technology Partnership Pilot Project began at the Maracas Conference Office in March 1977. Seven individuals-the project coordinator, two professors from Southwest University, the teacher designated for the distance-learning project, and three other classroom teachers from Maracas Conferenceworked together on creating a framework which was used to build the units of the Technology Partnership Curriculum Initiative.

\section{Creating the Framework for Technology Partnership}

\section{The First Steps}

The team's goal was to begin the process that would ultimately lead to the development of competency-based, integrated units of study which would include skills and concepts from social studies, science, reading, and language arts. To do this, the team began trying to understand the conceptualization of the Technology Partnership curriculum. At that time there was no Innovation Configuration or operational definition to clearly identify the components of the units. The unit descriptors were limited to the competency-based, integrated, service-oriented, and project based components.

The first major task undertaken at this session was to use the 1997 report of the North American Division's Curriculum Future's Commission, Focus on Adventist Education for the Twenty-first Century (FACT 21), to evaluate the Partnership Technology competencies. The team wanted to see if Partnership Technology competencies (Volume 5, Section M, pp. 48-51), which had been developed in the San 
Fernando Conference, were congruent with the essential elements or broad outcome statements of $F A C T 21$. These competencies which were already assigned to one of the four domains-physical, mental, spiritual, and community-were used as an organizing framework for including the essential elements from FACT $2 l$ and the competencies for Joel Baker EFG curriculum (Barnes, 1998). The discussions led to a focus on broad themes for the development of the units. The team then created unit descriptors for six units and assigned competencies to each descriptor. Each competency and essential element was then aligned with each of the unit with which there was a fit. A matrix was created to allow the team to evaluate if all the competencies were being included in the units.

Two of the unit foci were selected from Barker's EFG program. The team had hoped that the students in the pilot project could partner with students from the Twentyfirst Century Preparatory School, an institution that was using Barker's EFG program. Bettie indicated that this plan never materialized because "we realized that we were biting off way more than we could chew" (Book 5, Section B, p. 6).

Next the units' topics were placed into a yearly plan. A fixed number of weeks was assigned to each unit. Afterwards, the group placed the skills and concepts from the NAD curriculum guides in social studies, science, reading and language arts on index cards and grouped them under the descriptors. This configuration enabled the group to see how the skills and concepts were to be taught to every grade. One of the six units was eliminated and its skills and concepts were assigned to the remaining units. 
"We were very much feeling our way at that point," reported Leon (Book 4, Section C, p. 33). The rationale for grouping certain skills in selected units came from the idea that the group had to place all the NAD content skills in this curriculum framework. Since the Technology Partnership was a new and innovative curriculum initiative, Bettie knew that the NAD curriculum committee would feel more comfortable if the team could show where all the content skills would be covered during the year. By the time they were finished, the team realized that it was impossible to fit all the social studies and science skills and concepts for 1 year in the selected units of study.

Assistance was sought from the NAD associate director of elementary education, Dr. Sandra York. She understood their dilemma and suggested that the team use the unit descriptors as guides for selecting NAD skills and concepts. Dr. York wanted them to be cognizant, however, of what content skills they were and were not covering in the units of study. Using this feedback as a guide the team decided to use only those skills and concepts that had major relevancy to the theme of the unit. The rest were set aside for the another school year.

The result of this session was skeleton outlines for five units of study which included the unit descriptors, the Partnership Technology competencies, and the NAD skills and concepts. 


\section{Unit Descriptors}

The descriptors for five units-Keys; Business, Industry and Technology (BIT); Well Into the Future; Lest We Forget; and Family, Issues, and Celebration previously named the American Home-that emerged from that session are described as follows:

$\underline{\text { Keys }}$ is an introductory unit to help the learner develop processes or procedures primarily to establish a foundation which would give students the skills they needed to work with technology in the units that would follow.

Business, Industry, and Technology (BIT) is described as a unit which would help the learners to explore the history of a business site using a time continuum to acquire an understanding of how business has changed and/or adapted to technology. Through BIT they would analyze the forces that affect the change of business on a local/global level. and create or run a business of the future. This unit's name, overriding theme, and content were adopted from the BIT unit in Barker's EFG program.

Well Into the Future is a science-oriented unit which was designed to teach principles and concepts of personal wellness and to encourage students to adopt wellness practices.

Lest We Forget is primarily a social studies unit focusing on conflict resolution. It was designed to teach students skills for resolving conflicts in which they might be personally involved, and for developing mediation skills.

Family, Issues, and Celebration was a self-exploratory unit designed to teach cultural appreciation and examine personal insights into social and health issues affecting individuals and families. 


\section{Curriculum Development at Southwest University}

The development of the Technology Partnership Units of Study began at Southwest University's Summer Institute with a curriculum development team that contained some of the members who were involved in conceptualizing the units of study earlier that year. This team included two of the developers of Technology Partnership-Leon, the broadcast teacher, and Linda, a vice-principal-and Nancy, a professor from Southwest University; some individuals who were studying curriculum design; and Joe Mills. from Southwest University who was facilitating the curriculum development process at the institute.

\section{Getting Started}

This team met for the first time on the sixth day of the institute. This meeting was simply a discussion by the group about how to begin the work of designing the Technology Partnership Units of Study. During this discussion, the group examined the work of Steven Levy (1996) in his book Starting From Scratch. Levy's ideas for curriculum development were based on the needs of his students. The group considered the possibility of developing a literature-based or an inquiry-based format for the units of study. The group also examined Intelebration (Burton,1997), an integrated curriculum which utilized several innovative models such as multiple intelligence, project-based learning, thematic instruction, cooperative learning, and inductive thinking.

Joe also shared the templates created by Green and Werner (Volume 5, Section N, pp. 1-5), which would be used to organize the daily lesson plans for the units. During the 
discussion, concerns about the need to select appropriate assessment tools were raised. Joe referred to Gardner's (1993) Multiple Intelligence framework and Marzano and his colleagues (1997) Dimension of Learning framework. He emphasized Dimension 1, "building positive attitudes and perceptions," and Dimension 5, "reflective thinking," in his discussion with the group. He indicated the intensity and level of commitment that was needed for the curriculum by expressing to the team that they were going to be "living and breathing this project" (Book 4, Section K, p. 1).

\section{Facing Challenges}

During the remainder of the week the meetings involved discussions about elements that were directed toward beginning work on the units. In spite of the discussions, no clear path appeared to begin the development of the Technology Partnership Units of Study. This first week was frustrating for both Joe and the curriculum development team. The members on the curriculum development team kept changing. Different individuals were absent each time the team met. When Joe was asked to describe a typical day for the team he said, "The one word that I would use to describe a typical day in the curriculum development process at summer institute would be chaos. Ha, Ha" (Book 4, Section D, p. 1)!

Joe described in more detail the difficulty he experienced in facilitating the curriculum development process in the context of the summer institute.

I think that it could have fit better if I had been a little more assertive, maybe, assertive or pro-active. It's easy to look back to see how I should have done it. Or the fact that I should have done some things differently; but the focus at summer institute was on instruction and developing a 
repertoire of instructional skills or strategies from techniques or methods. Of course, we had counted on having experts, people returning for the second or third or fourth time to the summer institute and that just did not happen. We had very few people who were returning. . . So we ended up with novice or fairly new people being involved in the curriculum development. So not only were they doing the curriculum development but they were trying to get in some practice for their teaching. They were wanting to learn the strategies better and get some practice. So we had some people who were there during the morning, which was when we had the $\mathrm{K}-12$ school children on site being taught by the different cooperative families. Some of our curriculum development members would slip out and go work with their cooperative family while they were teaching these $\mathrm{K}-12$ students. Then in the afternoon, after we were done with the $\mathrm{K}-12$ students, Dr. Smith, and I . . were teaching advanced instructional strategies for people who wanted to learn more than basic cooperative learning and the dimensions of learning framework. So, almost every afternoon my entire curriculum development team dissolved. So, quite often there would be just one or two or three of us at the most in the classroom working. As a result it was like we never had everybody there in the moming; we never had everybody there in afternoon and just to try to get together and do processing and debriefing was virtually impossible. (Book 4, Section D, p. 1)

Although, Joe understood what was happening to his team, he was especially frustrated with results of not having individuals whose only responsibility was this project.

And probably the thing that frustrated me the most about that situation was that whenever someone was gone for an hour or two and then they came back in to the curriculum development team, you had to take precious time catching them up, explaining what you did while they were gone and the reason why it was that way. (Book 4 , Section $D$, p. 1)

At the end of the first week, Joe, and one other team member left for 2 days to attend a professional development meeting. A decision was made for Linda to continue the curriculum development process on the first 2 days of the following week. "Keys" was selected as the unit on which the remainder of the team would concentrate. 
Two members of the curriculum development team were present to work on "Keys." Progress was made on the unit. Joe returned in the middle of the week. He addressed the issue of the team membership, indicating that a commitment must be made by all on the team to work diligently to develop the Technology Partnership Units of Study. Since were fewer less than 7 days left to work on this project, he called for this commitment to be indicated no later than the following day. A few of the group members decided to drop out. The group was reduced to six individuals.

\section{Making Progress}

The group discussed the content of the units. They highlighted the need for an Innovation Configuration to operationalize the components of the units. They discussed the components that were already selected-integrated curriculum. project-based, serviceoriented, technology integrated, and competency-based-to guide the development. Leon reviewed the seven foci of Technology Partnership as were listed in the article that he and Betty had written. Two of the members of the group contributed the idea of projects being the vehicle to the Keys unit. The need for additional direction for the development of the unit was still being felt; nevertheless, the group continued working.

After reviewing the work which was completed on Keys, Joe decided to have the two team members who had begun the work on this unit continue its development. The other members of the team would begin working on the unit "Lest We Forget." Near the end of the second week of the curriculum development, the team had a conference call with Ebony and some of her teachers in the Appalachian Conference. Ebony was unable 
to be a part of the curriculum team at Southwest University as she had planned; however, she and a few of the teachers from her conference who were trained in the teaching strategies were working on a unit. They were developing "BIT" as a simulation. Since they were further along in the development of their unit, they were able to call and dialogue with the team at Southwest University about the process they were using.

Ebony and her group shared insights of the process they were using. They chose to use a simulation to organize the content of "BIT" after determining that about $80 \%$ of the competencies could be met through this model. They explained and gave examples of how they fit the competencies into the simulation. They described the activities and explained how they revisited the competencies, and made adjustments during the unit development. Ebony highlighted the need for teachers using this unit to have a repertoire of teaching strategies and the need for staff development or training to be provided for them. She addressed many of the questions and concerns of the team from Southwest University.

During the last week of the development, the team continued to work on Keys, and Lest We Forget. When the week ended there was a draft of step-by-step plans for Keys. Lest We Forget was in progress but not completed. The members of the curriculum team met with Bettie, the coordinator of the Technology Partnership pilot project, on the last day of the summer institute to process the work they had done. During this meeting, work assignments for the continued development of the units of study were delegated. Four individuals from the curriculum development team would be responsible for completing four units of study. Each person was responsible for one unit. 
"Well Into the Future" was the only unit which was not assigned to someone at that meeting.

\section{Final Meeting of the Curriculum Development Team}

A 6-day session of the curriculum development team was held at Maracas Conference office. Included in this group were Bettie, Leon, and Linda, three of the developers of Technology Partnership, three professors, and a research assistant from Southwest University. Prior to this meeting the team members received an e-mail message from Bettie reminding them about the dates of the meeting. Bettie also wanted each team member to suspend their work on the units of study because she wanted them to examine a particular approach to the development of the units which she and Leon Linda had discovered. This approach was based on the principle of beginning with the end in mind (Covey, 1989).

Bettie indicated that the purpose of this session was to complete the Units of Study for the year. She indicated that the week would be an intensive one. In an E-mail message to the team she also indicated that the process of the unit development was being clarified with Dr. Smith's and my help (Volume 4, Section N, p. 1). This statement was made in reference to the creation of the Innovation Configuration for the Technology Partnership initiative. Everyone was encouraged to review the most current packet of information on the unit plans which she would be sending via mail. She further encouraged the team to become familiar with how each unit plan was put together and to make notes. 
The meeting began with Bettie giving an update on what was happening with the pilot project and issues regarding the services that EMG was rendering to the schools. The team then reviewed a handout on the Technology Partnership pilot project (Book 5, Section F, p. 1) which provided the definition, vision, mission, and goals of this initiative. A question was directed to Bettie to define the Technology Partnership Curriculum Initiative. This led the team to revisit the draft of the Technology Partnership Innovation Configuration, which had been created during the summer institute at Southwest University.

\section{Revisiting Technology Partnership Innovation Configuration}

As the team revisited the definition of AE21, the Technology Partnership initiative and the Technology Partnership Units of Study were identified as separate but related entities. A graphic representation was created identifying the Technology Partnership initiative as the distance-learning pilot which included the following components: (1) units of study, (2) staff development, (3) business partnership, and (4) research. At this point, it was clear to the group that the draft of the Innovation Configuration needed to reflect only the components of the Technology Partnership Units of Study. The need for an innovation configuration for the entire Technology Partnership initiative was voiced, but no attempt was made to begin this process at that time because there were other pressing concerns which needed attention.

The team worked on revising the Innovation Configuration (IC) for the Technology Partnership Units of Study and completed the work on three of the focus 
areas. They discussed and agreed upon the idea of starting each unit with the community event as a foundation for planning each unit of study. This would mean that the unit would be conceptualized around a project which would serve the community, and the learning activities would be linked to its completion. This idea had been mentioned in the development team during the summer, but there had not been consensus from the team to put this idea into practice.

On the morning of the second day, the purpose of the group-to work on the units of study-was reiterated. However, there was consensus that the work on the units could not continue until the IC was clear. Joe spoke favorably of the interactive process of the discussion. "Well, another good day. I feel the conversation going on is getting more open, more meaningful. and more productive" (Book 5, Section C, p. 2). Bettie mentioned the importance of reflection each day before going on with the curriculum development process. The focus for the morning was the revision of the additional components of the innovation configuration.

That afternoon, the group continued working on the IC. The discussion moved from a focus on assessment to the concept of project-based learning. Dr. Smith shared the background of the concept of project-based learning coming from the ideas of John Dewey and William Kilpatrick. He also spoke of the need to use the language of the research community in the IC and the units, since Technology Partnership was utilizing elements such as a project-oriented approach and other components that were a part of the scholarly community. The revision of the IC was completed during the afternoon session of the second day. 
As the day ended, the team reviewed the curriculum development process that had already taken place. Bettie emphasized the need to conceptualize the units based on the IC. Joe was asked to teach a concept formation lesson on the broadcast the next day. This gave him an opportunity to experience the dynamics involved in the teaching and learning process via satellite.

\section{The Revision of the Units of Study}

The third day's session began with the group revisiting the components of the IC. Bettie again underscored the need for the conceptualization of the units to match the IC. It was stated that, as the units were being reconceptualized, they should include declarative and procedural knowledge, elements from the Dimension of Learning (Marzano et al., 1997). The team was encouraged to "begin with the end in mind" (Covey, 1989) or select the project or the community experience that would guide the development of the unit activities. The revision process would begin with Keys.

On the day before, the team was able to view the video of the broadcast teacher teaching during the first official day of school, which had begun on the day the team began its meeting. Concerns were expressed about the lack of use of a variety of teaching strategies, structures, and techniques on the broadcast. Therefore, as the group looked at completing the units of study, the need to assist the broadcast teacher in preparing the lessons for teaching Keys, the first unit, was so pressing that it consumed the curriculum development team's time for the rest of the week. 
Linda had completed this unit during the summer institute It was rewritten for the broadcast. Now the team was revisiting this unit for the third time. The group discussed ideas on how this unit could be reconceptualized. Whereas the additional work on Keys may have been time consuming and frustrating at times, it demonstrated: (1) the need for the curriculum development process to include time for reflecting and improving the team's work; (2) the non-linear nature of curriculum development projects (Hargreaves \& Fullan, 1998); (3) the need for Leon to be trained and supported in the use of the teaching strategies included in the units; (4) and that adapting the lessons for the pilot, in addition to all the other broadcast-related tasks, was a challenge with which Leon needed assistance.

After the team reconceptualized the unit, they divided the responsibilities to complete certain agreed-upon activities for the unit. A template was formatted to reflect the three time compartments of the broadcast. Specific content and processes were included in the activities for some of the days that were yet to be taught. Though the group worked hard, they were not able to completely revise Keys with the level of detail that they desired to include. However, they were able to decide specific procedures that could be utilized in the delivery of each unit and to create templates for specific processes.

\section{Support for Technology Partnership Curriculum Initiative}

During the week, Dr. Harry Sales, one of the developers of Technology Partnership pilot project, visited with the curriculum development team. He shared his 
concern about the need to have a key person at NAD who would serve as a guardian for the project since he was no longer able to fill this role. It was felt that one of the associate directors of education in the NAD office of education could provide the kind of support that would be needed. Dr. Sales had been at the Pocono Union at the inception of the idea of the pilot project. but was now serving elsewhere.

The dean of the School of Education at Southwest University, Dr. Claudette Benn, also visited the curriculum development team during the week. She met with the team while Dr. Sales was present. Dr. Benn was able hear Dr. Sales tell the Technology Partnership story, tour the broadcast studio, listen to feedback about the students who were involved in the pilot project. and dialogue with the teachers whose schools were involved in the project.

During this meeting concerns were voiced by the university representatives about the limited amount of funds allocated for research in the Technology Partnership 19971998 budget. The team brainstormed with Drs. Benn and Sales about the possibility of acquiring additional funds for the qualitative/quantitative research agenda of the project. The idea of writing grants to secure funds from the public domain was seen as a viable option. Dr. Benn's support was needed, and she was willing to assist with finding funding sources to financial support the Technology Partnership pilot project.

\section{Processing the Curriculum Development Process}

Throughout the week, Bettie tried to keep the team focused on the pilot project goal of the week-the continued development of the product, the units of study. Though 
the team was involved in personal reflection of the process, there was very little open dialogue of the feelings of confusion and frustration emerging from team members' journals. The time for working on the units was short, and there were no plans for the group to reconvene after this date. As the week ended, the journals still reflected frustrations about several issues.

Some of these issues were: (1) the role of the different entities, especially that of the team from Southwest University, in the curriculum development process; (2) the fact that time was not being taken to process the personal feelings and perceptions of the individuals on the team; (3) the unavailability of secretarial help to type and print drafts of materials that were prepared by the team; (4) the amount of time that was being spent on revising Keys after over 30 hours had already been invested in it; (5) key individuals being absent during critical discussions thus causing time to be wasted in keeping them current when they returned; and (6) who would direct the research component for the project.

On the last day of this session Dr. Sales came to address some of the concems of the group. One of the major concerns was about roles. The confusion about roles could be traced to unclear communication. Originally, it was Dr. Smith's understanding that the developers wanted Southwest University to be in charge of the curriculum development of the Technology Partnership. In March 1997, when Dr. Sales asked Dr. Smith what Southwest University could contribute to the pilot project, he suggested that the university could commit to handling the staff development, the curriculum development, and the research elements. 
Dr. Smith felt that Dr. Sales was pleased with this response and since no one spoke to the contrary he assumed that Southwest University was expected to handle these particular areas. Shortly thereafter, in April, 1997, Bettie Richards, the coordinator for the pilot project, sent an E-mail to the Pocono Union Technology Committee indicating that Southwest University was going to "prepare the teaching strategies not only for this pilot, but for the teachers as well" (Volume 4, Section N, p. 4).

As the team processed some of the conflicting issues, they realized that there was a misunderstanding about the role Southwest University was expected to play in the curriculum development. The misunderstanding was addressed during that session by $\mathrm{Dr}$. Sales. He clarified his role, Bettie's role, and the role of Southwest University's team. For the first time the university's team understood their role in the curriculum development process. They were not in charge of the development of the units of study; they were only expected to link the skills and concepts in the unit outlines with the strategies that could be used to teach them.

Clarification was also provided about the concern on the research agenda and who would direct the efforts of the research team. A preliminary research agenda for the pilot project was being developed by a team of professors from Southwest University. Though there was much enthusiasm to carry out various aspects of the research agenda, funding for its implementation, which involved travel to the pilot sites, was almost non-existent. Although all the issues were not addressed, the open communication fostered during this session allowed many to dialogue candidly about their own feelings, frustrations, and 
concerns. The session ended with an informal agreement to continue this kind of open dialogue in the future.

\section{Outcomes of September's Session}

The major accomplishments during this week were the revision of the Technology Partnership Innovation Configuration, the revision of Keys to meet the needs of the broadcast setting, the pledge of additional support from the dean of Southwest University School of Education, and the open dialogue that clarified the roles of all who were involved in the project. Though funds for research were limited Linda and I continued collecting data for the project throughout the year. Whereas I collected data using qualitative approaches. Linda used both qualitative and quantitative approaches in collecting and analyzing data for the pilot project. A report about her findings was presented to the North-American Division of Seventh-day Adventist, Pocono Union, Maracas Conference. and Dr. Benn from Southwest University.

\section{Analysis of the Curriculum Development Process}

Parker (1994) identifies three types of teams: the functional team, the self-directed team, and the cross-functional team. The functional team looks like the military model that has permeated businesses for decades. The team leader is the boss to whom the workers report. Parker also cites Development Dimensions International description of another kind of team, a self-directed team, as an intact or cohesive group of employees who are responsible for a 'whole' work process or segment. This team delivers a product or service to an internal or external customer. To varying degrees, team members work 
together to improve their operations, handle day-to-day problems, and plan and control their work. The third kind of team, a cross-functional team, is identified as a group of people which a clear purpose, and who represent a variety of functions or disciplines in the organization and whose combined efforts are necessary for achieving the team's purpose.

Of the three types of teams, the curriculum development team for Technology Partnership most closely resembled the cross-functional team. Its membership was diverse including: (1) K-12 teachers, (2) conference administrators, and (3) representatives from higher education. Though this team had no clearly defined members, there was, however, a core group of individuals who worked consistently on the curriculum development process. Whereas some $K-12$ teachers were involved in at least one of the curriculum development sessions, most of the members of this core group were present for all the major development sessions which have been described in this chapter. The composition of this core group included: (1) three of the developers of the Technology Partnership Curriculum Initiative, (2) three individuals from the university, and (3) a conference associate superintendent of education. Though they represented different entities, their goal was the same-to prepare the units of study for the pilot project. The success factors for cross-functional teams, observations, and interviews were used to analyze the curriculum development process. Reflections on this aspect of the Technology Partnership Curriculum Initiative are summarized in the remaining paragraphs in this section. 
Throughout the entire curriculum development process, the developers sought to protect the integrity of the curriculum design as it was originally conceptualized. The creation of the Innovation Configuration was particularly significant because it provided operational descriptions of the components of the unit which the developers wanted to include. Including all the critical elements of Technology Partnership that the developers wanted in the Innovation Configuration helped to address the integrity issue.

During the entire curriculum development process time was also an issue. The curriculum development team held its first meeting in March 1997, 5 months before the pilot project was scheduled to be implemented in the classroom. Since there was little time to complete the units of study which was needed for the classroom implementation phase, the product took priority over the process. This lack of time made it difficult for the team to effectively communicate about their expectations for the product-the units of study or their goals for the process. This process needed to include the development of the partnership between Southwest University and the conference/union. They needed to identify a model which could be used to build this partnership and develop guidelines/norms to nurture this relationship which was emerging simultaneously with the development of the product.

There was no formal plan to use the mindstyles or specific skills and abilities of team members to complete their tasks and strengthen the team. Advantageous use of individuals' talents happened inadvertently rather than by design. All the members of the team did not have the same experiential understanding of the use of teaching strategies which were included in the units of study. Thus a misunderstanding arose at 
the last curriculum development session because the message related to the "preparation of teaching strategies" which was communicated as the task for the curriculum development during Southwest University Summer Institute was not understood as it was intended by those who were responsible for this session.

The commitment and support from key stakeholders-NAD. the Pocono Union, and Southwest University-for the pilot project was very strong. All felt that the development and implementation of Technology Partnership Curriculum Initiative had the potential to positively impact Seventh-day Adventist education. However, in spite of these positive elements, conflict within the team arose. This resulted from some members of the team feeling that they were unable to process their feelings of frustration about various issues. Some members from the university felt that their role in the process was not well-defined and they wanted this to be clearly delineated. Though the team communicated openly about some of their issues during the last meeting of the curriculum development team, there was a need for a systematic communication plan to promote ongoing dialogue of team members. The team functioned as a team only during meeting times when the group met formally. Communication at all other times was on an unplanned and individual basis.

The various points of conflict or misunderstanding that confronted the curriculum development team were a normal stage of team development. The feelings of frustrations that ensued were also normal. Though team members were knowledgeable about the developmental stages of groups, it was difficult for them to deal with the periods of dissonance when they actually experienced them. 
Given the limitations in time and all the issues which needed to be addressed while developing a partnership between the university and those working with schools, which Dixon and Isler (1992) represent as having an "oil and water" quality, it was expected that some conflict would arise among team members. Allocating an adequate amount of time and implementing structures and systems that support effective communication could have helped to move the team to a stage of high performance. Though there was no formal performance appraisal of the team's work, some informal appraisal was done through group processing at the end of several of the curriculum development sessions.

\section{Summary}

This chapter provided a description of the three key curriculum development sessions that were involved in the development of the Technology Partnership Curriculum Initiative. All of the session involved the use of collaborative teams, working together to create a product-the units of study. Time was an issue in all of these sessions. There was an inadequate amount of time to develop the University/NAD/union/conference partnership and the curriculum initiative before the implementation process began. Several of those who served on the curriculum development team invested hundreds of hours, working alone or with a few others, to complete the units of study. Thus, many of the units which the developers hoped would be prepared before school began were completed shortly before they were to be 
implemented in the pilot project. The implementation stories of two teachers in the pilot project are told in chapter 8. 


\section{CHAPTER EIGHT}

\section{THE TEACHERS}

\section{Introduction}

The purpose of this chapter is to tell the stories of two teachers, Annie and Billy, whose schools were involved in the distance-learning pilot project. It is my goal that the reader would become acquainted with these professionals and understand how the Technology Partnership Units of Study were implemented in the pilot project. Each story includes a brief introduction of the teacher, a description of his/her school, a description of a typical day and other critical aspects of the implementation process, and my observation of 2 days at each site. This chapter ends with a reflection on the implementation process.

\section{Annie}

Annie completed the teacher education program at a college in one of the Northeastern states. She chose teaching after taking a high-school aptitude test which indicated that nursing or teaching would be a good choice of profession for her. After graduating from college, she began her teaching career in a small elementary school. After the $10^{\text {th }}$ year of being a full-time mother, she went back to teach in an extremely stressful setting. She taught a group of primary students for a half-day, drove the school 
bus, and substituted in one of the classrooms in the afternoon. She worked 3 years in this school before moving to another. She worked for 8 more years as a teacher and 1 year as a principal before getting involved in the Technology Partnership pilot project.

Annie has been involved in several professional growth activities. She has participated in training in the 4MAT framework on at least four different occasions since 1994. She attended Technology Partnership workshops during the summers 1995 and 1996. She taught Storypath-a strategy used to teach content, decision-making, and thinking skills to various learning styles-during the Technology Partnership summer workshops in San Fernando Conference. She brought ideas from the 4MAT framework and the Technology Partnership workshops into her classroom. She is a member of the Association for Supervision and Curriculum Development (ASCD). She also served as a representative on a subcommittee in the San Fernando Conference that was responsible for making decisions on a variety of issues on education. She attended the workshop on change at the Association of Seventh-day Adventist Secondary Administrators (ASDSA) and was able to broaden her understanding of the process involving educational change.

While working in San Fernando Conference, Annie dialogued professionally with a colleague who worked as a teacher in her school and another educator who had trained her to use the 4MAT framework. She indicated that she and the colleague were constantly sharing ideas. She visited his classroom and he visited hers. Frequently he gave her counsel. After this colleague moved, she maintained contact with him whenever the two met or when she saw his name on-line in the SDA chatroom. On a few occasions, she spoke to the individual who trained her in the 4MAT model. Talking 
to her two colleagues afforded her an opportunity to vent, provided validation for the things she was doing, as well as offer assistance and counsel. She used some of the ideas that came from their discussions in her classroom.

Annie classified herself as an average to avid reader. She reads educational materials such as books on brain strategies, discipline, and sports. She reads Educational Leadership, the journal from ASCD. Her reading has given her ideas about discipline and methods of teaching.

Playing the piano and listening to music--both classical and religious are favorite pastime activities for Annie. She loves playing the piano. The weekends are key times for getting involved in music. She plays hymn arrangements such as "Precious Lord" at home, and shares her musical talent with her church family. Annie has used music to stimulate the children in her classroom.

Traveling is an enjoyable activity for Annie also. Over the past 2 years, besides job-related travel to Florida, she has traveled to visit family in New Jersey, Pennsylvania, Virginia, and Michigan. For vacation, the family usually goes to Virginia Beach. A unit on sea creatures was an outgrowth of a trip to Virginia Beach, where she visits the Marine Science Museum which features sea animals such as jellyfish and sea turtles. She has included relics from her trips in some of the units she taught in her classroom.

Annie is actively involved in a local Seventh-day Adventist church. She attends church regularly and assists with nurturing individuals in a Bible study group. She also serves as the secretary of the Sabbath School and is church pianist. She values her church affiliation because it has conveyed the message to the students who attend the school and 
church that she is involved in the church's activities. Annie's predisposition towards a wide range of activities is confirmed by her Gregorc Style Delineator scores, which implied a strong preference to the Abstract Random style. Her style reveal her tendencies to be involved in a variety of activities.

\section{Her School}

Annie taught at Morris Town Elementary, a one-teacher school in Maracas Conference. The school had an enrollment of nine students in Grades 1-7. It was made up of four African-Americans and five Caucasians. There were three students, two boys and one girl, in the distance-learning pilot project. The school is located close to a fairly busy town with a population of about 30,000 . The school building housed a kitchen, a small classroom, a large classroom, and an office. The office adjoined the main classroom on one side and the kitchen was located on the other side. The school was located on the same property as the church which sponsored it.

Only the large classroom was currently being utilized for school. The other was sometimes used as an indoor playroom and the schoolyard provided a suitable amount of space for the students to play a variety of games. This was Annie's first year at Morris Town Elementary. She was excited about her school's involvement in the distance learning pilot because she had been involved with the Technology Partnership Curriculum Initiative when she worked in San Fernando Conference. 


\section{A Typical Day: Annie's Story}

The broadcast day began with students getting the materials that Leon had faxed to the school that day. The students stamped the date, copied, and then distributed the materials which the broadcast teacher sent. The master copies were placed on the teacher's desk and the materials were then distributed to the students in the pilot project. "There is a schedule for the students to call in to the studio before the broadcast. They take turns" (Volume 4, Section B. p. 1). The broadcast began each day at 12:15 p.m. Eastern Standard Time (EST), so the students had to be sure that they telephoned the broadcast teacher or they would not be able to interact.

Before the broadcast teacher began his presentation for the day, an 'opening slate', a picture background with information for the student to think about, was first displayed on the screen. The teacher explained, "When the opening slate comes up the kids are supposed to be sitting with paper, pencil, and other materials" (Volume 4, Section B, p. 1). She also commented on what the children were supposed to be doing when the broadcast teacher came on-"listening and taking notes" (Volume 4, Section B, p. 1).

Annie described the first segment of the broadcast on a typical day by saying, "The first 20 minutes of broadcast time could be anything--teaching a concept, reviewing. ... He interacts with the different schools" (Volume 4, Section B, p. 1). During that time, he interacted with the students from the different schools. Annie communicated a few more details about that interaction. She indicated that at times, when Leon was broadcasting, that he would inform certain students know that he was going to be calling 
on them for responses. Therefore, the students would be ready to respond when called and little time would be wasted. "He tries to save satellite time by alerting the kids that he is going to be calling them. As he ends this session he gives them an assignment" (Volume 4, Section B, p. 1). This assignment could be something they had the materials to do, or it could be something that they had to use the technology to complete. Sometimes he would send them to the Technology Partnership web page to search for "BJ Pinchback," a resource page under the Technology Partnership virtual classroom that provided other links to resources that could be used in completing their assignments.

One of the mediums through which the students could communicate with the broadcast teacher during the 45 -minute assignment time was the chatroom. From the onset of the broadcast, there were plans to use a program called "Palace" to provide chatroom service. Annie explained why this plan was quickly abandoned. "The opening series on Palace was raunchy. The kids could get into areas of Palace that were not appropriate" (Volume 4, Section B, p. 1). The alternate plan for chatroom access for the pilot project involved the use of MIRC, a program that was being utilized by the Pocono Union. Through MIRC, the satellite schools and the broadcast teacher could continue communicating during the times between broadcasts.

As we continued our discussion about assignments, she provided me with a list of possibilities of what the students' assignments could be. She explained that the broadcast teacher could ask them to "Go to MIRC, go to the Internet, work on Taba, work on a project, read these articles, or anything" (Volume 4, Section B, p. 2). The completed work was faxed to the broadcast teacher. Annie explained that after the students had 
faxed completed work to Leon, the originals of their work were placed on her desk. She initialed each piece of work indicating that it had been faxed. She saved the originals, which they had faxed to the broadcast teacher, until they were needed by the students to complete their portfolio.

I inquired about what usually happened during the second segment of the daily broadcast. This was a 30-minute segment of time in which Leon again interacted with the eight schools. Annie indicated that the students called in to the broadcast studio again.

Frequently he would check back about what they had come up with so far. I think he redirected them to more work. They might be given additional assignments, something else to do during that next time off. You know, he kind of checked on what they had done and then clarified a bit. He might have taught something new, and he may have directed them to another assignment or further work in what they were already doing. (Volume 4, Section B, p. 1)

At the end of the second broadcast, there would be another 45 -minute period during which the students interacted with the broadcast teacher as needed and completed assignments.

During the third segment of the broadcast she recounted what the broadcast teacher did. "He introduces the CLQ or HOM" (Volume 4, Section B, p. 2). These are the Christ-like Qualities and the Habits of Mind which are a part of the daily routine of the program. She explained that during this segment of the broadcast, the students could be asked to journal or to do a T-Chart which provided very concrete examples of observable behaviors or statements of individuals who were demonstrating a particular CLQ or HOM. When I questioned Annie about how the broadcast teacher reinforced these characteristics, she indicated that this was done by repetition, by asking the students 
when had they used these, or for examples of how these qualities changed their behavior. The broadcast ended after this session. Annie summarized the flow of the different segments of the broadcast by explaining that anything could be taught during the first or second segment of the broadcast. The CLQs and HOMs were always in the same slot during the last part of the day.

\section{My Observations-Day 1}

The room felt somewhat warm. The students spoke softly among themselves. Three students in Grades 5 through 8 were in the pilot project and they were sitting in the section of the classroom that was designated for the pilot. The monitor, wireless keyboard, fax machine, telephone, and all the other materials and equipment necessary for the pilot project were set up in this section as well. One student called in to the studio so that they could be connected with the broadcast teacher and the other satellite schools. They waited for the broadcast teacher to come on the air at 12:30 p.m. Eastern Standard Time. The younger students were sitting at their desks in another section of the classroom; they sat close to the classroom teacher.

During the first segment of the broadcast, Leon came on the air and introduced the activities they were going to work on that day. He planned to use the Taba inductive strategy. This would involve the students in classifying data, which were written on strips of paper, into three or four groups. The groups would then be named and described in terms of their attributes. The other assignment would involve checking their heart rate after a period of physical activity. After Leon went off the air, the students had about 30 
minutes to begin working on the Taba exercise. During this broadcast, the students hardly looked at Leon on the monitor.

The students had until 1:15 p.m. to work on the assignments that Leon had given them. They did not start working right away. Annie came over to their section of the room to help them focus on the Taba inductive-thinking assignment. She asked them to write the numbers of the sentences they felt belonged together and select a name for each group of sentences.

One of the students went outside and returned shortly thereafter. He began working on a math assignment and he did not get involved in the Taba exercise. The two other students tried to involve him, but he seemed to have withdrawn from the activity. He indicated that he had given some input to the other students which they heeded. He continued to work on math. The teacher tried to assist them again. She gave them paper clips to hold the sentence strips that they had grouped.

At about 1:12 p.m., the student who was previously uncooperative called in to the studio to be connected for the second broadcast session. He tried two times before getting connected. The students in Grades $1-4$ were slightly noisy at about 1:15. Annie stood at the back door of the room and asked this group to run three laps. The students in the broadcast wanted to run with them also. She encouraged them to concentrate on what they were doing. After ascertaining that the broadcast teacher was not on the air, Annie changed her mind and allowed them to run for a few moments. They ran quickly and came back inside before the second broadcast session started. 
Leon came back on the air at $1: 18$. One of the students turned on the VCR to tape the broadcast. They recorded each segment of the broadcast every day. Leon explained that he hoped they had worked on the Taba lesson. He asked them to get into teams with their materials. During this time, the students did not give much attention to the assignment on which Leon was focused. One student worked on math, another was coloring on a sheet of paper, and the third sat uninvolved. One of the students complained about someone sticking out her tongue at him. Leon continued to interact with his virtual classroom unaware that the students at this particular school were not attentive.

Leon called on a student in one of the Northeastern states to give him the attributes and name of a group of sentences. The students in two other schools contributed to the lesson. As I observed this lesson being taught, I realized that Leon had adapted the use of this strategy for the broadcast. As the lesson progressed, the students at Morris Town Elementary seemed attentive at times and distracted at other times. On one occasion the students rushed to press the button on the $M$ and $M$ box, indicating that they wished to give a response to the activity in which they were engaged. Leon asked them a question. He called on one of the boys at the school, and he responded. The younger students were a little noisy at this time. The students in the pilot project asked them to be quieter. They lowered their voices. The teacher reminded one student to stay on task. As the lesson progressed, the broadcast teacher announced that he would show a video clip of the heart. Annie asked the younger children to look at the video clip too. He showed them footage of a living heart. The students were asked to take notes. The 
students in the pilot project were more attentive as the teacher showed this clip. After this was shown, he asked the students from three schools for feedback. The students responded, but they could not be easily heard. Leon asked them to check their resting heart rate, and begin the activity of checking their heart rate after $1,2,3,4$, and 5 minutes of sustained activity. Before Leon went off the air, he encouraged the students to begin working on their assignments.

Two of students became involved in checking their heart rates. The other student called the classroom teacher, indicating that he did not know what to do. He called out to Annie, but she did not hear him. One of his classmates was able to get him involved in the assignment. He ran around the classroom for about 10 seconds. Then he dropped to the floor to do 10 situps while one of his classmates held his feet. He did six jumping jacks before 1 minute was up.

The students seemed to be distracted again for a period of time. Two of the three were writing their names using some fancy form. They returned to their exercises after one student indicated that they were wasting time. Another student exercised. The student who was uncooperative during the first broadcast now tried to get another student to do the exercises also. She did not cooperate. At this time, Annie gave some input which helped them to focus. She asked them to pick a number to decide who would do their exercise first, second, or third. They followed her suggestion and began the exercises all over again. They worked together and helped each other complete the various exercises they had chosen to do for the 1 minute span of time. 
As Annie sat on the floor and worked with younger children who were making a poster; she kept a keen eye on the group of older students. She instructed them to multiply their pulse rates by 4 after they had counted it for 15 seconds. The students worked on the board to calculate their pulse rates. They exercised for 1 and 2 minutes and then checked their pulse rates. At 2:17 they were still involved in this activity. The room was a bit noisy as they did this activity in the classroom. Annie asked the students in Grades I through 4 to clean the areas around their desks. After this was done, she asked them to place their heads on the desks and listen until she was finished talking. She spoke with a soft soothing voice asking the older students to work quietly on Taba because they were getting too wound up on the pulse rate assignment. Since they had 3 days to do this activity, they did not have to finish everything on that day.

Annie reminded the students to call the broadcast studio at 2:29. They waited about 2 minutes before Leon came on the air for the last segment of the broadcast. He clarified details about this assignment. He reiterated that taking their resting heart rates was part of the assignment. He talked about using this activity in the community event for this unit. Leon listened to the students from other schools give their input. The interactions were not clear so it was difficult to understand what they were saying. Leon did not repeat what was said so the students at this school did not receive the full benefit of this part of the lesson.

When I inquired whether they were listening to the broadcast, they responded affirmatively. The time for the broadcast expired, and Leon was cut off before he was able to bring closure to the lesson. As the broadcast ended, the students were given a 
chance to play in the room that adjoined the classroom. Before they were dismissed, the students completed an evaluation sheet about their performance for the day. Annie checked these to make sure their perceptions of their performance for the day were the same as hers. This sheet was to be taken home to be signed by their parents.

\section{My Observations-Day 2}

During the first segment of the broadcast on this day, Leon continued to work with the students on the lab activity involving the reading of their resting heart rate. Leon placed himself in an inset box on the monitor. He demonstrated how they could use Microsoft Excel to make a chart to display this information. He used data from one of the students at Morris Town school and from a student in another school to do the demonstration. The students were attentive during this time. They sat directly in front of the television screen. They seemed animated while he was trying to show them how to do this. They chattered back and forth in relation to the activity. They appeared to be sincerely interested. The rest of the students in the room were really quiet.

Leon showed them how to do the chart with the information about their pulse rates using various graphic options. He assigned the students the task of creating a graph with the data from their resting heart rates. He asked to hear from those students who had questions and then instructed everyone to work in groups to complete this assignment. Again, Leon was suddenly cut off.

As the students grappled with what they needed to do, the teacher sought clarification from them regarding the assignment Leon was expecting them to work on 
during this 45 -minute space of time that was dedicated to the completion of assignments. The children understood that they had 3 days to complete the exercise but that the 5 minutes of exercise for heart rate must be done today.

Today, Annie asked the students to do their exercises right outside the door. The two boys went outside, but the girl remained indoors for a few minutes to input data into a spreadsheet she had created from Microsoft Excel. They were focused on completing their assignment. The students alternated between running, resting, and checking their heart rates during the different intervals of this lab exercise. They worked more cooperatively than they did the day before. During this activity, they timed each other individually or they were all doing the same activity together. There seemed to be more of a spirit of camaraderie between them. No sounds of bickering voices could be heard.

I noticed the opening slated just before the second segment of the day's broadcast began. It said, "We will rise above all challenges. What is the number one area of importance for your personal wellness plan?"

The students were out of the room when Leon began the second segment of the broadcast. He told them they were going to work on (1) personal wellness plan, (2) Taba, and (3) the circulatory system. The students chattered and did not seem to be paying close attention at this time. Leon began to review elements from the circulatory system. He asked such questions as: how many chambers are in the heart? Which is the largest of the three transport systems? What was the smallest transport system? He showed a video clip on this body system. As he taught about the arteries, only one of the three students 
seemed to be looking at the monitor. He continued the lesson by teaching them about the arteries with the aid of a diagram.

Leon asked the students to take out the Taba data on sentence grouping. He asked the students to suggest attributes for categories of data that were formed. He asked for volunteers to give answers. He wrote down the critical attributes on a board. He asked for the critical attributes of a second group of sentences. He encouraged them to give responses. Some of them did. One student from Morris Town was taking notes on the critical attributes. Soon, this segment was over.

After the second broadcast session was over, the three students returned to the lab activity involving heart rate. They exercised for 5 minutes but waited too long to check their heart rates. The data were not accurate. They decided to redo the exercise by playing basketball for 5 minutes. The heart rate information seemed to be more accurate now. Team spirit was observed again as they took turns using the computer to graph each of their individual data. At about 2:25. one of the students called in to the studio for the last broadcast of the day. Music was being played in the background until Leon came on the air.

When Leon came on at 2:32, he spoke to the students about spring vacation and encouraged them to relax during this time. He informed them that he would send the vocabulary test on the next day, and he encouraged them to complete their outstanding assignments. As they neared the end of this broadcast, Leon showcased some of the work that a student from one of the other schools in the pilot had done. The students were not focused while this was being shown. One was drawing; another was organizing papers. 
No one seemed to be paying attention. During the last 30 seconds Leon encouraged the group to have fun during their spring vacation which began the following Monday.

\section{Billy}

Initially, Billy was not interested in teaching. His mom, dad, and grandmother were teachers. In spite of this family history, he decided that computers rather than teaching would be his career choice. He began classes at Southwest University in the 1980 s with the goal of becoming a computer programmer. He started rethinking his choice after he began struggling in his technology classes due to an inadequate background in technical mathematics. His mom had taught him how to use a graphic organizer which looked like a "T-Chart" to analyze problem situations. She would use this graphic organizer to look at the pros and cons of choices the family had to make. Billy decided to use this technique to look at his current career choice. After looking at what he wanted to do in life in this light he thought, "This is a teacher" (Volume 4, Section A, p. 48). He made a decision after the end of the first quarter to enter the teacher education program and has not had any regrets.

He has recently received a master's degree in Administration and Supervision. During this program, he studied philosophy, financial management, current trends in education, facilities planning, and supervision of instruction. He was motivated to get this degree because he wanted to be trained as an administrator. This training has helped him in several ways. He feels that he has improved his organizational skills, and this has helped him think about the learning styles of students. He is more knowledgeable about 
educational issues and has incorporated some of the ideas he learned into both his teaching and administrative responsibilities.

Throughout Billy's teaching career, the computer has continued to be one of his hobbies. About five years ago, he started a computer bulletin board service which allowed family members from all across the United States to stay in contact with each other via E-mail. Through this medium, Billy was able to stay in touch with them. On this bulletin board. he placed an encyclopedia that his students in the classroom could access. Games which his students could play at home could also be accessed from the bulletin board service. He used the bulletin board service as a tool to build a relationship with them especially through the use of its chatroom and E-mail capability. Much of what Billy knows about the computer is self-taught.

Billy is a lover of the outdoors. He has a passion for activities such as skiing, backpacking, camping, bicycling, and canoeing. He has spent his summers and other vacation times at various outdoor sites. He has walked about 500 miles of the Appalachian Trail from Maine to New Hampshire and from Spring Mountain, Georgia, to the Smoky Mountains in Tennessee. He has visited the Cherokee National Forest, the Everglades in Florida, and the Sequoiyah and Redwood forests in British Columbia. He has traveled to Utah to ski during spring break. The students in his classroom have gotten involved in Billy's hobbies. He has brought back video of wildlife from his trips to share with his students. He buys postcards and sends them to his kids to keep them well informed of what he is doing. He has taken his students spelunking and tobogganing in Michigan. 
Another of Billy's hobbies is woodwork. He has made a display case for his wife's collection of horse figurines, a custom-designed computer desk for another family member, and a quilt rack for his mother-in-law. He has created a master bedroom out of his garage. Billy has used this hobby in his profession. He has made a sign for the school. He and his students worked together, building and painting bird feeders, which were appropriately placed in nursing homes as an outreach project. He has taken his interest in three-dimensional drawing into the classroom and has taught his students how to draw. Billy`s scores on the Gregorc Style Delineator revealed a strong preference in the Concrete Random style. This indicated that he would be comfortable doing the kinds of activities in which he had been involved.

Billy reads books on religious topics, computers, and building homes. Apart from his devotional reading, he reads to learn how to do the things he desires to build, or do on the computer, or whatever he wants to accomplish. Of particular interest to Billy is his passion for studying end-time events as they relate to history, Scripture. prophecy, and world news. He shares insights from his reading with his students at school. His television viewing habits include watching the history channel and frequently watching the news. He is particularly interested in programs dealing with World War I or World War II.

Music is one of Billy's interests. He particularly likes instrumental music. Billy listens to classical and some country music in his car and nature music while he is working. All the singing he does is done in the congregation at church. Music helps him to forget about school and relieves stress. Billy is involved in church activities and he 
serves his church as an elder. He preaches once per quarter. He has done multimedia presentations for the church in which he has involved the children. He has also used his computer skills to produce a pictorial directory for the church. He believes that being involved in church activities has helped him to be much closer to the Lord and to be more service-oriented.

\section{His School}

Miles SDA Elementary is located in a rural part of a Midwestern state which is a part of Lavantille Conference. It lies in the heart of a community of about 4,000 people but also serves a nearby community of about 15,000 . The school has a population of 13 students. Eleven of these are Hispanic Americans and two are Caucasian. There are nine students in Grades 5 through 8. The school has two large classrooms with a gym and an adjoining room. Only one of the classrooms was being used at the time.

The school building alone occupied the property on which it was located. The grounds outside the school were spacious enough for the number of students who attended the school. Equipment for play was appropriately placed in one corner of the grounds. This school is located in the Central Time Zone. Each day they received the broadcast at 11:15 Central Time. Lunch for this group could not be at noon. Billy had to adjust the schedule so that the children would have brunch just prior to the broadcast, at about 10:40 a. m. 
A Typical Day: Billy's Story

I began my interview with Billy by asking him to describe a typical broadcast

from beginning to end. He explained what happened right after lunch, at about 11:10.

We would have what I called 'ready set.' which means kids are coming and they are getting settled for the broadcast. And at that time, there is somebody that is designated that will pick up the phone and dial in and get the tape set and the channels set, and get everything set. (Volume 4, Section B, p. 11)

Thus, when the broadcast teacher comes on, everything is running smoothly. I asked him to describe the activities that were involved in 'ready, set.' Billy explained,

It is a matter of you know, you've gotten your drink; you've used the restroom; you've found your books; you've found your pencil; you've found your notes, you are sitting at the table, you may not be real quiet yet, but you are getting yourself physically ready to learn. (Volume 4, Section B, p. 11)

I probed about the other tasks that are involved in getting equipment ready for the broadcast. Those tasks included setting the television monitor on the correct satellite channel on which EMG would show the interaction. setting the videotape in the VCR to record the day's lesson, calling the broadcast studio to get connected for the interaction with the teacher and the rest of the school, and making sure the TV was on. This readiness activity could be completed in about 5 minutes.

Billy indicated that, "usually there is about a 5 -minute wait before Leon actually comes on... . Usually Leon throws up a slate, he calls the opening slate" (Volume 4, Section B. p. 11). This 'opening slate' is usually a thought-provoking question. Some of the students respond at that time and others do not. Billy, would like to see all of them answer this question. 
At $11: 20$, the broadcast teacher usually came on. Billy described what typically happened during that time.

He'll talk !5 minutes or so. Later in the year it was 20, but at first it was 15 minutes. And that is where he ... teaches any skills that he wants to teach or reviews any material that he thinks that they are having trouble understanding. Then he does an interaction of some sort. Then they go off line and they do some kind of activity. . . . it could be one activity or it might be two or three activities. They could be team-based or they could be individually based, and then the process is repeated all over again at 12:10. (Volume 4, Section B, p. 12)

At that time, one student would get everything ready for the second broadcast.

They will do another 'ready, set' at 12:10, be seated at the table at 12:15. When the broadcast teacher came on for this session, Billy explained,

He will teach probably a little more in depth at this second broadcast, teaching English and writing skills and anything like that, and any other heavier content. Children listen during that time for 30 minutes; and then he goes off, and during the off time, they repeat the process of doing an activity or finishing an activity. (Volume 4 , Section B, p. 12)

At $1: 25$, someone would do 'ready set' again. The students would be seated and then at $1: 30$ the teacher would come back on for the last 15 minutes of broadcast time. Billy reported, "This is a little more relaxed; at least, it seems to be for the children."

During that time, the broadcast teacher would focus the students on such elements as the Christ-like Qualities (CLQ), which deals with social/character-building skills, or the Habits of Mind (HOM), which deals with life-long habits found in Dimensions of Learning (Marzano, 1994). He explained:

And the kids respond to that by filling out a $T$-chart or talking live on air with him about how they feel about these things or what they see; and then, as soon as he goes off, they know that the great day has ended; and it is now time for P.E. So, at that point whenever he goes off, sometimes 
they get a little anxious, you know, they think he's gonna end and they can tell he's gonna end it, you have to put the reins on a little bit. But, then we go out and do a group P.E. game or activity. Something like that. So that is a typical day. (Volume 4, Section B, p. 12)

I questioned Billy further about some of the CLQs and HOMs to which the students were introduced during the year. I learned that some of the CLQs included active learning, cooperation, being understanding, responsibility, compromising, and selfcontrol. During the interview, he mentioned that conflict resolution was one of the HOM they had studied during the year. When I inquired, I learned that a T-chart is a teaching strategy used in teaching a social skill or CLQ such as self-control. This strategy uses a " $t$ " to write concrete examples of behaviors, words. and feelings that can be seen, heard, and felt if a particular CLQ was being demonstrated.

The children would give suggestions about what should be placed in the chart. He'll say, 'Raymond, give us something that looks like.' Sometimes he'll ... ask for a specific person. He does that usually by random call. He might rotate a card or something. He might pick somebody. The kids don't know who it will be. (Volume 4, Section B, p. 13)

\section{Observation-Day 1}

When I arrived in Miles SDA School, the students were playing volleyball in the gym. I received a warm greeting from them. They invited me to join one of their teams after learning that volleyball was one of my favorite games. When I consented, they all cheered. When the game was finished, the students lined up to go inside. Some got drinks and went to the rest room. Others came inside and were quietly seated as they got ready for the next activity. 
In the classroom, the teacher shared the schedule, which reflected times the broadcast was aired for both schools.

$$
\begin{array}{ll}
\text { 11:10-11:15 a..m. } & \text { Ready set } \\
\text { 11:15-11:30 a.m. } & \text { Broadcast I } \\
\text { 11:30-12:15 p.m. } & \text { Down Time } \\
\text { 12:15-12:45 p.m. } & \text { Broadcast II } \\
\text { 12:45-1:30 p.m. } & \text { Down Time } \\
\text { 1:30-1:45 p.m. } & \text { Broadcast III } \\
\text { 1:45-2:25 p.m. } & \text { Catch-up time }
\end{array}
$$

Billy indicated that it was typical for Leon to fax or E-mail materials about 30 minutes before the broadcast. He found this frustrating because he felt that it did not allow him enough time to sort materials or get a general understanding of the work so that he could help his students. Therefor while his students ate their brunch at 10:40 a. m.. Billy used that time to process the materials that had been sent by the broadcast teacher.

The students at this school used headphone sets to listen to the broadcast. Billy had a set also. In this way the students could participate in the broadcast without noise a distracting to them or their younger schoolmates. The use of this device allowed Billy to listen to get a general idea of the concepts that were presented and the assignments they were expected to complete. He recorded all the assignments so that he could check on how well his students were doing. As we neared the beginning of the broadcast for that day, the students took out their books and materials and put on the headphones. All the 
students sat at a half-moon table. Billy put on his special head phone which allowed him to move about so he could supervise both groups. I was given a headphone to use so that I could hear the broadcast.

At 11:22 a.m., when Leon did not appear on the monitor, Billy decided to check the equipment. All seemed to be well. Leon came on shortly thereafter. The opening slate read, "What is the weight of the human brain? How many brain cells do you have?" Three students, all girls, wrote down this information. Leon indicated that it was 12:22 p.m. EST. He checked to make sure all the schools could see him. He told them about the new unit they would be starting the next week. The TV monitor blinked, and Leon could not be seen for a moment. He informed the students about assignments that needed to be completed: an Internet hunt, the personal wellness plan. the nervous system, and their portfolio.

During this broadcast, the students realized that some of the information they needed for work on today's tasks they had not received. Leon told them they would be working on their wellness plan during that first broadcast. He used the Elmo projector during this activity. Leon talked about the first thing in the wellness plan being the opening paragraph. He clarified that this paragraph was a general statement about what they were going to do. Some of the sub-categories he suggested could be included in the plan were fitness/exercise, mental wellness, diet, spiritual wellness, rest, and social wellness.

The students chatted a little during this time. Leon asked them to use "I will" statements in their plan. All the students took notes. He explained that the third part of 
the wellness plan was the benchmark statements. He complemented the students who gave a definition of "benchmark." He told students to include a benchmark in their plan that was between $21 / 2$ to 5 years long. He wanted two benchmarks for each aspect of the plan. The students were fairly attentive during this session. This segment of the broadcast ended, and the students were left to complete unfinished assignments.

The downtime, the time when Leon is not broadcasting, was devoted to working on assignments. At the beginning of the downtime, Billy wrote ideas on the board that were related to the wellness plan. He explained to the group that there were no vocabulary words for that week and that they would be quizzed on last week's vocabulary. He reminded them that each student had to have his or her 'back work,' (work that had not been completed), finished on or before May 1 .

After Billy had clarified directions and instructions, the students began working on various assignments. One student went to the teacher's laptop to work. Another student went on the Internet. A third student used the computer to prepare a very colorful background to answer her directed-reading questions. After she had E-mailed her work to Leon via a "file attachment," I inquired about how long the students had been working on the wellness plan they were currently doing. The answer I received indicated that this was the seventh week they were on this assignment. Two students worked on their portfolios. One of them noted that she did not get all her work done on time. Another student sat at the computer working on assignments that had been written by hand for his portfolio. All of the students seemed to have been engaged in some kind of activity during the downtime that day. They worked without controversy. 
During that time, Billy showed me some of his management system. He showed me a chart on which he tracked the students' assignments. It showed the assignments that the students had or had not completed. The chart also helped to see the volume of work that an individual student as well as the entire group needed to complete. During this time, Leon faxed the remainder of the students' work. Billy ascertained that the students had enough to keep them focused before turning his attention to the younger students.

Billy received the papers that were faxed by Leon shortly before the second broadcast. The papers had to be sorted and copied for the students. Billy tried to share the time in which he was caring for the needs of the younger children with taking care of the paperwork that had just been received for the older students. He reiterated that he did not like getting the students' work at the last minute. Though he was not upset about it, he felt that the situation needed to be changed.

As the students got ready for the second segment of the broadcast, those in Grades 1 to 4 went into the gym for a break. Billy could supervise their play with the help of his outdoor monitor, an electronic monitor which allowed him to see the students playing in the gym. Leon came back on the screen at 12:30 p.m. The students could see him but there was no sound. One student told him on the phone that they could not hear him. Billy tried to adjust various points on the hardware to get sound again. The sound returned after 2 or 3 minutes. Leon showed one of the student's projects. Afterward, he showed some creative work that Billy's students had done on a Taba assignment. The students seemed pleased that work from their school had been displayed. Leon showed 
them how to correct spelling errors. He asked them to check their creative homework to make sure errors were corrected. He answered the students' questions during this time.

Leon explained to the students that they could work in teams to do the "Internet Hunt" activity. He commented that they would also look at a few other things about the nervous system and how it works. He played an audio tape. He searched for a video of the nervous system. He talked to the group about the nervous system. He lectured for about 10 minutes on the cells. The students took notes and were reasonably quiet in spite of the fact that Leon was talking only during this part of the broadrast. On several occasions, Leon placed himself in a small inset box in a comer of the screen to show a visual. He talked about the portfolio reflection sheet and about evaluating the students' work. Leon did most of the talking. There was very little interaction with the students. He gave them assignments to do and then went off the air.

During the downtime, all the students lined up to go outside for physical education. Billy seemed to have a way to get the students to move in an orderly fashion. The students clamored to play volleyball again. After physical education, the students worked on their assignments. A student called and talked to Leon about an assignment. Soon the opening slate was seen on the screen, and a student called in to the broadcast studio so that the school could be connected to interact during this broadcast.

As the 'opening slate' was shown on the screen, all the students settled down and put on their headphones. The students waited for the broadcast to begin. At 1:35 p.m. Leon came on and checked to see whether the schools were connected to the studio. He announced that one school was not yet connected. He told them to e-mail answers to 
questions he was going to ask. He played a short Sesame Street video which had information about the nervous system in song and action. He introduced a T-chart for the CLQ-“Offering Support to Others." Leon placed himself in the inset box as he did this activity.

The students offered suggestions on what they would see and hear if they were practicing this quality. One student suggested that he would hear others asking someone if they needed help with their homework or something else. They suggested that they would see some providing direction for others; sharing materials, information, or notes; and someone helping another to find something. Leon quickly wrote down each of their suggestions on the T-chart. He asked them how they would feel if this quality was being demonstrated. A student from one school gave suggestions for the $T$-chart that would enable an individual to feel that someone cared about them.

The broadcast ended with Leon being abruptly cut off, indicating that all the time allocated for this segment had been used. The children scampered away from the table as soon as the broadcast was over. They got involved in completing assignments during the downtime. They copied materials, faxed assignments, and worked on the computer. Billy encouraged them to work quietly because it was study hall time.

\section{Observation-Day 2}

Before the broadcast began, the students gathered around the table. Some spoke in Spanish. Soon Leon came on. He told them that that day was the final broadcast for the unit "Well Into the Future." He also informed them that they should have gotten the 
materials that he had sent them that morning. They were going to use them in the first two segments of the broadcast. For the final portion of the broadcast, he explained that he would alert them about an assignment that he wanted them to complete over the weekend for the next unit.

Leon did some forecasting about the upcoming unit, The American Home, by sharing some pertinent information with the students.

You will be working together in teams of two for quite a bit of the time during the next unit. So, I want you to be thinking now about somebody you can work effectively with in your teams. We are going to divide the team into pairs for part of the activity. There will be team-oriented activities; there will be individual, but we are going to put a new thing in there, and that's pair activity. (Volume 4, Section J, p. 8)

He gave them information about software that he was sending for each school to load into their computer. Each school would have to send it to the next school via overnight mail. They would need to use this software for the next unit. The students at Miles Elementary now realize that they have forgotten to dial in. The could hear Leon but they could not communicate with him without the telephone phone. They dialed in and Leon placed them into his communication system. He informed them that today they would be discussing the personal wellness plan for the last time.

He told them that he was now going to share a complete wellness plan from one of his students. He checked with two of the schools to see if they are experiencing some problem or had some questions. Leon placed himself in the inset box and adjusted the document on the screen so that it could be read by all. As he read this wellness plan, he tried to suggest corrections which could be made. 
Leon said, "This is the first complete one I have seen with all of the pieces put together, and it looks very good" (Volume 4, Section J, p. 8). He gave some additional feedback and asked if anyone had any additional questions about the wellness plan. One student called in and asked about making changes to improve his wellness plan. Leon answered:

Absolutely! At any point. These things can be worked on at any time until you place them in the portfolio. Once they are in the portfolio, then they are the way you feel they need to be for my evaluation of your portfolio. So the process of you sending them in ... I'll mark it up here and send it back to him so he could take a look at it and make any adjustment or changes that I suggest. Some of them are going to be things that have to be changed like putting that apostrophe in the word won't. There may be some suggestions that are just that-a suggestion and you don't have to take it. (Volume 4, Section J, p. 8)

Leon encouraged the students to use spellcheck to edit their work. He affirmed the student who had sent in the completed plan. He spoke to the students about sharing their work so that they could benefit from the feedback of all the students in the virtual school. Leon concluded this segment by giving specific information about elements on the computer that could be used in formatting their work.

He gave additional specifics about the length of sentences and how much information needed to be included in the "benchmark" statements, or statements reflecting a standard which students expected to reach. The students at Miles Elementary listened to Leon carefully. During the broadcast they asked for clarification on the benchmarks and the subcategories of the wellness plan.

Leon interacted with the students from about five schools during that first segment of the broadcast, answering questions that would guide them in the completion 
of the wellness plan. Often there was an echo in the background as they spoke. He encouraged the group to work on their assignments and to get ready to play a game during the next broadcast. He indicated that it would be fun.

During the downtime, one of the students worked on completing her personal wellness plan. Another checked the E-mail while yet another worked on Billy's computer. Leon sent articles for the directed reading activity for different reading levels. Billy whispered in a student's ear. He asked him to move away from another student who was busy working.

Leon began the second segment of the broadcast directing the attention of the students to the quote on the opening slate: "Between stimulus and response there is a space. In that space lies our power and freedom to choose our response. In those responses lie our growth and our happiness" (Volume 4, Section J, p. 8).

Leon also explained the idea behind the personal wellness plan. The goal was to prepare the students to make the right choices when they are faced with decisions that have to do with their health and wellness. He elaborated on the value of demonstrating integrity at critical moments such as when an individual fulfilled his commitment to exercise after being tempted to do otherwise.

The game that the students were going to play was explained next. Leon was going to ask questions which the students had to answer. They were encouraged to answer without using their notes. He indicated that there would be some graphic in this activity, but there were none. He asked questions about the skeletal, respiratory, nervous, and integumentary system. Examples of some of the questions are: Who can name for 
me the three types of tubes that transport blood through the body? What is the full name of the arteries that carry blood to the lungs? Where do the capillaries pick up oxygen in the lung? Most of the schools were very involved in the game.

At times three or four schools called in to answer the same questions. Some were calling before they had the answers. There were at least 40 interactions with the schools during this game. The students at Miles Elementary called in at least 10 times. Throughout the entire interaction he affirmed the students.

During the downtime while the students worked on their assignment. I sat with one of the students whom Billy said had been "the glue for the program" (Volume 4, Section A, p. 7). This student had been instrumental in speaking encouraging words to the rest of the students in the classroom when they had been discouraged with the pilot project.

Billy's technological knowledge was evident. When there was a glitch in the technology, and the students were unable to hear the broadcast, he adjusted the connections. Sound was restored in a few minutes. He indicated that during the winter months, he had to go on the roof and clean snow off the satellite dish to be able to receive a clear broadcast. He was able to do troubleshooting with the technology. At 12:33 p.m. only one student had headphones on. The others were not quite ready for the broadcast yet. Billy asked the boys to sit down. Soon everyone was in place.

Leon came on the screen and explained the first activity for the next unit to the group. He explained that the first project in this unit involved researching their family history for which the students had to gather information over the weekend. He 
questioned the students about how a family could demonstrate their ancestry. He placed himself in an inset box as he brainstormed with the students. Students from two schools indicated that family ancestry could be demonstrated through the use of a family tree. $\mathrm{He}$ received feedback from at least six schools about the information that they could be gathering over the weekend for their family tree. As they shared additional details for this project, the time for the broadcast expired and Leon was suddenly cut off.

As the broadcast ended, Billy focused the students on an activity, a neuroscience treasure hunt. He read them the directions and allowed them to choose two areas to explore. They chose to explore the effects of drugs on the spinal column. They worked together on this activity. There were complaints that only three persons in the group chose the activity; nevertheless, they all continued to work on this activity. One student seemed to take the lead in speaking out in this activity. Shortly thereafter, the group broke up and went out for physical education.

\section{Summary}

In this chapter I have described the teachers, their schools, and summaries of a typical day in the pilot project. I have also included detailed descriptions of my observations on 2 days at each site. Though there were some differences, the teachers' descriptions of a typical day and what I observed were very similar. It included: (1) Leon interacting with the students for 1 hour, divided in two 15-minute and one 30minute segments of time; (2) students being taught with strategies/structures which encouraged reflection and higher-order thinking (use of the Taba inductive strategy and 
structures such as T-Charts); (3) the teaching of Christlike Qualities which includes the social/character-building skills from the cooperative learning framework (Johnson, 1997; Johnson et al., 1998; Kagan, 1994) and Habits of Mind (HOM) which includes life-long habits from the Dimensions of Learning framework (Marzano et al., 1997); (4) students involved in projects; and (5) students involved in the use of technology such as fax machines, VCRs, E-mail, Internet, word processing, and spreadsheets.

After surveying the activities included in a typical day, I questioned the teachers further about other aspects of the implementation process that were not always visible. Their interviews revealed additional information about several areas listed in the first paragraph of this summary. Two themes emerged from the analysis of the data from these interviews. These themes are discussed in chapter 9. 


\section{CHAPTER NINE}

\section{THE THEMES}

\section{Introduction}

The idea that change is a process is well documented in the literature (Fullan, 1991; Hall \& Hord, 1987). The experiences of the teachers in the Technology Partnership pilot project supported this viewpoint. They were involved in a very complex initiative that had tremendous potential. As I examined the teachers' stories and reflections about their first year, I realized that they had had similar experiences. Through the analysis of the data and my own reflections of the implementation process, two themes were apparent. I entitled the first theme "Managing Change." It explored the management issues of the pilot project. The second theme, which I entitled "Instructional Support," addressed the training and support issues of the implementation process.

\section{"Managing Change"}

Though beginning the classroom implementation of the pilot project was exciting, it was expected that management issues would arise. The management issues 
which developed during the first year related to: (1) the role of the teacher, (2) the use of technology, (3) the use of cooperative groups, and (4) the challenges with student assignments.

\section{The Roles of the On-site Teacher}

Before the pilot project began the teachers had conceptualized some of the roles they were expected to fulfill. On a pre-broadcast survey, completed during the orientation week, some of the classroom teachers indicated that they expected to fulfill a wide variety of roles. Some of these included supervising the upper grades, supporting the students in the pilot project, teaching the lower grades during the broadcast, and providing public relations services. During the classroom implementation phase the roles they expected to fulfill were closely related to the roles they actually had to fulfill during the year. Annie described her supervisory role during one of the interviews. She said:

My role was to basically keep people on task, and going; but it didn't take a lot of brain power to help me to realize that wasn't all I was going to be doing. I mean, I had no illusions about that, I realized I was going to be in there. (Volume 4, Section B, p. 2)

I probed for specific tasks in which she felt she would be involved. She added that she thought she would be

making sure they were online at the correct time, supervising that they were paying attention during broadcast; that they were on task with their activities; in reality there was much more which, this I expected so it is kind of hard to say whether it was said or I always knew that I had to spend a lot more time supervising ... focusing their activities, focusing their attention on their activities and getting them started ... keeping track 
of 'hey, have you really turned your work in?'(Volume 4, Section B, p. 16)

Billy also felt that his role involved much supervision. However, he indicated that he was a passive supervisor. He shared how he shifted from the role of a passive supervisor to a more active one. He commented:

As it turns out. you know, children need to be supervised and you just can't assume that just because you tell them to go do something that they are going to do it. So you have to be there to monitor and to guide and to encourage and that's what needed to be done. I, unfortunately, took a more passive role. (Volume 4, Section A, p. 24)

Later Billy made deliberate efforts to take a more active role in supervising the students who were in the pilot program. He felt compelled to change his role because he could see that his students were not completing their work and were experiencing frustration. He described this change in role:

Well, as time passed then I realized, 'No it can't be that way. It has to be more active.' So I began tracking their work more myself. I had a lot of problems doing that because you get one ear tuned in, it was almost as if I, myself, could not keep things organized, and that was partly due to the fact that I had one ear tuned in to what he was saying and sometimes he would give assignments that I wasn't expecting him to give, and I would not catch those, or I would catch those but not other ones. . . On an active role it would be more like going over to the team and asking them where they are and what they are supposed to be doing; and if they are not there, try to find out ways to help them get there, to that point, and help clarify misunderstandings, try to keep them on target, keep them on task and try to check if their work is coming in. Actually monitoring and checking off that the work is coming in, and sending out a letter or a note occasionally to mom and dad letting them know they are far behind, or they are current on grades. (Volume 4, Section A, pp. 24, 25)

In their responses on the pre-broadcast survey, teachers also indicated that they envisioned filling the role of resource person. Thus they would be involved in 
performing various tasks such as preparing students for the pilot project, training the students in the use of technology, assessing students' work, providing feedback, assisting the students in developing problem-solving skills, articulating concerns about the program to the responsible parties, and communicating to the parents and community.

A significant amount of the classroom teachers' time involved supervising students. The two teachers in this study also described several other specific tasks they fulfilled during that first year. Some of these tasks included solving problems with hardware, faxing the students' work to Leon. making sure that the students had the materials they needed for the broadcast each day, keeping track of the assignments and projects students needed to complete for the unit. getting students to complete and turn in the work assigned by Leon, and communicating with parents. The tasks that they envisioned they would perform were very closely related to the ones they actually performed in the pilot project.

After the first segment of the daily broadcast was over each day, Billy indicated, "I try to make sure that they have a "good strong start" (Volume 4, Section A, p. 2). I quizzed him about some of the specifics involved in giving the students a "good strong start." He indicated that he would give them an overview of what they needed to do. He said, "I put it in front of them and tell them to read it, call the broadcast teacher or E-mail. If he specifically says to do something I may ask teams to work together" Volume 4, Section A, p. 2). He elaborated further on this role by saying:

I monitored work that was assigned. I monitored work that was turned in. I monitored attention. If Leon was online, were they listening, not listening, that kind of thing. I also monitored quality of work, using a 
rubric. Usually 1 did not grade it per se, it was on a scale of $1-4$, more or less, what quality of work that appeared. Did it seem like they did the work that was asked of them in that assignment, and also did the quality seem to be high or low, so the rubric addressed those two issues, but it wasn't necessarily grading them. And when the kids turned in their work they had two options, they could fax it to Leon. And if they faxed it to Leon, it had to have a little blue stamp that they had faxed it.... I would not accept the work as turned in unless it had that. The second thing they would do is they could E-mail it. But if they E-mailed it. I had to see that a carbon copy was for me. So those were the two ways that I tracked the work that was actually turned in. I guess I did call parents a few times to let them know that things were going well, or not going well. (Volume 4, Section A. p. 26)

These two teachers also filled the role of resource persons. Annie elaborated on how she fulfilled this role:

Because there would be occasions when I saw someone was really not understanding something and I would say what can we do about it or if I thought that the class as a whole was not catching on to something I might call and say. 'there seems to be a problem with'... and he would take time to try to clarify and then in another broadcast or sometimes he might call my kids and whatever. (Volume 4, Section B, p. 21)

Another role which the classroom teachers played was that of collaborator. This role was assumed quite often in the teachers ${ }^{\circ}$ meeting which happened on a monthly/bimonthly basis. Typically these meetings were held on a Thursday evening. At first the meetings were scheduled but later, meetings were held on an "as announced" basis. Usually they lasted for about $1 \frac{1}{2}$ hours. These meetings were very meaningful to both Annie and Billy because they provided support for them.

Many times this role involved only collaborating with the broadcast teacher. Billy indicated that "there was also a personal interaction too ... where it is one on one as a satellite teacher and the homeroom teacher. And that got a lot more down to the nitty gritty, you know, specific students that were not understanding things, or not doing 
things, or maybe clarification on my part for what was assigned" (Volume 4. Section A, p. 18).

Billy indicated that he dialogued with Leon more towards the beginning of the pilot than towards the end. Sometimes he just had technology questions or questions about other aspects about the program. Billy also called Leon on different occasions. He explained:

Sometimes it was like something really exciting that we had discovered, or done, that I wanted to share, a different, new idea, or something that we were implementing that was going well. Other times it was calling to vent frustration, such as certain students not doing a certain assignment. or not working and what were we going to do about that. And I guess the other issue would be the technical end of things. You know, I have to contact him; we can't get in the chat room, do you have any suggestions, and those kinds of things, or a website was not working. ... Some of them were short calls and others were long. We tried to do the long ones more after school or before school.... Well, the technical questions or short questions about students behavior, those were oftentimes done during the day. If it was a long chronic problem with a student then I would call after or before school; if it was a neat innovation, or unique idea, or sometimes I guess I would let things accumulate, like maybe cute little school things we were doing, like I just got headphones and this is what we are doing, and this is working great now, and share that idea with him. (Volume 4, Section A. p. 19)

Annie also revealed that during the broadcast she tried being "eyes for Leon"

(Volume 4, Section B, p. 4). Because he could not see what was happening at the schools she provided him with feedback on her students. On one occasion she alerted Leon that one student was feeling that Leon was calling on another classmate more than he was being called on. She commented on the collaborative relationship between herself and the satellite teacher by saying, "It is a team thing. We are team teaching in a sense. 
... There are trials and we have to encourage each other" (Volume 4, Section B, p. 4).

Annie also indicated that she would call and collaborate with Leon on other occasions.

When I thought someone was really not understanding something and I would say, 'what can we do about it?' Or if I thought that the class as a whole was not catching on to something I might call and say, 'there seem to be a problem with ....' and he would take time to try to clarify it in another broadcast. Or sometimes he might call my kids and whatever; also I would call if something major was happening. (Book 4, Section B, p. 21)

The teachers' collaboration with Leon also involved the use of the grading system which emerged during the course of the pilot. The familiar grading system with As. Bs, or Cs was not utilized. Their work was evaluated with four letters "B," "G," "D," and "C." "B" indicated that the work was at a beginning level. "G," which meant growth. indicated that there was improvement in the quality of the students' work. " $D$ " indicated that an acceptable level of competency had been developed. A " $C$ " grade indicated that the expected level of competence was achieved in the work which was completed. Annie explained that she even listed Leon in her register as another teacher. This collaboration was an important part of the implementation process.

\section{The Use of Technology}

Another management issue in the pilot project involved the use of technology. The implementation plan for the pilot, included an in-kind grant of 200 hours of satellite time from Educational Management Group for the delivery of the curriculum in the pilot project. As final plans were being made to begin the classroom implementation phase, the developers planned to introduce the technology that was to be used in the pilot. This was done during the week-long orientation session which was held at the Maracas 
Conference office. The teachers and their supervisors were able to view and interact with the equipment in the studio. They were also able to see some of the application of technology to which the students would be exposed.

The Innovation Configuration had already indicated that a variety of communication technologies were to be used in the program. Communication technologies were defined by the developers and the members of the curriculum development team as the use of such technology as telephone, fax machine, and VCR. It also included the use of computers and software programs such as E-mail. Web/Internet. word processing, graphic applications, spreadsheets. database applications, CD-ROMs, and Power Point. The data collected on the project indicated a very diversified use of technology throughout the entire program.

On a daily basis the students used the telephone to interact with the broadcast teacher and the schools that were involved in the pilot. At various times. "MIRC," Pocono Union's chatroom, was used to facilitate a similar type of interaction with the broadcast teacher and the schools in the pilot. The use of the fax machine and electronic mail were part of the routine for receiving and sending assignments, asking and receiving answers to questions, and sending and receiving messages.

The students were able to learn a variety of computer-related skills. Some of these skills included word processing and related skills such as finding, saving, retrieving and printing files; sending and receiving electronic-mail; using the Internet to obtain information, and using various types of software such as Power Point, Corel Word Perfect, Microsoft Word, and Microsoft Excel to develop graphic designs. Billy 
explained. "Kids do not have to learn software. It is a myth. The kids explore to figure out things they don't know... They do stuff I don 't know" (Volume 4, Section A, p. 7).

Both Billy and Annie indicated that no formal techniques were used to teach the students how to use the technology. Annie felt that they learned by "being immersed in the program" (Volume 4, Section B, p. 2). At times Leon helped them figure out what they needed to do to get the results they wanted. At other times, they asked for help whenever they were not sure what to do; they helped each other; they explored the "help" section on the computer, or they simply tried several options in an effort to assess what they needed to do.

Billy, who was very experienced in the use of technology, gave more details about how the students learned to use the technology in the classroom.

They grabbed onto the principle of using software, as opposed to skills of using software. In other words I didn't have to tell them the first step, turn on the computer; second step, go to start; you know, step, step, step. . . . So they leamed very quickly to operate a lot of the software based on principle, because a lot of it is the same, it's just maybe the software program developer put it in a different spot than another one did, or maybe did something a little different. It was just amazing to see them, eventually it got so they were ahead of me in using Microsoft Word. (Volume 4, Section A, p. 28)

Though it was exciting to watch the students handle the technology with a degree of confidence, it created several challenges for the pilot project during that first year. The first challenge was with the reception and installation of the equipment. This happened so late in the month of August that it delayed the beginning of school until September 4, 1997. During the first half of the year there were several problems with its use. At times these problems disrupted the school day. Though this situation improved as time went 
by, the teachers and students initially faced several problems such as not having sound during the broadcast, computers or Internet connection not working, and not having knowledge that the auto-receive button for the fax machine was not appropriately programmed so that work for the students could be received. Billy gave his view of the technological problems in this summary:

Lots of glitches in it, where you would get half a broadcast. or no broadcast for a whole day and no broadcast for two days. One day it would be because somebody cut a telephone line and another day it might be a blizzard, raining, or too much snow on the satellite dish... I would have to go up and brush it off and another day it might be because the cord came out of the back of the machine and I didn't notice it, or something like Leon dropped a piece of equipment and it failed. This was constant. It got better by the end of the year. It was running pretty smooth. For a good half of the year it was pretty frustrating. We just all put up with it and kept going. (Volume 4, Section A. p. 43)

In order to deal with the problems, the teachers tried to troubleshoot themselves, or called EMG's NOW Channel where one of the technicians assisted them with solving their technical problems via the telephone. If the teacher and the technician could not solve the problem, then a technician who serviced the area in which the schools were located would be dispatched to rectify the situation. Whenever technological problems affected the reception of the broadcast, there would be alternate activities for the students. Leon would communicate instructions and assignments to them via fax or electronicmail or they could work on assignments that had been previously assigned.

Yet another challenge that the schools faced with the technology was not having enough hardware and Internet connections for the students. Billy commented on the state of the availability of technology in the classroom with this statement: 
Well, I think towards the end the idea of using technology in a classroom the way we are using it, I think is an excellent idea. However, I think on the other side of the fence ... we just need more of it. In other words, there needs to be more of a $2: 1$ ratio on a technology, as opposed to a $6: 1$. I think overall there is a higher interest in learning when the technology is available. (Volume 4, Section A, p. 28)

\section{The Use of Cooperative Groups}

The management of cooperative teams was one of the challenges of the classroom implementation process for which the teachers did not feel prepared to handle. The conflict arising within the teams was communicated to the broadcast teacher and the project coordinator. As they grappled with the need to provide support to the teachers facing this challenge, they found an individual who dealt with managing teams in the business sector. On one broadcast this individual shared information about the stages that cooperative teams go through with both the students and teachers. He confirmed that the conflict in the groups was a normal stage in the process of team formation. Annie felt that this really helped both students and teachers.

As Billy reflected on this "in-group fighting" (Volume 4. Section B, p. 3), he commented on the discussions the teachers had during staff meetings on this subject:

I think a lot of us felt that we were not qualified to put those groups together. And I myself read a book called Tribes and did some teambuilding exercises. But I had a lot of trouble with some kids and it was very frustrating and I wasn't sure how to help them. I did a number of things that the book suggested and things like that. But still it was a problem throughout the year. (Volume 4, Section A, p. 17) As Annie reflected on this aspect of the program she said, "I wish we had known more what to expect when we formed cooperative groups" (Volume 4, Section B, p. 15). She further elaborated about the use of groups she said: 
I think that most of us have done something with cooperative groups in our rooms before, but the thing was, it wasn't such a large proportion of the work; it's fine for half-hour or even two hours; that's OK. But when they are every day working so closely together it took a while for that to start to come together and be productive. (Volume 4, Section B, p. 13)

As I observed the groups at each of the sites during the last trimester of the school year, I noticed the broadcast teacher was using a technique that is utilized in assisting individuals who are working in teams to reach their maximum potential. Leon was interacting with the students with a lesson in which he taught social skills (Johnson \& Johnson. 1996; Kagan. 1994) or "Christlike qualities" (CLQs), as it was called during the pilot project. He taught the students a lesson on "offering support to others." The students' responses identified practices that could be associated with this particular quality. There were times he taught "Habits of Mind" (HOM) (Marzano et al., 1997) such as "thinking outside the box."

He often taught these concepts through the use of a "T-chart" (Kagan, 1994). Quite often Leon asked the students to give concrete examples of behaviors they would see and hear if the social skill, CLQ, or HOM was being practiced. Both teachers indicated that the teaching of the CLQs and the HOMs had a positive effect on students. There were times when they saw evidence of use of these principles or heard students' comments which indicated they were voluntarily using them.

In one interview Billy commented on the students' positive application of the CLQs and HOMs with these words:

We would be playing at recess and they would shout at the other teams to remember the CLQ for the week, you know. So it was on their mind and I think overall I was seeing people actually demonstrating more self control. I can't see they are being more responsible, but I think they were being 
like more understanding, more encouraging of one another. There was definitely compromising taking place, maybe more so than on a usual basis. (Volume 4, Section A, p. 27)

The interviews with both teachers revealed that the CLQs and HOMs were regularly included in the last part of many of the daily broadcast sessions. Individual accountability was assessed through quizzes, projects, and individual assignments. Though the students sat in the same area for the broadcast and worked in close proximity to each other, I saw little manifestation of the other elements of cooperative learning as defined by Johnson and his colleagues (1998) (such as positive interdependence, group processing, and face-to-face interaction) during the 2 days I observed at each school. Cooperative learning could not happen when its basic elements-positive interdependence, individual accountability, group processing, face-to-face interaction, and social skills-were operating in isolation. To be used effectively, all the basic elements of this framework must work together to create a dynamic learning system.

The data reflecting the difficulty to implement cooperative learning prompted me to make a connection between what actually happened during the attempted use of this framework in the pilot project and the relevancy of a conclusion drawn from educational research during the 1970s. Though the 1970 s was an era of implementation of innovations, writings like Goodlad, Klein, and Associates (1970) Behind the Classroom Door, Sarason's (1971) The Culture of School and the Problem of Change, and Gross, Giacquinta, and Bernstein's, (1971) Implementing Organization Innovation exposed the problem that many implementation efforts involved little change in practice. Attempts to evaluate the effectiveness of some of these programs that had not influenced changes in 
educational practice prompted Charter and Jones (1973) to caution the research community about the "risk of appraising non-events."

\section{Management of Students' Assignments}

Soon after the pilot project began the classroom teachers to noticed the large volume of work that the students were expected to complete. Billy described it as "way too much work for what any reasonable person can possibly, even an adult. can do in a given time" (Volume 4, Section A, p. 40). Annie said. "There were times when we got bogged down. The kids had too much work to do" (Volume 4, Section B, p. 5). As a result Billy, felt that "frustration and anxiety was running really high in the classroom all the time" (Volume 4, Section A, p. 40).

Billy felt that this was due to the open system of the pilot project where kids had to figure out things for themselves; there were no reference points such as links where the students could find some help to do their work. In addition it was difficult during this first year of the pilot project for those who were developing the units the to decide the amount of work to include in the units of study since there was no time for feedback for field testing the curriculum documents. It was also difficult for Leon to guess what the students could do in a reasonable amount of time because there was no previous data available for him to check what was previously done. So he was experimenting and cutting new paths within an area in which no one else in the K-12 system of the Adventist church had traveled before. Thus it was expected that this type of misjudgment of the amount of work students could complete would occur. 
Billy elaborated on the issue of the completion of assignments, which was closely

related to many factors including the volume of work, with the comment:

Well, you have to remember too that if a kid doesn't do an activity, maybe he was given time but he just didn't do it. ... So on average, because we didn't have time to finish, there is often times maybe things that Leon thought they should have been able to finish but they had not, and that could have been due to either laziness or couldn't get the material, or couldn't find the material, you know, there are numerous reasons why. So I can say it could have been easily rectified without having things one on top of each other all the time. That really drains the energy for them to have enthusiasm to get going the next day. (Volume 4, Section A. p. 42)

Billy indicated his preference for the students doing fewer activities and doing them well than attempting a large number of activities and having only about $30 \%$ understood or finished in the allocated time.

Billy indicated that for the first month of the pilot he did not teach math because the students were so "overwhelmed with stuff and the technical stuff was always messing up" (Volume 4, Section A, p. 6). While the technical problems improved as time went by, the paperwiork for the students continued to be a challenge throughout the year.

Another challenge associated with the paperwork was the fact that it was not coded. Billy commented on the management of the volume of paper:

It just seemed like I never could really get things organized in a fashion that I could easily do it. You know, I think it was just a delusional paper trail that was not easily identifiable, or traceable, and it just got jumbled up. (Volume 4, Section A, p. 20)

Annie spoke of her concern about not knowing the type of materials that were being sent to the students and how to manage "this blizzard of paper" (Volume 4, Section B, p. 15). She hinted about the developmental nature of classroom implementation issues in her statement about the organization and management of the paperwork as "an issue 
that we didn't realize" (Volume 4, Section B, p. 16). Annie indicated that as the pilot progressed that she felt free to make choices about how much work her students would be given to complete.

In Billy's reflections he indicated, "I am just discovering how to fix the paperwork. We are kinda fumbling rather than it happening by design" (Volume 4, Section A, p. 3). He developed a system by which he could track the work that students had to complete and how much was actually completed. He used this tracking system to point out projects or assignments that were overlapping each other thus making it difficult for students to stay abreast of their work. Billy did not freely adjust students' work like Annie did. Therefore he was very concerned about the amount of work students were completing and harbored cover fears about how much they were learning.

Apart from the volume and the coding of materials, there was the issue of the large volume of time that was needed for the students to complete their assigned work. Billy described this situation:

We did not have enough computers to allow each student to do high quality work the way they wanted to. So, some assignments required computer time and there was just not enough time during the day to be able to get all the kids done. If you had to do an Internet search, each child has to do that, and that search is going to take an hour, then that would be six hours. School is six hours long, obviously you can't be doing that all the time. So one thing we started doing during the year, which was one of these conference calls that we did get, was we started providing links to help the kids go right to the site to get the information and then cut down on the time invested in that. So that helped, but if you are doing Microsoft Power Point presentations, that requires computer time and if you have only one computer, you have six kids, you know you run into some time issues there, really critical, harmful, often times getting the project done. (Volume 4, Section A, p. 21) 
He summarized some of his feelings about the management issues that have been discussed thus far with the comment:

There was a combination of too little time with too many activities that needed to be done and oftentimes those activities were overlapping one another. Most children, I feel, cannot keep track of probably more than a few things at a time. (Volume 4, Section A, p. 30)

Another challenge of the pilot involved providing feedback to the students. My interview with the teachers indicated that getting prompt feedback on students' work was a major concern. Billy said. "The first half of the year there was no feedback. I have kept on telling Leon about this; ... the more feedback he gives it is better" (Volume 4, Section A, p. 7). He continued his discourse about feedback:

They are used to doing the papers. getting comments. and then get the paper back right away.... So, what happened is that my kids got less and less work in, and as the feedback increased later in the year. then the work picked up more. (Volume 4, Section A, p. 23)

The students reacted very positively to feedback from Leon. Billy commented that the students loved recciving feedback from Leon. He felt that receiving feedback helped to improve both the attitude and the behavior of his students.

The teachers felt that the inadequacy of feedback was partially due to Leon being overwhelmed by the entire program. Support was needed to assist with grading and providing timely feedback. This need was recognized by the teachers and director of the pilot project. Someone was hired during the second semester to assist in this area. Though this was an issue that affected the students' outlook on the program, the teachers in this study were very sympathetic toward the workload and responsibilities of the broadcast teacher. Annie voiced her feelings when she said, "Poor Leon couldn't grade 
all these papers and send them all back; and towards the end of the year we were getting more stuff back" (Volume 4, Section B, p. 20). In reference to responses from Leon that were not as prompt, Billy contended:

Leon was so overwhelmed with his own grading papers, and answering phone calls, you know he had such an amount to do, that he was not able to respond to us as quickly as we needed him quite often. ... I really felt sorry for him. (Volume 4, Section A, p. 21)

Billy also addressed a companion issue that at times was as inadequate as feedback on students' assignments which he termed "follow-through." By this he was referring to Leon's requiring the students to be accountable for the things they were asked to do. He expressed his view on this in one of the interview sessions by saying:

Well, Leon did some trying, I think from his end, but there was, I think he was just too overwhelmed to be able to follow through. You know on several occasions you might ask somebody to do something, but there wasn't any follow-up to make sure they were doing it. So, those things just did not work out. It pretty much fell to me to make sure that anything Leon asked them to do had to be checked to make sure they were doing it. That kind of stuff. In some ways that was disappointing because I had set the tone as being a passive supervisor earlier in the year, so I was never really able to catch back up, and put myself in charge of making sure these things happen. There was kind of a lax attitude about getting work done through the whole year, and I think that was unfortunate. (Volume 4, Section A, p. 25)

In considering recommendations on the issue of feedback Billy's suggestion was, "I would rather see less satellite time and more support staff, such as people to grade papers" (Volume 4, Section A, p. 23).

As I reflected on the teachers feedback and what I understood about Leon's responsibilities, I realized that he was being expected to fill a demanding role during this first year. He dialogued with me about some of his responsibilities. Besides teaching 57 
students in his virtual school with strategies that challenged him and through a technological configuration and setting to which he was not accustomed, Leon had other responsibilities. Some of these involved having to answer approximately $45-50 \mathrm{E}$-mail messages a day, grading students assignments, dealing with the interpersonal problems his students experienced as they worked in groups, answering the questions of students who telephoned, handling technological issues in the studio, and many other broadcastrelated tasks. I began to understand more about how Leon was challenged in his role as the broadcast teacher.

\section{"Instructional Support"}

Throughout the implementation of the pilot project the teachers needed instructional support. support that should have been available in the workplace, as they journeyed through change process. Since a goal of the Technology Partnership pilot project was to teach students in ways that would encourage them to use higher-order thinking skills, it necessitated that those involved in this project be trained and supported in the use of teaching strategies that could accomplish this. Through the data collected in this study, it was evident that the developers of this initiative foresaw the need for the pilot to include staff development that would provide this kind of training and support.

During the early stages of the development of the initiative, however, no plans were made to clearly conceptualize this staff development component. Among other factors, I cite time limitations as a key factor which affected its conceptualization. Therefore, during the first year of the pilot project, support for the teachers mostly 
involved the use of faculty meetings. It became "the vehicle" for providing encouragement and pursuing solutions for issues encountered in the change process.

\section{Faculty Meetings}

The stage for open communication and support during the pilot project was set at the orientation session in July 1997. At that time, the teachers who attended were encouraged to share their pre-broadcast logistical and management concerns. Discussions ensued and several key issues were resolved. The project director knew that additional concerns would arise once the school year began, so plans were laid for the teachers to meet on a regular basis. These meeting were mostly held via telephone.

During the first semester the team of teachers met several times a month with Bettie and Leon to deal with the management concerns. At first these meetings were scheduled but later they were held whenever they were needed. Annie recounted some details about a typical meeting:

Generally we would start out by 'how are things going? Any problems anyone was having? Any announcements to be made? Do you have all of your equipment? Is it working?' Somebody was having trouble, and somebody would give suggestions on it and we all spent a lot of time working out kinks in the program. Like "what did you do about not getting on, or time inserts' or things like that which were extremely helpful because everybody had input. We also were able to know that someone else was having a problem with this or that ... so it was very helpful. (Volume 4, Section B, p. 17)

These meeting were helpful to both teachers involved in this study. Billy indicated that faculty meetings were times to discuss some of the issues they were facing and to propose solutions. 
We talked about issues that we were struggling with, proposing solutions, and trying to make those things a little more clear or making some small changes or big changes and to kind of encourage one another to hang in there. ... Sometimes it was just as simple as 'you know, we are being overloaded here, we need to adjust something so that the kids can get their work done.' Sometimes it was being overwhelmed with so much material that you couldn't keep it together and how to handle that. And a lot of discussion was just what to do with children who were not doing their work, like team building, like exercises, you know, that cooperative learning part. (Volume 4, Section A, p. 17)

Being able to discuss concerns with other colleagues who were involved in the same program was worthwhile. "At first when I started having problems," Annie mentioned, "I thought 'it could be me'; then I found out that everybody was having the same problem" (Volume 4, Section B, p. 20). Realizing that there were others who were experiencing the same kind of challenges made them less disheartening. Billy indicated that "problem solving ... and lots of re-evaluation" (Volume 4, Section A, p. 18) were two areas on which they focused the discussions of their meetings.

Annie summed up the support she felt by saying, "Knowing that you are not in this boat alone; being able to pick up the phone and talk to Leon has helped" (Book 4. Section B, p. 4). Though they met less frequently during the second semester, both teachers knew that there were various ways by which they could communicate with Bettie and Leon whenever they needed to.

\section{Staff-Development Training}

\section{The Challenge}

The staff-development component which could have provided additional support for the teachers of the Technology Partnership pilot project never materialized during the first year. It was only during the last meeting of the curriculum development team in 
September 1997 that the components of the Technology Partnership Curriculum Initiative became clear to all team members. Having a shared understanding of the proposed change is a prerequisite to implementation (Fullan, 1991). During that meeting the initiative was identified as having four components: (1) units of study, (2) staff development, (3) research, and (4) business partnerships. The draft of the Innovation Configuration included some initial ideas about staff development and business partnerships (see Table 4, p. 91). However, additional work was needed to clearly operationalize them. The need of an Innovation Configuration for the entire initiative was mentioned at that meeting, but there were so many other pressing issues that no time was allocated to accomplish this.

\section{Staff-Development Opportunities}

Very early in the implementation process the classroom teachers in the pilot project saw the need for staff-development training in techniques to facilitate cooperative groups. Although there was some information given on cooperative learning theory and techniques, Dimensions of Learning, and 4MAT during the orientation week, it did not provide an adequate number of demonstrations, practice, and feedback which is necessary when learning to use complex teaching strategies with a high level of competence (Joyce, 1992).

Earlier, during the development of the Technology Partnership Curriculum Initiative, training in the teaching strategies that were used in the units of study, and which included the use of techniques for facilitating cooperative groups, was available for 
teachers during a 4-week intensive course from Southwest University. Though this institute was available for all teachers in North America, Leon was the only teacher in the pilot project who attended this session.

Leon had been present at the 4-day training session for the administrators of Pocono Union. He was only present however for the last 2 weeks, after most of the demonstrations in many of the strategies such as concept attainment, Taba inductive, graphic organizers. Dimensions of Learning, and multiple intelligence (Joyce \& Weil. 1996) had been presented. He was not present when his team went through the beginning phases of group formation; he was able to only witness the demonstration in inquiry training, questioning strategies, and the overview of study groups. His involvement in many of the practical applications of the strategies, when students were being taught during the institute, was limited because the curriculum development team of which he was a part met at the time the institute participants were interacting with the students. Thus, Leon received a minimal amount of benefit from the training in teaching strategies during the institute.

\section{An Issue and a Temporary Solution}

Since the classroom teachers were not trained in managing cooperative teams, when "in-group fighting" (Volume 4, Section B, p. 3) began to occur early in the classroom implementation process, they were unable to deal with it. It was difficult for Leon to deal with this issue as well. Having to manage groups of children via satellite technology only complicated an already challenging aspect of the program. The 
technology used in the broadcast allowed the students to see Leon, but it did not allow him to see them in their schools. It was impossible for him to see and effectively deal with the inappropriate behaviors manifested in his virtual classroom. Leon expressed this sentiment and his need for support when he said,

I can't see faces. I can't see body language. I don't hear the conversations. I don't see the things happening, so it's really tough for me. I have to take a lot longer because I have to verbally debrief everybody involved so I can get a feel for what's happening. It's terribly time and energy consuming. (Volume 4, Section C, p. 25)

As Anne considered this issue of managing cooperative groups in the classroom she made the following comment:

When we had our staff meeting, we agreed that more cooperative training would've been helpful. Strategies that when we form our groups and different things that could happen within groups and how you would deal with those situations; for instance if you were the child that withdraws or a child that won't do their share, the kids for whatever reasons don't work well together; how do you deal with those situations? (Volume 4, Section B. p. 16)

The help provided for teachers via satellite on group management was a one-time session. The research literature on this type of session indicates that it is designed to provide awareness and not support for implementing lasting changes in teaching practices. According to the research by Joyce and Showers (1995), review of theory, which is often the focus of a one-time or "one-shot" session, will enable only 5 to $10 \%$ of the participants to transfer the training they receive into classroom practice. Thus, without a significant amount of training involving demonstration, practice, feedback, and coaching, it would be difficult for the classroom teachers to effect a change in behavior in the cooperative groups at their sites. 


\section{Embedding Instructional Support in the Workplace}

The use of different teaching strategies and techniques in the curriculum were both challenging and rewarding aspects of the pilot project. Apart from initial training, ongoing training was needed for the other teaching strategies which were included in the Technology Partnership Units of Study. Some of these strategies included concept attainment. Taba inductive, and techniques from the Dimension of Learning model. Leon. who was trained in the use of 4MAT, spoke of his challenges with these strategies during the pilot. He confessed:

I was teaching in ways I'd never taught before. You know, I had never worked with Taba, concept attainment. ... I don't know if they are structures or strategies. I forget which, turn to your neighbor stuff, those kinds of things. I did not figure out how to do those well in that setting, until about the end of the year. (Volume 4, Section C, p. 40)

I probed to find out how some of the other strategies included in the units worked in the context of a satellite broadcast setting. Since satellite time was so precious. Leon wanted to make sure that it was guarded. He spoke about using the concept attainment strategy via satellite. "You have to use it more sparingly.... Again, one of the things that we really want to do is to use the interactive time as a debriefing time. You're bringing meaning to the learning, engaging the kids in meaningful discussion" (Volume 4, Section C, p. 41). Some of the other strategies which worked well with the satellite delivery system were graphic organizers and the T-charts which were used in teaching the CLQs and the HOMs. He indicated that he had difficulty in teaching the BIT unit, which was written as a simulation, because it did not work well in the broadcast setting. 
When Leon reflected on those things he would do differently in another orientation session for teachers, he said, "I'd spend more time on helping the teachers ... understanding multiple intelligence, understanding cooperative learning, understanding 4MAT learning styles, those sort of things" (Volume 4, Section C, p. 25). I was curious about why he mentioned cooperative learning, so I questioned him further about the challenges associated with the use of this strategy. He indicated that he felt that cooperative learning was the strategy that was most needed. He further explained:

Our experience this year was that the cooperative learning was the toughest experience in the classrooms. They [the students] adapted well to just about everything else, but working together took a long time to get. It took a couple of classrooms almost the entire year. One member of one of the classrooms, I'm not sure yet that she can ever get past her own hangups about working with other people. (Volume 4, Section C, p. 25)

The attempt to use cooperative groups in the pilot consumed a lot of Leon's time and energy during this first year. He told me:

I didn't feel I knew it. I was on the phone an awful lot answering a lot of E-mail about cooperative groups, change groups. What can you do about this group member? This isn't working. This person is not doing what they are supposed to be doing. This person is doing it all. You know, I spent a lot of time dealing with that during the first $2 \frac{1}{2}-3$ months. There's still, in 1 or 2 classrooms, 1 or 2 students with this prevailing attitude that they shouldn't have to work with other people. Other people drag them down. They don't feel that they should help other people learn. That is not their responsibility. The other person, they're not learning. Well that's too bad, that type of thing. I need to help the teachers in the classrooms be prepared for these much better-to be able to facilitate the team stuff. Because it's way too time-consuming for me to handle from my end. I did it, it was just massively time-consuming. In 1 week I spent probably . . 6 hours, between two schools handling some major team situations. (Volume 4, Section C, p. 25) 
As Leon shared his challenges about strategies that worked or did not work for the broadcast, I felt that his point of view could have been influenced by: (1) the limited amount of training he had in the strategies in the units, and (2) the lack of structures in the workplace to coach him in adapting the strategies for use in the broadcast. Leon's reflection on the use of teaching strategies indicated that receiving feedback and support would have benefitted him professionally.

As I reflected further on Leon and how the use of the strategies in the pilot project challenged him during the first year, I began to see how the Levels of Use (LoU), one of the diagnostic tools of the CBAM, the Concerns Based Adoption Model (Hord et al., 1987), could have supported him in his teaching. Because the focus of LoU is assessment to support the implementation of an innovation, its use in the pilot project would have enabled Leon to continually reflect and examine how closely his teaching matched the components of the Innovation Configuration for the units of study. The feedback from LoU could have been used to personalize the instructional support he needed to implement cooperative learning and all of the other strategies the curriculum more effectively.

\section{Students Reactions to the Strategies}

Though they struggled with understanding some of the strategies, the students reacted positively to many of the interactive teaching strategies. Both teachers felt that the CLQs and the HOMs affected students' attitudes towards each other. Billy indicated that "in sports, there is where you see the tensions. I see them trying to use some of the 
tools they use in the pilot" (Volume 4. Section A, p. 6). He had heard a student say that she did not get mad on one occasion because she "thought outside the box" (Volume 4, Section A, p. 5). "Thinking outside the box" was one of the HOMs.

Annie described the students' reactions to concept attainment, a teaching strategy used to teach concepts inductively.

Those worked great. The kids were involved. The kids really like those. Then after that they go to their teams to figure out what he is asking. You know, he gives them more data and then they have to guess and figure out. They really thought that was cool. (Volume 4. Section A. p. 42)

Annie spoke positively about the use of different teaching strategies in the pilot. In her reflections she commented:

I think, that it was good, teaching them to think; they would have difficulty finding something because they were . . . having to think; over the year some of these things got easier. Like the first time they had a concept attainment lesson my kids said 'ugh!'At the beginning of the year when they were given a Taba [a teaching strategy used to teach inductive thinking], my kids said, 'What on earth do we do?' They couldn't even come up with any attributes, but by the end of the year they were doing it, so their thinking process really expanded and that was very exciting.

(Volume 4, Section B, p. 19)

Billy reported that his students enjoyed concept attainment also. However, as he observed some of their struggles with more complex strategies like Taba, he felt the need for more modeling of some of the techniques for the students so they would be able to handle their assignments more effectively when left to work independently or in groups. Billy perceived the need for a greater variety of techniques to be used during the broadcast. I understood what Billy meant because I had made some similar observations. 
When Leon was broadcasting, the students did not see him in a variety of positions. Often they saw him in a position that was similar to that of a televison newscaster, because only his upper body was shown. I believe that this, along with the children's seating arrangement, could have contributed to the lack of attention which I observed at Morris Town Elementary. The use of more visual aids such as video clips, pictures, objects, and other broadcast techniques would add more variety to the broadcast and effect a change in how Leon was seen on the televison monitor.

\section{Effect of the Pilot on the Teachers}

In spite of the challenges associated with the use of the strategies during the broadcast, the pilot project began to achieve two of its teacher-related goals which included (1) modeling teaching strategies and structures for training Adventist teachers using the Technology Partnership Satellite Network, and (2) relieving some of the teaching load of teachers in one-teacher schools. Billy attested to being influenced by the strategies used in the pilot. He reflected on how the pilot affected him professionally. He commented:

Professionally I think it was a good experience, because it opened up to me, 'Say there are other people out there that are feeling the same as me, that something needs to be done about our curriculum, that we are not harnessing all that we need to.' There are gaps here and there and I appreciated the opportunity to grow professionally like learning new strategies and seeing how those might be applied. (Volume 4, Section A, p. 44)

He spoke about how he had slipped into a role of being a "survival teacher" (Volume 4, Section A, p. 7). Often he would take only a few minutes to go over the assignments the 
students were to do for the day because in a multi-grade setting the time to meet all the needs of the various grades would be limited. He commented further on the challenge of teaching in this setting and how he was affected by the pilot project:

You know, it takes a lot of time to create them and with all my other responsibilities and extra time grading, it just didn't make sense to do it that way. However, I see the pilot giving me the opportunity to use them. I have more time in the pilot to plan, as opposed to having to grade now. (Volume 4, Section A, p. 32)

Both teachers felt that the pilot project gave them time to give more attention to the students in the lower grades. Billy indicated:

I had more time to create maybe more interesting assignments as opposed to just assigning a work sheet to do because I had time to create it. That's what's fun about teaching, is when you create and guide and fill in the gaps where the kids are having trouble, instead of just assigning them a set of work sheets. (Volume 4, Section A, p. 32)

Annie, who had been involved with Technology Partnership when she worked in San Fernando Conference, indicated that she had grown professionally also. She expressed, "I learned a lot of new strategies. It was much better than any class I could have taken because I was doing hands-on" (Volume 4, Section B, p. 10). I questioned her further about some of the strategies she learned. Some of the ones she named were concept attainment, Taba, pair and share, and mix and match. Annie communicated her satisfaction about her involvement in the non-traditional ways the students in the pilot were taught:

Having a chance to finally make a difference. ... To me the idea of changing the curriculum to the approach we are trying to form.... Instead of handing a kid a book and saying memorize these facts or saying that this is what you should do. The child has to analyze and evaluate and use some higher-order thinking skills, and therefore that learning becomes his 
rather than in one ear and out the other. It's just, the learning can be so much more meaningful. And that to me was very exciting. That's something we, Leon and I, used to sit and talk for years, "if only". . . And so here was a chance to do the "if only," and that was very exciting. Still is. (Volume 4, Section B, p. 15)

As I listened to the teachers' comments on how the pilot affected them professionally, I understood its potential to reach its goal of training teachers through the modeling of innovative teaching strategies. I again reflected on some of the challenges Leon faced in using the strategies and of the dire need for him to be trained and supported in using them. This would enable him to accurately model the strategies to those educators who were observing him on the broadcast.

\section{Summary}

This chapter presented an analysis of the reflections of the two teachers as they journeyed through the change process involved in the first-year implementation of the Partnership Technology Curriculum Initiative. It discussed the two themes: (1) "Managing Change" which highlighted the management issues in the pilot, and (2) "Instructional Support" which addressed the issues of training/support for the initiative. The management issues of the pilot revolved around the roles of the teacher, the use of technology, the use of cooperative groups, and the management of students' assignments.

The need for initial staff-development training and on-going support in instructional strategies was the other issue which arose during the first year of this change process. The management and training/support issues which surfaced were those that would be expected during the first year of implementation of a complex, innovative 
project like Technology Partnership. Research has shown that the implementation of similar innovations requires an investment of 3 to 5 years (Kochan \& Kunkel, 1998; Showers et al., 1996, Teitel, 1997). Given the complexity of this undertaking, those involved in the development and implementation of this project did an amazing job. The challenges that resonate from the developmental nature of a project like this present opportunities for those involved in change processes to learn valuable lessons about developing and implementing innovative curriculum initiatives. The lessons which could be learned from the themes are chronicled in the conclusions and recommendations of chapter 10. 


\section{CHAPTER TEN}

\section{CONCLUSIONS AND RECOMMENDATIONS}

\section{Introduction}

The purpose of this study was to tell the story of the Technology Partnership Curriculum Initiative. In chapter 1,1 presented much of the background information on Technology Partnership from its early beginning in San Fernando Conference to the plan to implement it in the distance-learning pilot project. In chapters 4 through 7 , I related the story to answer the following research questions: (1) What is the Technology Partnership Curriculum Initiative? (2) How were the Technology Partnership Units of Study developed and implemented in two schools of the pilot program? and (3) What are the implications of Technology Partnership for curriculum development in general and specifically for curriculum development in the North American Division?

I answered these questions by conducting a qualitative inquiry using interviews, observations, surveys, documents, and field notes as tools for data collection. The analysis of the data and my interpretations of the findings led me to draw some plausible conclusions about implementing innovative curriculum initiatives. The findings of this research are documented in this chapter. 


\section{General Conclusions}

Through my review of the literature and the data from the study of the different segments of the Technology Partnership Curriculum Initiative, I witnessed the welldocumented struggle between theory and practice that often presents a challenge to those educators who are implementing change initiatives (Berman \& McLaughlin. 1978; Eisner, 1991) From my analysis of the data collected for this study I drew some conclusions which may apply to curriculum developers. These conclusions encompassed five areas: (1) Innovation Configuration. (2) staff development. (3) research, (4) time. and (5) university/school partnerships.

\section{Innovation Configuration}

My survey of the literature on implementing innovations revealed that curriculum innovations need to be clearly operationalized before they can be developed and implemented (Charters \& Jones, 1973). An Innovation Configuration (IC), one of the components of the Concerns-Based Adoption Model (CBAM), is a system which can be used to operationally define and describe the goals as well as the attributes of educational programs (Hord et al., 1987).

This process was used to describe the components included in the Technology Partnership Units of Study. Although the Innovation Configuration for the Technology Partnership Units of Study presented a picture of what the developers felt should be included in the curriculum, it was not carefully examined to ascertain whether it clearly reflected the four domains-physical, mental, spiritual, and community-on which the units 
were to be developed. Thus some aspects of the program were not fully addressed in the IC. The IC more closely reflected two of the four domains, the mental and the community. It did not clearly define the spiritual or the physical domain. Moreover, it did not address the supporting role of the classroom teacher in the project.

The Technology Partnership Innovation Configuration was created to define the components of the units of study. It did not define the other components of the curriculum initiative, which included staff development, research, and business partnership. Though some research was conducted, plans to implement initial and ongoing staff development training for the teachers and business partnership for the pilot were never fully realized, largely because they were not concretely defined. Having an Innovation Configuration for the entire initiative would address the issue of roles that created a conflict during the curriculum development process. It could also strengthen the partnership between the North American Division of Seventh-day Adventists (NAD), Southwest University, Pocono Union, and Maracas Conference.

The effective use of the IC for this initiative would have been enhanced if it had been supported by components such as the other two units of the CBAM model (Hord et al., 1987): the Stages of Concern (SoC) survey and the Levels of Use (LoU) interviews. Without the use of an interrelated system such as CBAM, the chances of implementation of an innovation are reduced. 


\section{Staff-Development Training}

Many of the problems encountered with the use of teaching strategies in the pilot project could be managed by heeding some of the messages of the research on staff development. Research has shown that training is necessary for the implementation of an innovation involving complex teaching strategies (Fullan, 1991; Joyce \& Showers, 1995; Murphy, 1999). Staff development for the individuals involved in this process should be designed so that they would be able to transfer their training into practice. This transfer was needed both in the curriculum development and the classroom implementation processes of the Technology Partnership pilot project.

Research has shown that transfer of training can be accomplished through staffdevelopment programs utilizing a design like the Joyce and Showers Training Model (1995). This model includes a presentation of the theory, demonstrations, practice, feedback, and coaching. Joyce (1992) estimated that about 20 demonstrations are needed as a base for adequate skill development for a model of teaching of medium complexity. He also indicated that 20 to 30 practice sessions utilizing a new strategy are needed before a sense of control and comfort can be achieved with the new procedure.

Henriquez-Roark's (1995) research on staff development in one public school district showed that the extensive demonstration, practice, and coaching sessions recommended by Joyce (1992) could be facilitated by teacher study groups. She discovered that study groups (1) supported and encouraged implementation of innovations and long-term change, (2) provided structure that was essential for acquiring new teaching skills and strategies, (3) exerted the pressure and motivation required to 
continue practice, (4) encouraged teachers to increase their repertoire of teaching strategies. and (5) motivated teachers to focus on curriculum and instructional issues. Hargreaves (1997) concluded that many change efforts are directed from "the neck up," addressing only what goes on in teachers' and children's heads. These efforts focus on assessment standards, higher-order thinking skills, and problem-solving skills for children, or on strategic planning, cognitive leadership, or organizational learning for teachers. He argued that attention should be paid to what Goleman (1995) calls "emotional intelligence" which includes self-control, zeal, persistence. and the ability to motivate oneself. Hargreaves believes that paying attention to "emotional intelligence" can impact students' classroom learning as well as the teachers' professional learning. Combining systems like CBAM and teacher study groups has the potential to address both cognitive and emotional work of teachers.

\section{Research}

Making provision for systematic collection of data during the development and implementation of school improvement efforts such as Technology Partnership Curriculum Initiative is of vital importance. In his survey of 40 years of school change, Miles (1998) made some significant comments relating to school improvement and organizational self-renewal. His insight on educational change highlighted the importance and benefits of "data feedback" for reflective updating of change initiatives. He concluded that organizational data, fed back to meetings which accommodated grouplevel process analysis, induce support and goal-oriented attention to problems facing 
educational organizations. This focus could result in action decisions, and structural and cultural changes that foster greater organizational health. Miles saw this kind of organization as instrumental in inventing new procedures, moving toward new goals, producing new kinds of products, diversifying itself, and facilitating growth, development, and change.

From the onset of the development of the Technology Partnership Curriculum Initiative its vision was clear, and it was also evident that "data feedback" also needed to be an essential component. Plans for the collection of data were formulated by a research team from Southwest University. Two researchers from the university carried out some of these plans with a small budget funded by Technology Partnership and Southwest University. The data which were collected provided critical feedback that the University/NAD/Union/Conference team could use to make decisions to improve the Technology Partnership Curriculum Initiative. Although "data feedback" was seen as a necessary component, the research process could have been strengthened by (1) developing its clear definition in an Innovation Configuration, (2) planned financial support, and (3) definite plans for its dissemination and use.

\section{Time}

An adequate amount of time is needed for developing and implementing curriculum and organizational initiatives (Showers et al., 1996; Teitel, 1997 ). Time restrictions affected the work of the curriculum development team and the entire Technology Partnership Curriculum Initiative. It contributed to the chaos and the 


\section{7}

fragmentation that were experienced during the development of the curriculum. The shortage of time prevented the curriculum development team from adequately reflecting on content and process of their work. It also contributed to teachers and their administrators receiving only about 2 hours of awareness-level information on teaching strategies rather than implementation training during the orientation session before the pilot project began.

\section{University/School Partnerships}

Traditional school/university interaction has been characterized by the hierarchical model of the university as the educators of teachers. Whereas recent attempts at interaction favor more collaborative relationships such as Professional Development Schools (PDS), successful partnerships utilizing this design have been complex and problematic (Lieberman. 1992; Sirotnik \& Goodlad, 1988). Dixon and Isler (1992) indicated that "given the anxiety produced by even the thought of change, it is not surprising that faculty of both colleges of education and schools would choose to 'coast by' one another for so many years" (p. 28).

Despite the challenges associated with using this design, it holds the potential of positively impacting all partnership stakeholder groups. Greater understanding, acceptance, and willingness to work through the complex issues surrounding the culture, tasks, and roles of both entities might allow for a greater degree of collaboration between them. The university could experience growth and impact schools in a more extensive way if they were perceived as willing to come into school/university partnerships as 
supportive learners. Button and Ponticell (1996) indicate that "this requires that university researchers give up the exclusivity of their expert status and welcome the expertise of others in the educational community as teachers, learners, and researchers" (p. 18). This stance could enable the university to take the first step to ease feelings of anxiety that are generated by collaborative change initiatives. True collaboration to improve the educational process will only happen when it is viewed by all entities as a "win-win" situation.

In the North American Division of Seventh-day Adventists there has been little collaboration between the university and its school systems. Previous attempts at collaboration were limited to projects like the Profile Studies-biannual studies of curriculum and instruction conducted by Paul Brantley at Andrews University; university representatives providing occasional one-time in-service workshops; and university and field representatives serving on educational boards, executive committees, and a few curriculum committees (Brantley, 1995a). Thus, in striving to forge a collaborative partnership to develop and implement the Technology Partnership Curriculum Initiative, Southwest University and the field-based organizations were attempting something that had not been a practice in the SDA system.

In developing the Technology Partnership Curriculum Initiative, representatives from the union/conference in the North American Division and Southwest University were anxious to collaborate. But even with a high degree of commitment and expertise on both sides, there were still issues of roles, ownership, and professional identity. It was difficult for the group to adequately allocate time to communicate openly, clarify roles, 
and develop a common understanding about how to deal with all the issues that challenged them. When conflict surfaced among team members towards the end of the last curriculum development session, efforts were made to deal with the feelings of frustration in a way that would strengthen the partnership. There was a fair level of success in the collaboration because both entities remained committed to the project during the first year.

\section{General Recommendations}

Curriculum developers should use a model like the Concerns-Based Adoption Model (Hord et al., 1987) which includes the Innovation Configuration. the Stages of Concern, and the Levels of Use, when developing and implementing innovative curriculum. The Innovation Config uration can be used to operationalize the components of the proposed change. The Stages of Concern questionnaire can provide information to document teachers' concerns and provide data for paying attention to the emotional dimension of practitioners which Hargreaves (1997) advocates. The Levels of Use interviews can help in tracking the use of innovations during classroom implementation. Impact studies of curriculum innovations can only be valid when curriculum innovations are clearly articulated, teachers' emotional needs are addressed, and the degree of implementation is monitored.

Initial and sustained training in teaching processes and strategies should be provided for those involved in developing and implementing curriculum initiatives. This training could be designed using a framework like the Training Model (Joyce \& Showers, 
1995) that would include a presentation of theory, demonstrations, practice, feedback, and coaching. A structure like teacher study groups advocated by Henriquez-Roark (1995) could be used to provide the ongoing and extensive practice necessary for transfer of training. This type of format has been shown to be effective in the transfer of training to the workplace.

Research should be an important component of school improvement initiatives. Plans for its clear conceptualization and implementation along with systems to receive and use the feedback it generates should be conceptualized at the inception of the change initiative. Systematic data collection could provide the feedback that is essential to organizational self-renewal. Taking steps to clearly conceptualize and implement this aspect of the curriculum initiatives could be an avenue that could contend with the challenges that lie between the gap of theory and practice-the written and articulated vision of change efforts and what is actually practiced and implemented.

A significant amount of time should be invested by curriculum development teams or university/field partnerships if they are to be expected to work effectively. This time can enable the team/partnership to experience all the developmental stages that affect groups. Besides the development of the innovation, this time could be used to address such issues as roles, team training, communication, conflict resolution, management support, and other success factors for teams as identified by Parker (1994). The time could also be used to study and adopt a partnership model such as the Professional Development School (Birrell, Ostlund, \& Egan, 1998; Holmes Group, 1990; Kochan \& Kunkel, 1998). 
An adequate amount of time would allow reflection to be an integral part of the development and implementation process. Structures that support reflection, such as the use of journals and sessions in which the content and the process of the team's work is reviewed, could enable members to make adjustments to improve their work. Paying attention to these factors could also include addressing the emotional dimension (Hargreaves, 1997) of those who are involved in curriculum development projects.

\section{Specific Recommendations for the Developers of Technology Partnership}

Based upon my review of the literature and the data gathered, I believe the following recommendations could be made to the developers and implementors of the Technology Partnership Curriculum Initiative:

1. The Innovation Configuration for the units of study should be revised to clearly reflect the spiritual and physical component that is indicated in the domains-physical, mental, spiritual, and community-upon which the Technology Partnership curriculum is built. This revision could assist the developers in ascertaining that the curriculum is designed to promote the "harmonious development" that is advocated in the Seventh-day Adventist philosophical statement (Curriculum Futures Commission, 1997). This revision could be significant since the Final Report (Volume 5 , Section M, p. 31) indicated that "there are few accountability measures that ensure 'harmonious' growth in these four domains." I felt that the IC could be viewed as a work in progress, a tool that should be regularly revisited to assess whether it reflected the philosophy and the learning design of this curriculum initiative. Addressing these issues 
could narrow the gap between the language we use to theorize our intent and what we actually practice.

2. Plans should be made for an Innovation Configuration to be developed for the entire Technology Partnership Curriculum Initiative so that components other than the Units of Study-staff development, research, and business partnerships-can be clearly defined and addressed.

3. Plans should be made to address how the Technology Partnership Innovation Configuration will be utilized in the development of future Technology Partnership Units of Study and in the classroom implementation process. The first draft of the Innovation Configuration was created in July 1997 while the curriculum development was in progress. Although it was revised at the last meeting of the curriculum development team in September 1997, no plans were made to indicate how it would be used during the remainder of the curriculum development or during the classroom implementation processes.

4. The partnership between North American Division, Pocono Union, Maracas Conference, and Southwest University should be clearly defined to outline roles, responsibilities, and operational norms and guidelines.

5. The members of the curriculum development team should be a defined group of individuals, representing all the entities of the partnership, who would continue to develop the Technology Partnership Units of Study for the remaining years of the pilot project. This would allow for the continuity of the development of the units as well as 
the development of synergistic relationships that are beneficial to the work of crossfunctional teams.

6. Sufficient funds should be allocated to effectively finance the systematic collection of qualitative and quantitative data on this curriculum initiative and organizational plans should be instituted to effectively disseminate and use the data to make improvements to the initiative.

7. The developers should continue addressing management issues of the pilot project including: a clear definition of the roles of the broadcast and classroom teachers in the project; a coding system so that the pages/activities in the units of study could be easily identified; and the volume of assignments that students are required to complete.

8. Additional support should be provided so that the pilot project can address other issues such as adequacy of feedback, follow-through, and computers with Internet access.

9. The curriculum development team, the broadcast teacher. and the classroom teachers should have initial and ongoing training in the strategies and models of teaching that have been incorporated into the units of study.

10. Adequate time should be allocated for the curriculum development team to complete the units of study before the school year begins. During the first year, most of the units were not completed before the school year began. Adequate time was needed: (a) for the units to be adapted to the broadcast since most of them were created for the regular classroom; (b) to clearly define the curriculum development process for the future development of units since during the first year this process seemed fragmented and unclear; and (c) to enable the team to reflect on the curriculum development process and 
to ascertain that the units of study incorporate all the components of the Innovation Configuration.

\section{Recommendations for Further Study}

1. Further study could be given using the Technology Partnership Innovation Configuration and the two other systems of the CBAM (Hord et al., 1987) in the implementation process. Without the use of such a comprehensive system, it would be difficult to document the impact on students and teachers.

2. The impact of the implementation of the initiative on student learning could be tracked for a 3-5-year period or longer.

3. Study could be given on providing ongoing training and support in the use of teaching strategies using a research-based training model such as the Joyce and Showers Training Model (1995) for teachers who are isolated from other professionals and who are geographically separated such as those in one-teacher schools.

4. A study could be conducted to describe the development and implementation process during the remaining years of the pilot project so that additional challenges and improvements can be identified and described.

5. A study could be conducted to discover which thinking processes and models of teaching are most suitable for use in a distance-learning program and how they can be adapted to the distance-learning medium.

6. A study could be conducted on the implementation of the Technology Partnership Curriculum Initiative in other settings such as large schools with individual 
grade levels, or in other organizational structures such as departmentalized or teamteaching situations.

\section{Summary}

The purpose of my study was to tell the story of the Technology Partnership Curriculum Initiative. Its descriptive focus can be viewed in four segments. First, there was the beginning stage in the San Fernando Conference when the design for this new curriculum was conceptualized. Next, there was the creation of a vision of using satellite technology for the delivery of Technology Partnership Units of Study to relieve some of the teaching responsibilities of the instructor in the one-teacher schools. Then there was the availability of training in teaching strategies for those who were involved in the pilot and the development of the units of study. Finally there was the implementation into the classrooms in eight one-teacher schools. The themes which emerged from the study, managing the change and collegial and instructional support, highlighted issues that were framed in the conclusions and recommendations of this study.

This entire curriculum initiative has provided a body of information on defining curriculum initiatives: training teachers and administrators in the use of innovative teaching strategies; and understanding some of the challenges involved in developing integrated units of study and implementing them through the use of distance-learning technology. The findings of this research could be helpful to others charged with developing and implementing curriculum initiatives in other educational settings. 


\section{REFERENCE LIST}

American Association of Colleges for Teacher Education. (1996). Business meeting agenda and table of contents. Washington. DC: Author.

Argyris, C. (1993). Knowledge for action. San Francisco, CA: Jossey-Bass.

Bandura, A. (1982). Self-efficacy mechanism in human agency. American Psychologist $37,122-147$.

Bandura, A., \& Adams. N. E. (1977). Analysis of self-efficacy theory of behavioral change. Psychological Review, 84, 192-215.

Banschbach, J., \& Prenn, M. (1993). A foundation for education reform: Mentor teachers Education, 114(1), 121-127.

Barnes. B. (1998). Learning architecture for the 2l" century. Glendale, CA: Griffin Publishing Group.

Barth, R. (1980). Run, school, run. Cambridge: Harvard University Press.

Becker, H. J. (1987. April). The impact of computer use on children's learning: What research has shown and what it has not. Paper presented at the Annual Meeting of the American Educational Research Association, Washington, DC.

Berg, M., \& Murphy, D. (1992). Can we mass produce a college/school partnership for professional practice? Action in Teacher Education, 14(1), 57-61.

Berlin, B. M., \& Jansen, K. (1989). Changing teachers. Education and Urban Society, 22(1), 115-120.

Berman, P., \& McLaughlin, M. (1978). Federal programs supporting educational change: Volume VIII. Implementing and sustaining innovations. Santa Monica, CA: The RAND Corporation, R-5989/8-HEW.

Birrell, J. R., Ostlund, M. R., \& Egan, M. W. (1998). Collaboration, communities, and Covey: A model for personal and professional change. The Clearing House. 76(6), 359-362.

Bonstingl, J. J. (1992). Schools of quality: An introduction to total quality management. Washington, DC: Association for Supervision and Curriculum Development. 
Brantley, P. S. (1987). Profile '87: Curriculum and instruction in SDA schools. Andrews University, Berrien Springs, MI.

Brantley, P. S. (1989). Profile 89: An assessment of SDA curriculum in North American Division schools. Andrews University, Berrien Springs, MI.

Brantley, P. S. (1991). Profile '91: An assessment of SDA curriculum in North American Division schools. Andrews University, Berrien Springs, MI.

Brantley, P. S. (1993). Profile '93 preliminary report: A curriculum impact study of North American Division Seventh-day Adventist schools. Andrews University, Berrien Springs, MI.

Brantley, P. S. (1995a. May). Teacher education in the NAD: A historical overview. Address given in Lincoln City, OR.

Brantley, P. S. (1995b). Profile '95: SDA curriculum and instruction in North American Division schools. Andrews University, Berrien Springs, MI.

Burton, L. D. (1997). Safari with a side order of service. Journal of Adventist Education, $59(5), 33$.

Button, K., \& Ponticell, J. (1996). Enabling school-university collaborative research: Lessons learned in professional development schools. Journal of Teacher Education, +7, 16-20.

Carnegie Forum on Education and Economy. (1986). A nation prepared: Teachers for the $21^{\text {st }}$ century. New York: Carnegie Corporation.

Cawelti, G. (1995). Handbook on research improving student achievement. Arlington, VA: Educational Research Service.

Charters, W., \& Jones. C. C. (1973). On the neglect of the independent variable in program evaluation. Eugene: University of Oregon.

Chein, I. (1981). Appendix: An introduction to sampling. In L. Kidder (Ed.), Selltiz, Wrightsman \& Cook's Research Methods in Social Relations ( $4^{\text {th }}$ ed.). New York: Holt, Rhinehart \& Winston.

Clark, R.E. (1983). Reconsidering research on learning from media. Review of Educational Research, 53(4), 445-459. 
Clark, R. E. (1985a). Evidence for confounding in computer-based instruction studies: analyzing the meta-analysis. Educational Communication and Technology, 33(4), 249-62.

Clark, R.E. (1985b). Confounding in educational computing research. Journal of Educational Computing Research, /(2), 137-48.

Clark, R.E. (1991). When researchers swim upstream: Reflections on an unpopular argument and leaming from media. Educational Technology, 3I(2), 34-40.

Clark, R. E. (1992). Dangers in the evaluation of instructional media. Academic Medicine, 67(12), 819-20.

Clark, R. E. (1994). Media and methods. Educational Technology Research and Development, $+2(3), 7-10$.

Corey, S. M. (1957). Introduction. In N. B. Henry (Ed.), Inservice education: Fifty-sixth yearbook of the National Society for the Study of Education. Chicago: University of Chicago Press.

Covey, S. R. (1989). The 7 habits of highly effective people. New York: Simon \& Schuster.

Cronbach, L. J. (1975). Beyond the two disciplines of scientific psychology. American Psychologist, 30, 116-117.

Cuban, L. (1993). The lure of curricular reform and its pitiful history. Phi Delta Kappan, $75(2), 181-185$.

Curriculum Futures Commission. (1997). Focus on adventist curriculum for the $21^{\text {st }}$ century (FACT 21). Silver Spring, MD: North American Division of Seventh-day Adventists.

Daley, E., \& Seltzer, M. (1987). Seventh-day Adventist research: A survey of church members and special constituencies. Princeton, NJ: Seltzer Daley Companies.

Darling-Hammond, L. (1994). Developing professional development schools: Early lessons, challenge and promise. In L. Darling-Hammond (Ed.), Professional development schools: Schools for developing a profession (pp. 1-27). New York: Teachers College Press.

Dixon, P., \& Isler, R. (1992). PDS stages in collaboration. Journal of Teacher Education, 43, 28-34. 
Dow, P. B. (1991). Schoolhouse politics. Cambridge, MA: Harvard University Press.

Dudley, R. L., with Gillespie, V. B. (1992). Valuegenesis: Faith in the balance. Riverside, CA: La Sierra University Press.

Eisner, E. (1991). The enlightened eye: Qualitative inquiry and the enhancement of educational practice. New York: Macmillan Publishing Company.

Ellis. A. K., \& Fouts, J. T. (1993). Research on educational innovations. Princeton, NJ: Eye on Education.

Ellis, A. K.. \& Fouts, J. T. (1994). Research on school restructuring. Princeton, NJ: Eye on Education.

Fullan, M. G. (1982). The meaning of educational change. New York: Teachers College Press.

Fullan, M. G. (1991). The new meaning of educational change. New York: Teachers College Press.

Fullan, M. G. (1993). Change forces. New York: Falmer Press.

Fullan, M. G. (1997). Emotion and hope: Constructive concepts for complex times. In A. Hargreaves (Ed.), Rethinking educational change with heart and mind (pp. 216233). Alexandria, VA: Association for Supervision and Curriculum Development.

Fullan, M. G., Galluzzo, G., Morris, P., \& Watson, N. (1996). The rise and stall of reform in teacher education. East Lansing, MI: Holmes Group.

Fullan, M. G., \& Hargreaves, A. (1996). What's worth fighting for in your school. New York: Teachers College, Columbia.

Fullan, M. G., Miles, M. B., \& Taylor, G. (1978). OD in schools: The state of the art. Vol. I: Introduction and executive summary. Final report to the National Institute of Education, Contract nos. 400-77-0051-0052. Toronto, Ontario: Institute for Studies in Education.

Gaikwad, S. M. (1991). Integrated thematic instruction: A descriptive case study of it adaptation and implementation. Doctoral dissertation, Andrews University, Berrien Springs, MI. 
Gardner, H. (1993). .Multiple intelligences: The theory in practice. New York: Basic Books.

Gibbons, S., Kimmell, H., et al. (1997). Changing teacher behavior through staff development: Implementing the teaching and content standards in science. School Science \& Mathematics, 97(6), 302-309.

Gibbs, J. (1987). Tribes:A process for social development and cooperative learning. Santa Rosa. CA: Center Source.

Glickman, C. D. (1990). Open accountability for the 90's: Between the pillars. Educational Leadership, $47(7), 38-42$.

Glickman, C. D. (1993). Renewing America's schools. San Francisco: Jossey-Bass.

Goetz, J. P., \& LeCompte. M. D. (1984). Ethnography and qualitative design in educational research. Orlando. FL: Academic.

Goldfried, M. R.. \& Robins, C. (1982). On the facilitation of self-efficacy. Cognitive Therapy and Research, 6, 361-380.

Goleman. D. (1995). Emotional intelligence. New York: Bantam Books.

Goodlad. J., Klein, M., \& Associates (1970). Behind the classroom door. Worthington. $\mathrm{OH}$ : Charles A. Jones.

Goodlad, J. (1975). The dynamics of educational change: Toward responsive schools. New York: McGraw-Hill Book Company.

Goodlad, J. (1984). A place called school. New York: McGraw-Hill.

Goodlad, J. (1988). School-university partnerships for educational renewal: Rationale and concepts. In K. A. Sirotnik \& J. I. Goodlad (Eds.), School-university partnerships in action: Concepts, cases, and concerns (pp. 3-31). New York: Teachers College Press.

Green, W. H., \& Henriquez-Roark, R. (1993). Study Groups in schools. Journal of Adventist Education, 56, 27-30.

Gregorc, A. F. (1982). An adult guide to style. Chicago, IL: Author.

Gross, N., Giacquinta, J., \& Bernstein, M. (1971). Implementing organizational innovations. New York: Basic Books. 
Guba, E. G., \& Lincoln, Y. S. (1981). Effective evaluation. San Francisco, CA: JosseyBass.

Gusky, T. (1986). Staff development and the process of teacher change. Educational Researcher. 15(5):5-12.

Hall, G. E., \& Hord, S. M. (1987). Change in schools: Facilitating the process. Albany, NY: State University of New York Press.

Hall, G. E. \& Loucks, S. F. (1977). A development model for determining whether the treatment is actually implemented. American Educational Research Journal, 14(3), 236-276.

Hall, G. E., \& Loucks. S. F. (1978). Teacher concerns as a basis for facilitating and. personalizing staff development. Teachers College Record, 80(1), 36-53.

Hannafin, R. D., \& Savenye, W. C. (1993). Technology in the classroom: The teacher's new role and resistance to it. Educational Technology, 33(6), 26-31.

Hardin, A., \& Kunkel, R. C. (1994). Professional development schools: An emerging national debate. National Association of Laboratory Schools, 19(1), 4-8.

Hargreaves, A. (1994). Changing teachers, changing times, : Teachers' work and culture in the postmodern age. New York: Teachers College Press.

Hargreaves, A. (1997). Introduction. In A. Hargreaves (Ed.) Rethinking educational change with heart and mind (vii-xv). Alexandria, VA: Association for Supervision and Curriculum Development.

Hargreaves, A., \& Fullan, M. (1998). What's worth fighting for out there. New York: Teachers College, Columbia.

Heck, S., Stiegelbauer, S. M., Hall, G. E., \& Loucks, S. F. (1981). Measuring innovation configurations: Procedures and applications. Austin: Research and Development Center for Teacher Education, University of Texas at Austin.

Henriquez-Roark, R. (1995). A descriptive study of teacher study groups. Doctoral dissertation, Andrews University, Berrien Springs, MI.

Hord, S. M., Rutherford, W. L., Huling-Austin, L., \& Hall, G. E. (1987). Taking charge of change. Alexandria, VA: Association for Supervision and Curriculum Development. 
Holmes Group. (1990). Tomorrow's schools: Principles for the design of professional development schools. East Lansing, MI: Holmes Group.

House, E. (1974). The politics of educational innovation. Berkeley, CA: McCuthan.

Johnson, D. W. (1997). Learning together and alone: Cooperation, competition, and individualistic learning ( $5^{\text {th }}$ ed.). Boston, MA: Allyn \& Bacon.

Johnson. D. W., \& Johnson. R. T. (1990). Social skills for successful group work. Educational Leadership, f7(4), 29-33.

Johnson, D. W., \& Johnson, R. T. (1996). Cooperative learning and traditional American values: An appreciation. NAASP Bulletin. 80(579), 63-65.

Johnson, D. W., Johnson, R. T., \& Smith, K. A. (1998). Active learning: Cooperation in the college classroom. Edina, MN: Interaction Book Company.

Joyce, B. R. (1991). The doors to school improvement. Educational Leadership, 48(8), 59-62.

Joyce, B. R. (1992). Cooperative learning and staff development: Teaching the method with the method. Cooperative Learning, 12(2), 10-13.

Joyce, B. R., \& Calhoun, E. (1996). School renewal: An inquiry, not a prescription. In B. R. Joyce \& E. Calhoun (Eds.). Learning experiences in school renewal: An exploration of five successful programs (pp. 175-190). Eugene, OR: University of Oregon's Clearinghouse on Educational Management.

Joyce, B. R., \& McKibben, M. (1982). Teacher Growth States and school environments. Educational Leadership, fO(2), 36-41.

Joyce, B. R., \& Showers, B. (1995). Student achievement through staff development. New York, NY: Longman.

Joyce, B. R., \& Weil, M. (1996). Models of teaching. (5 ${ }^{\text {th }}$ ed.) Needham Heights, MA: Allyn \& Bacon.

Kagan, S. (1994). Cooperative learning. San Clemente, CA: Kagan Cooperative Learning. 
Karrer, S. J. (1996). Teacher thinking and the change process: A qualitative study of experienced teachers learning and implementing new models of teaching. A doctoral dissertation. Andrews University, Berrien Springs, MI.

Kochan. F. (1996, November). Professional development schools: problems, solution. and benefits: University faculty speak. Paper presented at the annual meeting of the Mid-South Educational Research Association, Tuscaloosa, AL.

Kochan, F. K., \& Kunkel, R. C. (1998). The learning coalition: professional development schools in partnership. Journal of Teacher Education, $19(5), 325-333$.

Kozma. R. B. (1994). A reply: media and methods. Educational Technology Research and Development, $42(3), 11-14$.

Lieberman. A. (1992). School/university collaboration: A view from the inside. Phi Delta Kappan, 7f(2), 147-155.

Levine, M. (1997). Can professional development schools help us achieve what matters most? Action in Teacher Education. 19(2), 63-73.

Lewin. K. (1935). A dynamic theory of personality. New York: McGraw Hill.

Lezotte, L.. \& Levine. D. (1990). Unusually effective schools. A review and analysis of research and practice. Madison, WI: National Center for Effective School Research and Development.

Levy, S. (1996). Starting from scratch: One classroom builds its own curriculum. Portsmouth, NH: Heinemann.

Locke, E. A., Frederick, E., Lee, C. \& Bobko, P. (1984). Effect of self-efficacy, goals, and task strategies on task performance. Journal of Applied Psychology, 69, 241251.

Lortie, D. (1975). Schoolteacher: A sociological study. Chicago, IL: University of Chicago Press.

Loucks, S. F. (1983). At last: Some good news from a study of school improvement. Educational Leadership, 4l(3), 4-5.

Loucks-Horsley, S., Carlson, M.O., Brink, L. H., Horwitz, P., Marsh, D. P., Pratt, H., Roy, K. R., \& Worth, K., (1989). Devoloping and supporting teachers for elementary school science education. Washington, DC: The National Center for Improving Science Education. 
Marris, P. (1975). Loss and change. New York: Anchor Press/Doubleday.

Marzano, R. J., Pickering, D. J., Arrendondo, D. E., Blackburn. G. J., Brandt. R. S., \& Moffett, C. A. (1997). Dimension of learning. Alexandria, VA: Association for Supervision and Curriculum Development.

McGuire, M. (1997). Storypath foundations: An innovative approach to teaching social studies. Chicago, IL: Everyday Learning.

McLaughlin, M. (1998). Listening and learning from the field: Tales of policy implementation and situated practice. In A. Hargreaves. A. Liberman, M. Fullan, \& D. Hopkins (Eds.), International handbook of education change (pp. 70-84). Great Britain: Kluwer Academic Press.

Merriam. S. B. (1998). Case study research in education: A qualitative approach. San Francisco, CA: Jossey-Bass.

Miles, M. (1998). Finding keys to school change. In A. Hargreaves, A. Liberman, M. Fullan, D. Hopkins (Eds.). International handbook of education change (pp. 37. 69). Great Britain: Kluwer Academic Press.

Miles, M. B., \& Huberman, M. (1984). Innovation up close. New York: Praeger.

Murphy, C. (1999). Use time for faculty study. Journal of Staff Development, 20(2), 2025.

Murray, F. (1996). The narrow and broad readings of 'Tomorrow's Schools of Education.' Educational Researcher, 25(5), 28-30.

Murray, H. A, \& Others. (1938). Explorations in personality. New York: Oxford University Press.

National Commission on Excellence in Education. (1983). A nation at risk: The imperative for educational reform. Washington, DC: U.S. Government Printing Office.

Newman, F., \& Wehlage, G. (1995). Successful school restructuring. Madison, WI: Centre on Organization and Restructuring of School.

Nicholson, A. M., \& Joyce, B., with D. Parker \& F. Waterman. (1976). The literature on inservice teacher education. ISTE Report III. Syracuse, NY: National Dissemination Center, Syracuse University. 
North American Division Board of Higher Education and Board of Education, K-12. (1990). Risk and promise. Silver Spring, MD: North American Division of Seventh-day Adventists.

Ornstein, A. C., \& Hunkins, F. P. (1998). Curriculum foundations, principles, and issues. Needham Heights, MA: Allyn \& Bacon.

Ornstein, A. C., \& Levine, D.U. (1997). Foundations of education. Boston, MA: Houghton Mifflin Co.

Owens, R. G. (1998). Organizational behavior. Needham Heights, MA: Allyn and Bacon.

Papert, S. (1980). Mindstorms: Children. computers and powerful ideas. New York: Basic Books.

Papert, S. (1993). Children's machines. New York: Basic Books.

Parker, G. M. (1994). Cross functional teams: Working with allies, enemies, and other strangers. San Francisco, CA: Jossey-Bass.

Richey, H. G. (1957). Growth of the modern conception of inservice education. In N. B Henry (Ed.), Inservice education. Fiffy-sixth yearbook of the National Society for the Study of Education. Chicago: University of Chicago Press.

Rogers, E. M. (1962). Diffusion of innovation. New York: Free Press.

Rogers, E. M., \& Shoemaker, F. F. (1971). Communication of innovations: A crosscultural approach. New York: Free Press.

Rosenholtz, S. (1989). Teachers ' workplace: The social organization of schools. New York: Longman.

Rosenholtz, S. (1991). Teachers' workplace: The social organization of schools. New York: Teachers College Press.

Sarason, S. (1971). The culture of the school and the problem of change. Boston: Allyn and Bacon.

Schmuck, R. A., \& Runkel, P. J. (1974). Findings from the research and development program on strategies of organizational change at CEPM-CASEA. Eugene, $\mathrm{OR}$ : Center for the Advanced Study of Educational Administration, Center for Educational Policy and Management at the University of Oregon. 
Schmuck, R. A., \& Runkel, P. J. (1985). The handbook of organizational development in schools ( $3^{\text {rd }}$ ed.). Prospect Heights, IL: Waveland Press.

Senge, P. M. (1990). The fifth discipline. New York: Doubleday Books.

Seventh-day Adventist yearbook. (1998). Silver Spring, MD: General Conference of Seventh-day Adventists.

Showers, B., Joyce, B., \& Bennett, B. (1987). Synthesis of research on staff development: A framework for future study and a state-of-the-art analysis. Educational Leadership, $+5(3), 77-87$.

Showers, B., Murphy, C., \& Joyce, B. (1996). River city program: Staff development becomes school improvement. In B. Joyce \& E. Calhoun (Eds.), Learning experiences in school renewal: An exploration of five successful programs. (pp. 13-51). Eugene. OR: Clearinghouse on Educational Management University of Oregon.

Sirotnik, K., \& Goodlad, J. I. (Eds.). (1988). School-university-partnerships in action: Concepts, cases, and concerns. New York: Teacher College Press.

Slavin, R. E. (1983). Cooperative learning. White Plains, NY: Longman.

Slavin, R. E. (1990a). Achievement effects of ability grouping in secondary schools. Review of Educational Research, 60(3), 471-500.

Slavin, R. E. (1990b). Cooperative learning: Theory, research, and practice. Englewood Cliffs, NJ: Prentice-Hall.

Sparks, D. (1983). Synthesis of the research on effective teaching. Educational Leadership. $+1(3), 65-72$.

Sparks, D. (1997). A new vision for staff development. Principal. 77(1), 20-22.

Sparks, D., \& Hirsh, S. (1997). A new vison for staff development. Alexandria, VA: Association for Supervision and Curriculum Development.

Teitel, L. (1997). Changing teacher education through professional development school partnerships: A five-year follow-up study. Teacher College Record, 99(2), 311334. 
U.S. Department of Education. (1994, April 6). Goals 2000: Educate America Act fact sheet.<http:doc.gac.peachnet.edu/netfinder/Ne....20Act/The\%20Goals\%202000$\% 20$ Fact $\% 20$ Sheet.

U.S. Department of Labor. (1991). SCANS Report for America 2000-What work requires of schools. Secretary's Commission on Achieving Necessary Skills. Washington, DC.

Wenglinsky, H. (1998). Does it compute: The relationship between educational technology and student achievement in mathematics. Princeton, NJ: Policy Information Center Educational Testing Service.

White, E. G. (1903). Education. Mountain View, CA: Pacific Press Publishing Association.

Yin, R. K. (1994). Case study research: Design and methods $\left(2^{\text {nd }}\right.$ ed.). Thousand Oaks. CA: Sage Publication. 


\section{VITA}

NAME: Ingrid Wright-Jones

PLACE OF BIRTH: Trinidad, West Indies

EDUCATION:

1997 Ph.D. Curriculum and Instruction, Andrews University, Berrien Springs, MI

1993 M.Ed. Elementary Education, Livingston University (University of West Alabama), Livingston, $\mathrm{AL}$

1979 B.Sc. Elementary Education, Oakwood College, Huntsville, AL

\section{TEACHING/ADMINISTRATIVE EXPERIENCE:}

1997-Present Vice-principal, Spalding Elementary School, Collegedale, TN

$1996-1997$

Adjunct Professor, Andrews University, Berrien Springs, MI

Graduate Assistant, Andrews University, Berrien Springs, MI

1995-1996

Director of Instructional Support Systems, Selma, AL

Program Director for New Dimensions Community

Development Corporation, Selma, AL

1982-1996

Principal/Head Teacher, Temple Gate S.D.A. Elementary School, Selma, AL 